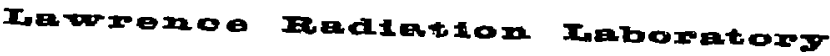 UHIYERSITY OF CALIFORHIA \\ LIVERM ORE
}

\section{UCRL-50886 INVESTIGATIONS AT HIGH TEMPERATURES:
CONDENSED-PHASE EQUIUBRIA AND VAPORIZATION STUDIES
WITH A MASS SPECTROMETER}

Ray G. Bedford

(Ph. D. Thesis)

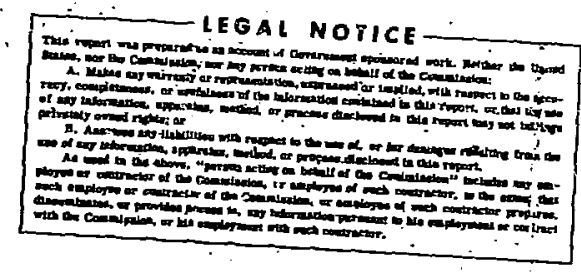




\section{PREFACE}

Parts I and II of this thesis report the results of studies of condensed-phase equilibria in rare earth oxide and oxide-fluoride sys-

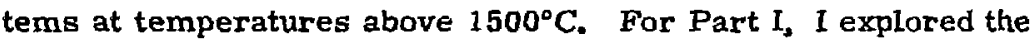
$\mathrm{Eu}-\mathrm{Eu}_{2} \mathrm{O}_{3}$ system in detail, deternining the compositions and melting points of the stable phases. In the course of this study I investigated equilibria between compounds in the Eu-Pt system and europium oxides at $1500^{\circ} \mathrm{C}$. Examinations of the $\mathrm{Sm}-\mathrm{Sm}_{2} \mathrm{O}_{3}$ and $\mathrm{Yb}-\mathrm{Yb}_{2} \mathrm{O}_{3}$ systems showed that previously reported reduced oxides were not stable at high temperatures. For Part II I studied ternary equilibria in the Eu-O-F system at $1500^{\circ} \mathrm{C}$ for oxidation states of europium between +2 and +3 , and equilibria in the En-O-F and Sm-O-F systems from $\sim 400$ to $1500^{\circ} \mathrm{C}$ for $\mathrm{Eu}^{+3}$ and $\mathrm{Sm}^{+3}$.

Parts III and IV discuss the results of vaporization studies made with the use of a mass spectrometer. Part III presents the determination of equilibria for sublimation of the element hafnium. Data were analysed by both the second-law and third-law methods; zirconium present as a dilute solute in the hafnium was used as a reference. Part IV is an investigation of the vaporization kinetics of GaN. I established the composition of the vapor species from GaN surfaces and examined vapor from these surfaces for the possible presence of nitrogen gas in excited states, 


\section{CONTENTS}

Preface

CONDENSED-PHASE EQUILIBRIA

Part I: An Investigation of the Eu- $\mathrm{Eu}_{2} \mathrm{O}_{3}$ System and the Equilibria Between the Europium Oxides and the Eu-Pt System, with Related Studies of the $\mathrm{Sm}-\mathrm{Sn}_{{ }_{2}} \mathrm{O}_{3}$ and the $\mathrm{Yb}-\mathrm{Yb}_{2} \mathrm{O}_{3}$ Systems

Abstract

Iniroduction

Melting of $\mathrm{Eu}_{2} \mathrm{O}_{3}$. . . . . . . . . . . . 3

Synthesis and Melting of EuO . . . . . . . 4

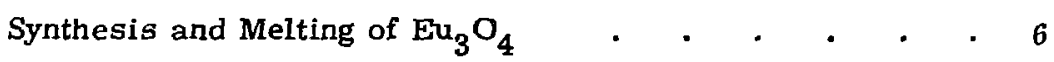

Investigation of Other Compositions between EuO and

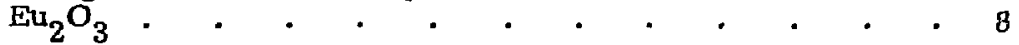

Study of the EuO- $\mathrm{Eu}_{2} \mathrm{O}_{3}$ System by the Removal of $\mathrm{Eu}$

from EuO at $1500^{\circ} \mathrm{C}$ by Platinum . . . . . . 9

The $\mathrm{Sm}-\mathrm{Sm}_{2} \mathrm{O}_{3}$ and $\mathrm{Yb}-\mathrm{Yb}_{2} \mathrm{O}_{3}$ Systems . . . . . 23

Conclusions . . . . . . . . . . . 25

Part II: Studies of the Eu-O-F and Sm-O-F Systems . . . 27

Abstract . . . . . . . . . . . 27

Introduction . . . . - . . . . . . 27

The $\operatorname{EuF}_{2}$-EuO System $\quad$ - . . . . . . . . 29

The $\mathrm{EuF}_{3}-\mathrm{Eu}_{2} \mathrm{O}_{3}$ and $\mathrm{SmF}_{3}-\mathrm{Sm}_{2} \mathrm{O}_{3}$ Systems $\quad . \quad$. 29

The Ternary System in the Region Bounded by the

Composition $\mathrm{EuF}_{2}-\mathrm{EuF}_{3}-\mathrm{Eu}_{2} \mathrm{O}_{3}-\mathrm{EuO}$. . . . . 38

Conclusions . . . . . . . . . . . . . . . 39

VAPORIZATION STUDIES

Part III: A mass Spec rometric Investigation of the Sublimation of Hafnium ard Zirconium from a Dilute Hafnium

Alloy

Abstract

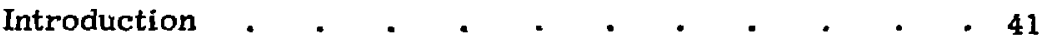

Equipment,.......... .43

Zirconium . . . . . . . . . . . 46

Experimental . . . . . . . . . 45

Calculations $. \quad . \quad . \quad . \quad . \quad . \quad . \quad . \quad .47$ 
Part III (continued)

Results

Conclusions

Hafnium

Experimental

iv

Background Corrections to Intensity Measurements

Results .. $. \quad . \quad . \quad . \quad . \quad . \quad . \quad . \quad .64$

Analysis of Errors . . . . . . . . . . 86

Conclusions

- 95

Part IV: The Kinetics of Sublimation of GaN and the Composition of Its Vapor

99

Abstract

Introduction

Experimental

Discussion

References

Acknowledgments 
INVESTIGATIONS AT HIGH TEMPERATURES:

CONDENSED-PHASE EQUILIBRIA AND VAPORIZATION STUDIES

WITH A MASS SPECTROMETER

CONDENSED-PHASE EQULLIBRIA

\begin{abstract}
Part I
AN INVESTIGATION OF THE Eu-Eu $\mathrm{O}_{3}$ SYSTEM AND

THE EQUILIBRLA BETWEEN THE EUROPIUM OXIDES AND

THE Eu-Pt SYSTEM, WITH RELATED STUDIES OF THE

$\mathrm{Sm}-\mathrm{Sm}_{2} \mathrm{O}_{3}$ AND THE Yb- $\mathrm{Yb}_{2} \mathrm{O}_{3}$ SYSTEMS
\end{abstract}

\begin{abstract}
The binary system Eu- $\mathrm{Eu}_{2} \mathrm{O}_{3}$ has been examined in detail over the composition range EuO to $\mathrm{Eu}_{2} \mathrm{O}_{3}$ at $1500^{\circ} \mathrm{C}$. Only one intermediate axide phase, $\mathrm{Eu}_{3} \mathrm{O}_{4}$, was found. Both $\mathrm{EuO}$ and $\mathrm{Eu}_{3} \mathrm{O}_{4}$ exhibit very narrow composition limits, while the monoclinic sesquioxide is stable over the composition range $\mathrm{EuO}_{1.45}$ to $\mathrm{EuO}_{1.50}$ at $1500^{\circ} \mathrm{C}$. The melting points found for the three phases were $1900^{\circ} \mathrm{C}$ for $\mathrm{EuO}, 2000^{\circ} \mathrm{C}$ for $\mathrm{Eu}_{3} \mathrm{O}_{4}$ and $2300^{\circ} \mathrm{C}$ for $\mathrm{Eu}_{2} \mathrm{O}_{3}$. Europium was quantitatively extracted from EuO by reaction with platinum in sealed capsules at $1500^{\circ} \mathrm{C}$, which resulted in the formation of an intermetallic phase plus a higher oxide of europium. The most europium-rich intermstallic phase found in these studies, EuPt ${ }_{2+x}$ has the fcc $\mathrm{MgCu}_{2}$ structure anci is stable over the composition range EuPt 2.0 $_{2}$ to $\mathrm{EuPt}_{2.8}$ at $1500^{\circ} \mathrm{C}$. There may be an additional phase besides the previously reported $\mathrm{EuPt}_{5}$ at plitinum-europium ratios above $3: 1$. No crystalline phases other than the sesquioxides were found in the $\mathrm{Sm}-\mathrm{Sm}_{2} \mathrm{O}_{3}$ or the $\mathrm{Yb}-\mathrm{Yb}_{2} \mathrm{O}_{3}$ systems.
\end{abstract}




\section{Introduction}

Brauer ${ }^{1}$ has reviewed the structural and solid-state chemistry of the lanthanon oxides, and Westrum ${ }^{2}$ has reviewed the thermodynamics and magnetic properties of the oxides and other chalcogenides.

When the work reported here began, the $\mathrm{Eu}-\mathrm{Eu}_{2} \mathrm{O}_{3}$ system had not been clearly defined. Although the oxides $\mathrm{Eu}_{2} \mathrm{O}_{3}, \mathrm{Eu}_{3} \mathrm{O}_{4}$, and EuO had been reported and their structures described, the possibility of other intermediate phases in the system still remained. ${ }^{3-7}$ However, it has since been established ${ }^{8}$ that no other phases exist in this system. Significant ranges of stoichiometry have been reported for $\mathrm{EuO}^{9}$ and $\mathrm{Eu}_{2} \mathrm{O}_{3}$ (cubic). ${ }^{10}$ The results reported here confirm the findings of Ref. 8 and present new data on the composition ranges of these oxides.

Optical and $x$-ray examination of samples prepared by metathetical synthesis in seaied containers indicated that $\mathrm{EuO}_{3} \mathrm{Eu}_{3} \mathrm{O}_{4}$, and

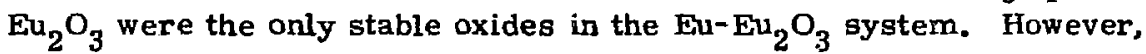
there had been some uncertainty about this conclusion because of interference by tantalum contamination in some of our early experiments. An investigation involving controlled quantitative extraction of Eu from EuO single crystals was devised, which unambiguously established the number of phases present in the range $\mathrm{EuO}-\mathrm{Eu}_{2} \mathrm{O}_{3}$ and provided data on the stoichiometries of these phases. Europium was removed from EuO through the vapor phase by equilibration with platinum in sealed containers at $1500^{\circ} \mathrm{C}$. These experiments also provided new information on the Eu-Pt system.

I applied the techniques and facilities previously_used in studying the reduced europium oxides to investigate the possible stability $c:$ divalent or other reduced oxidation states of samarium or ytterbiun in oxide systerns. SmO, $\mathrm{Sm}_{2} \mathrm{O}$, and $\mathrm{rbO}$ had all been reported, ${ }^{1-15}$ I was interested in characterizing these phases if possible and in comparing the samarium, europium, and ytterbium systems. Brauer et al. have reported that reduced oxidation states of $\mathrm{Sm}$ and $\mathrm{Yb}$ could not be prepared in binary oxides at temperatures up to $300^{\circ} \mathrm{C}$ and that the divalent ions could not be stabilized even in solution with $\mathrm{SrO}$ or C:O. ${ }^{16}$ Felmlee and Eyring have reported that the substances previously identified as $\mathrm{Sm}_{2} \mathrm{O}$ and $\mathrm{SmO}$ were actually $\mathrm{SmH}_{2}$ and 
$\operatorname{Sm} \mathrm{N}_{\mathrm{i}-\mathrm{x}} \mathrm{O}_{\mathrm{x}}{ }^{17}$ McCarthy et al, have also reported that divalent $\mathrm{Sm}$ can not be formed in titanates and is probably not stable in any oxide system. $^{18}$ My results, which include observations from reactions carried out at temperatures up to $2100^{\circ} \mathrm{C}$, confirm that in the binary oxide systems, reducing cunditions? ad to no new phases in which Sm or $\mathrm{Yb}$ are in reduced oxidation states. Reduced sesquicxides $\mathrm{Sm}_{2} \mathrm{O}_{3-\mathrm{x}}$ and $\mathrm{Yb}_{2} \mathrm{O}_{3-x}$ were found. Similar reduced lanthanon sesquioxides have been reported and the oxygen deficiencies shown to be due to vacancies in the oxygen sublattice. ${ }^{19}$ My measurements show that the oxygen deficiency in $\mathrm{Yb}_{2} \mathrm{O}_{3-\mathrm{x}}$ is approximately the same as that reported for the other reduced lanthanon sesquioxides.

\section{Melting of Ev $2 \mathrm{O}_{3}$}

I melted $\mathrm{Eu}_{2} \mathrm{O}_{3}$ in both tungsten and iridium crucibles, using an induction furnace $w$ ith a shielded tungsten susceptor. I measured temperatures with a disappearing-filament optical pyrometer sighted through a prism and window into a hole of $1 \mathrm{~mm}$ diameter in the lid and upper shields, and $I$ applied prism and window corrections. The crucibles were not sealed, but they had close-fitting covers, and I used an argon atmosphere to repress vaporization. The starting material was nominally $99.9 \% E_{2} \mathrm{O}_{3}$ that had been previously heated in air for several hours at about $1200^{\circ} \mathrm{C}$ in a platinum crucible and then stored in a desiccator. The oxide is monoclinic, colorless, and highly birefringent.

On being heated to $2270^{\circ} \mathrm{C}$ in a tungsten container, the sample melted and reacted with the crucible, producing a noticeable recess in the wall at the meniscus. This behavior is typical for reactions involving a gaseous product of the container material such as $\mathrm{WO}_{3}$. The europium oxide product appeared dark in color and contained small red crystals of $\mathrm{Eu}_{3} \mathrm{O}_{4}$ Lniformly dispersed throughout. A sample heated to $2280^{\circ} \mathrm{C}$ in an iridium crucible also melted. There was no evidence of reaction with the container: towever, enough oxygen was lost (presumably by vapurization) to yield a product that contained a significant amount of $\mathrm{Eu}_{3} \mathrm{O}_{4}$. Another sample heated in iridium to $2300^{\circ} \mathrm{C}$ appeared to have been only partly melted. Samples heated to 
$2250^{\circ} \mathrm{C}$ showed evidence of liquid formation only around the $\mathrm{Eu}_{3} \mathrm{O}_{4}$ inclusions. I maintained the samples at maximum temperature only for a few minutes because of rapid vaporization losses. This and the temperature gradients, which were unavoidabie even in the well-shielded crucible used for a susceptor, leave some doubt about the accuracy of the melting point measurements. I can only estimate the melting point to be in the range 2250 to $2350^{\circ} \mathrm{C}$.

My observations of the meiting of $\mathrm{Eu}_{2} \mathrm{O}_{3}$ were therefore not precise enough to confirm either the value of $2240 \pm 10^{\circ} \mathrm{C}$ given by Schneider ${ }^{20}$ or of $2330^{\circ} \mathrm{C}$ by Foex, ${ }^{21}$ but agree with the values near $2300^{\circ} \mathrm{C}$ as opposed to $2000^{\circ} \mathrm{C}$ reported by Mordovin. 22 Schneider determined the melting point in air, using an iridium container. Foex's measurement was also in air, using a solar furnace, and Mordovin's measurement was in argon under a pressure of $3 \mathrm{~atm}$.

Except for the presence of $\mathrm{Eu}_{3} \mathrm{O}_{4}$ inclusions, the optical properties and $x$-ray diffraction results for the melted $\mathrm{Eu}_{2} \mathrm{O}_{3}$ were identical to those for the starting material. The $x$-ray powder patterns corresponded to the ASTM data. 23

\section{Syntregis and Melting of EuO}

The starting materials were $\mathrm{Eu}_{2} \mathrm{O}_{3}$ (described above) and nominally $99 \%$ europium metal in ingot form. The europium ingot was handled in a steel glove box that could be evacuated to $3 \times 10^{-6}$ torr and filled with dry argon. A steel chisel was used to cut pieces of europium from the ingot as required, after the surface coating was scraped off. Normally, a clean europium surface would retain its shiny metallic appearance for several hours in the glove box before developing a noticeable tarnish.

Although a number of procedures have been reported for preparing EuO, most of them yield a product of questionable purity. 6, 12,24 $I$ avoided methods for which a metal other than europium is used as a reducing agent, ones for which the stoichiometry could not be closely predetermined (such as reduction by carbon), and ones requiring difficult procedures or specializeả equipment.

I prepared EuO by reducing $\mathrm{Eu}_{2} \mathrm{O}_{3}$ with europium metal in sealed, evacuated molybdenum crucibles. Reactions carried out even 
at moderately low temperatures in silice yielded products contaminated with silicate. (See also Ref. 6.) Reactions carried out in tantalum containers at temperatures high enough to melt $\mathrm{EuO}\left(\sim 1800^{\circ} \mathrm{C}\right)$ resulted in products which were contamirated by tantalum. The tantalum was found in two different forms. One was as an unidentified crystalline material thought to be a complex oxide, which was transparent, red or brownish in color, and birefringent. Tantalum was also found (by electron microprobe $x$-ray analysis) to be finely dispersed in the EuO, probably as precipitated meial that may have been in solution at higher temperatures. The occurrence of dispersed tantalum in EuO prepared in tantalum containers has also been reported by Guerci and Shafer. ${ }^{25}$ Samples of EuO which had been heated to $1800^{\circ} \mathrm{C}$ in tantalum were found to have melted. Of two samples heated to $1800^{\circ} \mathrm{C}$, one relted and one did not.

I prepared EuO without troublesome side reactions in molybdenum capsules, using an excess of europium metal. Samples were prepared by weighing the desired amounts of sesquioxide from the desiccator into capsules and transferring them into the glove box. The appropriate amount of metal was weighed on a torsion balance of $\pm 10 \mathrm{mg}$ accuracy and added to each of the capsules. After the lids were pressed on, the capsules were placed in previously weighed bottles which were capped and removed from the box. The final weights of the fiiled capsules were then determined on an analytical balance without exposing the samples to the ambient environment. After being weighed, the capsules were placed in a vacuum system that was then pumped out to $10^{-5}$ torr. The capsules were left in the vacuum overnight to allow evacuation and then were sealed by electronbeam welding (EBW).

A sample heated to $1870^{\circ} \mathrm{C}$ resulted in a compact product of EuO that had not melted. The excess europium metal was found primarily at the bottom and sides of the capsules. Samples heated above $1990^{\circ} \mathrm{C}$. and cooled at about $70^{\circ} \mathrm{C}$ per hr resulted in EuO boules rontaining large crystals that had grown from a melt. Excess metal was found at the bottom and sides of the boule and in the grain boundaries. 
Most of the Eu'? taken from several such preparations was then crushed, remelted in a sealed molybdenum container, and cool $x d$ slowly. About $1.5 \%$ Eu was added to ensure that the overall composition would remain on the metal-rich side of EuO. I estimate that the europium excess in the final product was from 1 to $5 \%$ by weipht. From this preparation i obtained single crystals of approximately $1 \mathrm{~cm}^{3}$. There was no visible excesa europium metal in this sample, but the surfaces of uncleaved crysta;s tarnished in air over a period of several months, probably becuase of the presence of europium metal in the grain boundaries.

These results are consistent with those of Guerci and Shafer. 25 However, I believe that as yet there is not enough evidence to conclude that EuO melts peritectically, as they suggest, rather than congruently. I estimate the melting point of EuO to be $1900^{\circ} \pm 50^{\circ} \mathrm{C}$, in agreement with the value suggested by Shafer. $9 \mathrm{X}$-ray powder diffraction analysis of this material gives a lattice parameter, $a=5.14_{4} \pm 0.005 \mathrm{~A}$ for the $\mathrm{NaCl}$ type structure, in agreensent with prior reports.

EuO crystals are dark reddish-violet in color and are opaque to visible light even in thin sections with he most intense illumination available on (rir micrascope (a mercury discharge lamp).

\section{Synthesis and Melting of Eu${ }_{3} \mathrm{O}_{4}$}

Attempts to prepare pure $\mathrm{Eu}_{3} \mathrm{O}_{4}$ from mixtures of EuO and $\mathrm{Eu}_{2} \mathrm{O}_{3}$ in sealed tantalum containers were unsuccessful. Extensive reduction occurred because of loss of oxygen by solution into the tanta! $\mathrm{xm}$. This reduction resulted in products containing large excesses of EuO. A preparation heated to $1820^{\circ} \mathrm{C}$ had completely melted. The product was principally EuO, containing some $\mathrm{Eu}_{3} \mathrm{O}_{4}$ with minor amounte of two or three other unidentified phases. The latter were lightly colored, transparent, and birefringent. They were coprecipitated with the $\mathrm{Eu}_{3} \mathrm{O}_{4}$ in banded eutectic-like structures. These materials may have been complex europium-tantalum oxides. .

A small sample of $\mathrm{Eu}_{3} \mathrm{O}_{4}(0.4 \mathrm{~g})$ was prepared by heating an equimolar mixture of $\mathrm{EuO}$ and $\mathrm{Eu}_{2} \mathrm{O}_{3}$ (actual $\mathrm{O} / \mathrm{Eu}=1.331$ ) to $2135^{\circ} \mathrm{C}$ in a sealed (by EBW) iridium crucible. l estimate the uncertainty in 
the initial oxygen-to-europium ratio to be about one part per thousand, primarily because of the uncertain composition of starting materials. The product had melted completely. Examination with a polarizing microscope showed the product to consist primarily of transparent, very dark-red crystals that were birefringent, appearing bright red under crossed polarizers. A very few bright white birefringent crystals were also seen in the sample, indicating the presence of a trace of $\mathrm{Eu}_{2} \mathrm{O}_{3}$. X-ray powder diffraction patterns agreed with the results reported by Barnighausen and $\mathrm{Brauer}^{5}$ and $\mathrm{Rau}^{6,26}$ for $\mathrm{Eu}_{3} \mathrm{O}_{4}$ (orthorhombic).

A larger preparation (15 g) was made by heating a mixture of EuO and $\mathrm{Eu}_{2} \mathrm{O}_{3}(\mathrm{O} / \mathrm{Eu}=1.333)$ to $2050^{\circ} \mathrm{C}$ in an iridium container and cooling at $40^{\circ} \mathrm{C}$ per hr. I was unable to make a leak-tight weld on this container, but the heating was done in an argon atmosphere to retard vaporization of the sample. The product completely melted. It consisted of relatively large Eu $\mathrm{Eu}_{3}$ grains $\left(\sim 1 \mathrm{~mm}^{3}\right)$ with traces of $\mathrm{Eu}_{2} \mathrm{O}_{3}$ concentrated at the grain boundaries. Although there was no visible sign of reaction between the sample and the container, there may have been some loss of europium by vaporization, yielding a product slightly more oxygen-rich than the starting material. Part of the product was ground and reheated to $1920^{\circ} \mathrm{C}$ in a sealed iridium capsule; no sign of melting was observed. A portion of the product was heated to $2140^{\circ} \mathrm{C}$ in a sealed molybdenum capsule and cooled rapidly. The product, which had completely melted, consisted of $\mathrm{Eu}_{3} \mathrm{O}_{4}$ with traces of $\mathrm{Eu}_{2} \mathrm{O}_{3}$, and was identical in appearance to the original material that had been cooled slowly. I could detect no sign of reaction with the container. Reheating in a sealed molybdenum container for $8 \mathrm{hr}$ at $1625^{\circ} \mathrm{C}$ had no detectable effect on the sample. These observations indicate that the $\mathrm{Eu}_{2} \mathrm{O}_{3}$ resulted from a slight excess of oxygen in the sample rather than from disproportion by a peritectic reaction.

I estimate the melting point of $\mathrm{Eu}_{3} \mathrm{O}_{4}$ to be $2000 \pm 100^{\circ} \mathrm{C}$. Part of the uncertainty in this figure is due to the fact that in some of the heatings the shielding was deliberately rearranged to establish a large temperature gradient $\left(\sim 80^{\circ}\right.$ from top to bottom) to facilitate crystal growth. Results from preparations in tantalum indicate the possibility of peritectic melting. The experiments in iridiun, and molybdenum do 
not support this conclusion, but neither do they provide direct contradictory evidence.

\section{Investigation of Other Compositions Between $\mathrm{EuO}$ and $\mathrm{Eu}_{2} \mathrm{O}_{3}$}

Several compositions between $\mathrm{EuO}$ and $\mathrm{Eu}_{2} \mathrm{O}_{3}$ were heated in sealed iridium or molybdenum containers in conjunction with the preparation and study of $\mathrm{Eu}_{3} \mathrm{O}_{4}$.

Mixtures with oxygen-to-europium ratios of $1.051,1.093$, and 1.401 that were prepared from EuO and $\mathrm{Eu}_{2} \mathrm{O}_{3}$ and then heated to $1970^{\circ} \mathrm{C}$ in EBW-sealed iridium capsules had completely melted. The samples with $\mathrm{O} / \mathrm{Eu}=1.051$ and 1.093 showed evidence of reaction with the containers. The metallic reaction product was not identified but may have been EuIr $_{2}$ (see Ref. 27) or EuIr $5^{*}$. The major oxide phase in the products was $\mathrm{Eu}_{3} \mathrm{O}_{4}$, with some opaque material (probably EuO) detectable by microscopic examination. X-ray diffraction analysis showed only $\mathrm{Eu}_{3} \mathrm{O}_{4^{*}}$. The sample with $\mathrm{O} / \mathrm{Eu}=1.401$ apparently did not react with the container. The product in this case consisted of approximately equal amounts of $\mathrm{Eu}_{2} \mathrm{O}_{3}$ and $\mathrm{Eu}_{3} \mathrm{O}_{4}$ with no other phase detectable either by $x$-ray or optical analysis.

Samples with oxygen-to-europium ratios of 1.17 and 1.25 , prepared from $\mathrm{Eu}_{3} \mathrm{O}_{4}$ and EuO, were heated to $2140^{\circ} \mathrm{C}$ in sealed molybdenum capsules and cooled rapidly. There was no indication of container reaction; $\mathrm{Eu}_{3} \mathrm{O}_{4}$ and EuO were the only phases detectable in the products by $x$-ray and optical analysis. The samples had been completely melted. The products were resealed in molybdenum capsules and heated to $1800^{\circ} \mathrm{C}$ for $8 \mathrm{hr}$ without effect.

The x-ray powder diffraction patterns of $\mathrm{Eu}_{3} \mathrm{O}_{4}$ were identical within our precision for samples prepared with either excess oxygen or excess europium, as were the qualitative optical properties. The existence of $\mathrm{Eu}_{3} \mathrm{O}_{4}$ in the presence of either EuO or $\mathrm{Eu}_{2} \mathrm{O}_{3}$, and the failure to observe ariy ether phases, are in agreement with other recent reports on this sysiem. 6-8

The presence of $\mathrm{Eu}_{2} \mathrm{O}_{3}$ in samples very close to the ideal composition for $\mathrm{Eu}_{3} \mathrm{O}_{4}$, and the concentration of the $\mathrm{Eu}_{2} \mathrm{O}_{3}$ in the grain boundaries of $\mathrm{Eu}_{3} \mathrm{O}_{4}$ preparations, indicate that the deviation from stoichiometry is very small on the oxygen-rich side. The 
appearance of the crystallized samples indicated that the stable composition range for $\mathrm{Eu}_{3} \mathrm{O}_{4}$ is probably narrow even near the melting point. Even in rapidly cooled samples, the $\mathrm{Eu}_{3} \mathrm{O}_{4}$ crystals did not appear to contain inclusions of EuO or $\mathrm{Eu}_{2} \mathrm{O}_{3}$.

\section{Study of the EuO-Eu ${ }_{2} \mathrm{O}_{3}$ System by the Removal of Eu} from EuO at $1500^{\circ} \mathrm{C}$ by Platinum

To confirm the absence of compounds other than $\mathrm{Eu}_{3} \mathrm{O}_{4}$ between $\mathrm{EuO}$ and $\mathrm{Eu}_{2} \mathrm{O}_{3}$, as $\mathrm{krell}$ as to investigate in more detail the stoichiometry of these three oxides, 1 studied the distribution of europium between the oxide phases and intermetallic phases in the Eu-Pt system at $1500^{\circ} \mathrm{C}$.

EuO single crystals weighing from 100 to $400 \mathrm{mg}$ were sealed by EBW into molybdenum capsules, along with pieces of chemically pure platinum thermocouple wire weighing $6 \mathrm{mg}$ to $1 \mathrm{~g}$. The platinum wire was auspended from molybdenum wire holders to avoid physical contact between the plainum and the oxide. Subsequently, several runs were made with the configuration shown in Fig. I-1. A tungsten-lined molybdenum cup was used instead of the molybdenum wire to contain the platinuin. Unfortunately, I did not have enough single crystals for these runs. I therefore used dense polycrystalline EuO from the same preparation used for the previous work. The sealed capsules were heated at $1500^{\circ} \mathrm{C}$ for about $5 \mathrm{hr}$ and cooled quickly. About $1.5 \mathrm{~min}$ were required for the temperature to fall below $700^{\circ} \mathrm{C}$. In the second series I did not use a quench gas, and the samples cooled more slowly, falling below incandescence in 5 to $10 \mathrm{~min}$. After being cooled the capsules were broken open to recover the oxide and platinum samples.

The product oxide phases were recovered intact and had the same size and shape as the starting EuO crystals. There was no evidence of vapor transport of oxide within the capsules nor of mechanical losses of oxide in transfers or recovery. After being weighed and examined with a low-power microscope, the oxide products were cleaved and examined further. The two-phase oxide products consisted of a central core of the lower oxidation state phase surrounded by an outer shell of the higher oxidation state phase. The boundaries were very sharp with no gradation in properties detectable. Samples were taken 


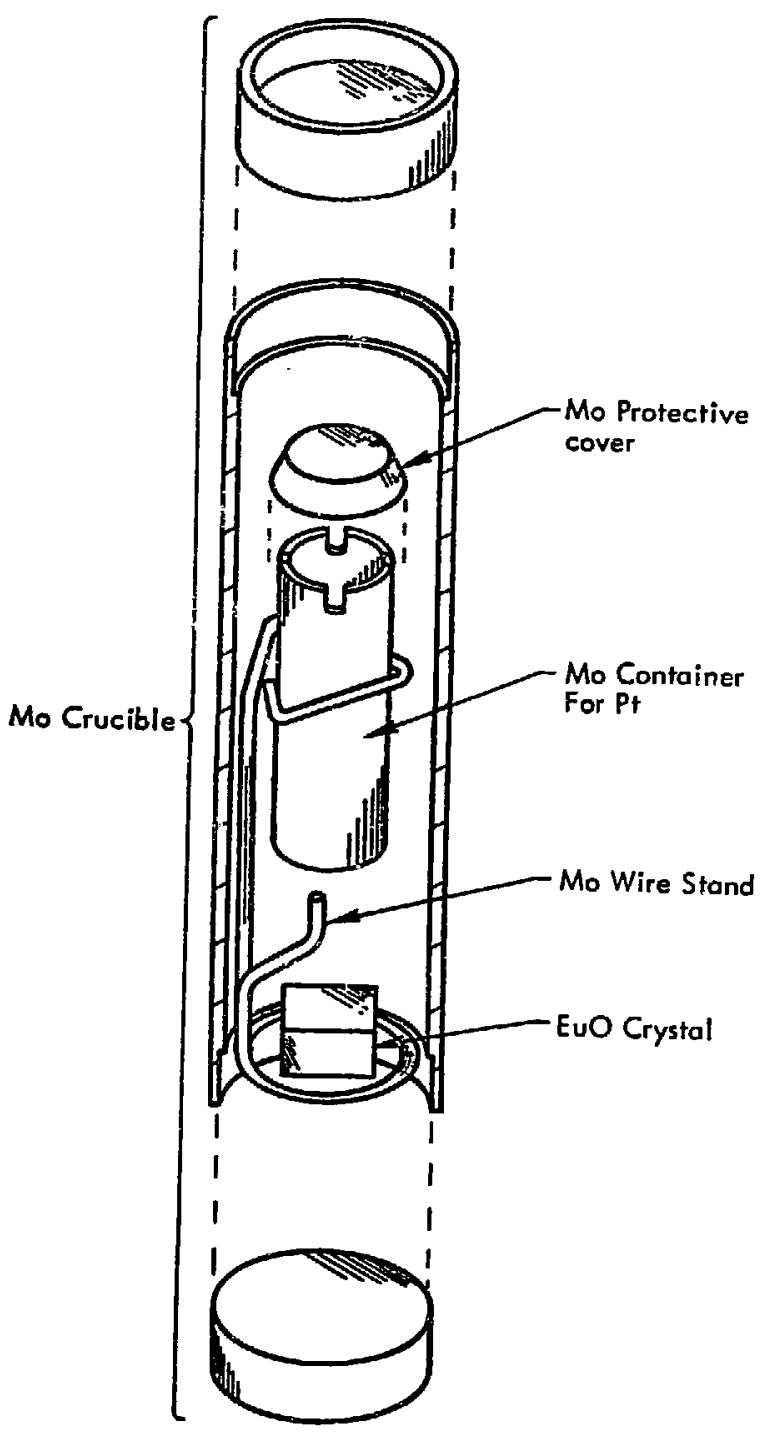

Fig. I-1. Sample configuration for extraction of europium from EuO by platinum. The protective cover prevents molybdenum particles from falling into the container when the capsule is opened. Early runs were made with platinum wire hung directly on the molybuenum wire stand. 
from the inner and outer phases for $x$-ray diffraction and exanusiation with the polarizing microscope. The x-ray and optical properties of the products of these experiments were identical to those described above for $\mathrm{EuO}, \mathrm{Eu}_{3} \mathrm{O}_{4}$ and $\mathrm{Eu}_{2} \mathrm{O}_{3}$. The results showed unambiguously that the only stable oxides in this system at $1500^{\circ} \mathrm{C}$ are the three mentioned above.

The samples changed as the initial ratio of platinum to EuO was progressively increased. At lower ratios ( $\mathrm{Pt} / \mathrm{EuO}<0.5$ ), not enough europium was extracted to increase the overall oxygen-to-europium ratio in the product oxide phase to $4 / 3$. In these samples a dense layer of polycrystalline $\mathrm{Eu}_{3} \mathrm{O}_{4}$ was formed on the external surfaces of the EuO crystal. Where the platinum-to-EuO ratio was further increased so that more than one-fourth of the europiurn was extracted from the oxide, the product was a homogeneous, dense, polycrystalline core of $\mathrm{Eu}_{3} \mathrm{O}_{4}$ with an outer layer of $\mathrm{Eu}_{2} \mathrm{O}_{3}$. With continued Eu extraction from the oxide, the outer layer of $\mathrm{Eu}_{2} \mathrm{C}_{3}$ became progressively thicker. However, the outer layers were not pure $\mathrm{Eu}_{\varepsilon} \mathrm{O}_{3}$. Small red crystals of $\mathrm{Eu}_{3} \mathrm{O}_{4}$ were uniformly dispersed in these layers. When enough platinum was added to give an oxide product with an oxygen-to-europium ratio of $1.45 \pm 0.01$ or more, the $\mathrm{Eu}_{3} \mathrm{O}_{4}$ core was absent and the product was Eu $\mathrm{Eu}_{3}$ containing small crystals of $\mathrm{Eu}_{3} \mathrm{O}_{4}$ uniformly dispersed throughout.

The metallic phase products were weighed and examined with a microsccpe and by $x$-ray diffraction. For runs in which the platinumto-europium ratio of the product was $3.45: 1$ or less, the surfaces of the products were very rough, and relatively large $(0.05 \mathrm{~mm})$ platelike crystals had developed. There was no evidence of liquid formation, and the platinum-phase molybdemum or tungsten interfaces were sharp with the interaction confined to very small regions at the points of contact between the sample and holder. In most cases there was no mechanical bond or a very weak one between sample and holder. The samples with Pt:Eu of 3.69 and 5.21 had completely melted. The platinum phase wetted the molybdenum and was strongly bound to it; however, the boundary observed under the microscope was very sharp with no evidence of reaction or corrosion of the original molybdenum surfaces. The samples with higher platinum-to-europium ratios were 
gimilar but had only partly melted. They retained the basic form of the original wire, and were smooth with coils stuck together by the crystallized liquid phase. The liquid phase is probably due to a eutectic reaction below $1500^{\circ} \mathrm{C}$ between platinum and the platinum-rich intermetallic compound.

Although the solubility of molybdenum in platinum at $1500^{\circ} \mathrm{C}$ is about 40 at.\% and there is a stable intermetallic compound of molybdenum and platinum, 28 believe the interactions of platinum with the containers did not have an important effect in this experiment except for the samples where a liquid phase was formed. This judgment is reinforced by the agreement between the first runs and the later runs in which tungsten-lined containers were used for the platinum. The solubility of tungsten in platinum is about 50 at. $\%$ at $1500^{\circ} \mathrm{C}$, but there is no platinum-tungsten intermetallic compound. The solubility of platinum in either molybdenum or tungsten is small. ${ }^{28}$ Spectroscopic

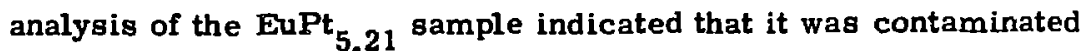
with about $200 \mathrm{ppm}$ molybdenum. The presence of molybdenum may have influenced the form and structure of the platinum phases that were melted or partly melted, but I think that even in these samples the platinum-europium ratiss are essentially the same as they would be in the pure equilibrium Eu-Pt phases. The molybdenum concentration on the products of runs for which tungsten-lined containers were used was about $30 \mathrm{ppm}$. Tungsten was not detected by either spectroscopic or $x$-ray fluorescence analysis in any of the products.

$\mathrm{X}$-ray powder diffraction analysis of the platinum-phase products gave additional information. The most europium-rich phase formed in these experiments has the fcc $\mathrm{MgCu}_{2}$ structure. The measured compositions of the products in equilibrium with two-phase mixtures of $\mathrm{EuO}+\mathrm{Eu}_{3} \mathrm{O}_{4}$ ranged from EuPt ${ }_{1.87}$ to EuPt 2.08 . The lattice parameters of these samples were identical within the precision of our measurements $\left( \pm 0.005 \AA\right.$ ), with a value of $7.72_{3} \AA$. This indicates that the products were all of the same composition, which is required by the fact that they were all in equilibrium with the same two oxide phases at the same temperature. The variation in the measured compositions of the samples is significantly greater than can be explained by the $\pm 1 \%$ uncertainties in weighing. Possible additional sources of 
error that may have contributed to the spread in experimental values are the interaction between platinum and the containers and some vaporization process by which small amounts of platinum are lost irrom the wire or oxide is lost from the crystai. The weighted average of the compositious of the irtermetallic phase in equilibrium with $\mathrm{EuO}+\mathrm{Eu}_{3} \mathrm{O}_{4}$ is $\mathrm{EuPt}_{2.02}$. The experimental compositions were weighted by the sample masses to account for differences in weighing precision. The lattice parameter reported for EuPt 2 by Elliott ${ }^{27}$ is $7.731 \AA$. The lattice parameter of $\mathrm{EuPt}_{2+\mathrm{x}}$ decreases linearly with increasing Pt concentration to a value of $7.62_{0} \AA$ for $\mathrm{EuPt}_{2,8^{\circ}}$ The dependence of lattice parameter on composition for EuPt $2+x$ is shown in Fig. I-2. The results of Harris ${ }^{29}$ for $\mathrm{EuPt}_{3}\left(\mathrm{MgCu}_{2}\right.$ structure type) are inconsistent with mine, which indicate that the $\mathrm{EuPt}_{2+\mathrm{x}}$ solid solution extends only to $\sim \mathrm{EuPt}_{2.8 \neq 0.1}$.

$\mathrm{X}$-ray diffraction results for samples with Pt:Eu ratios higher than 2.8 are inconclusive. The powder diagrams were either too poor in quality or too complicated for complet $e$ analysis. Compositions witis $P$ t: Eu ratios of 3.17 and 3.45 appeared to be two-phase mixtures of EuP ${ }^{\mathrm{h}} 2.8$ and another phase whose structure and stoichiometry are undetermined. Of the possible candidates for this phase, $\mathrm{Eu}_{2} \mathrm{Pt}_{7}$ seems to be the most reasonable. It is in agreement with our equilibration results, and preliminary single-crystal results on specimens from the EuPt 3,45 sample appear to be consistent $w$ ith one of the $\mathrm{Ln}_{2} \mathrm{Ni}_{7}$ structure-types. $30-33$

Powder cliagrams of the products with Pt:Eu ratios of 3.69 and 5.21 showed identical patterns corresponding to another unidentified phase plus some very weak $P t$ lines in the 5.21 pattern. The structure or stoichiometry of the phase producing these patterns has not been determined in this study, but it is probably EuPt ${ }_{5}$ which has been prepared by Broliger. ${ }^{34}$ Results from single-crystal studies of material from the sarapies with $\mathrm{Pt}$ :Eu ratios of 3.69 and 17.69 were consistent with single-crystal results for EuPt ${ }_{5}$ reported by Bronger. ${ }^{34}$ Although I do not have firm evidence, I believe that the reasor the $\mathrm{EuPt}_{3.69}$ sample appeared to be monophasic is that a $\mathrm{EuPt}_{5-x}$ solid solution is stable over a wide range of stoichiometriss extending from the ideal Pt:Eu ratio $\therefore, \cdots 1$ to compositions which are substantially 


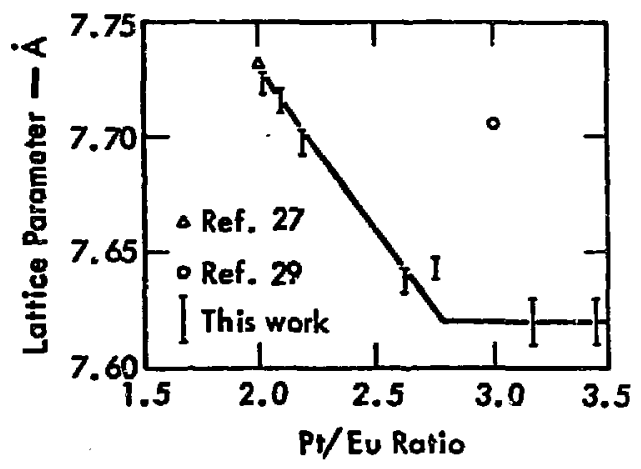

Fig. I-2. The fcc lattice parameter of EuPt $\mathrm{E}_{2+x}$ ve composition. Data obtained from measurements of back reflection lines of Debye-Scherrer powder patterns taken with CuK $\alpha$ radiation. 
platinum-deficient, and that the concentrstion of $\mathrm{Eu}_{2} \mathrm{Pt}_{7}$ in the $\mathrm{EuPt}_{3_{4}} 6 \mathrm{~S}$ was too low to observe by $x$-ray diffraction analysis. Products with Pt:Eu ratios of $9: 1$ and $17: 1$ contained mixtures of LuPt $_{5}$ and platinum. The platimum lines in these patterns were identical to those for pure Pt, with no detectable change in lattice parameter. Examples of $x$-ray powder patterns of selected products are shown in Fig. I-3. Table I-? gives $d$-spacings taken from the patterns from the $\mathrm{Pt}: \mathrm{Eu}=3.45$ and 5.21 samples. Professor Bronger kindly furnished a list of d-spacings for EuPt ${ }_{5}$ to be compared with the unresolved patterns of this study. Neither of my unidentified phases produces a pattern that corresponds exactly to Prof. Bronger's EuPt ${ }_{5}$, EuPt $_{5}$ obtained in a study involving similar equilibrations between europium fluorides and europiumplatirum phases at $1260^{\circ} \mathrm{C}$ produced patterns that corresponded to patterns from my products from the oxide equilibrations. ${ }^{35}$ Intermetallic products from the fluoride equilibrations with Pt:Eu ratios higher than 5:1 contained an unidentified phase not seen in the oxide experiments; $\mathrm{Pt}$ iines were not found in products from the fluoride experiments until the Pt: Bu ratio reached 95:1.

The results of the oxide-platinum equilibration experiments are summarized in Table I-2. I calculated the product compositions assuming that the weight loss of the oxide phase resulted only from europium loss and that all of this europium was transferred to the platinum phase. Ideally, the europium transfer could be measured both by the weight lnss of the oxide and the weight gain of the platinum, which should be identical, but in my early experiments I was unable to accomplish this ideal mass balance. In many runs the platinum came in contact with the capsile and could not be quantitatively recovered. Ever in those runs for which the recovery of the platinum phase seemed to be quantitative, and in the runs in which the platinum was placed in tungsten-lined cups, the weight gain of the platinum was always slightly less than the weight loss of the oxide. The discrepancy seemed to be the largest for the samples that contained the most platinum. Since the errors amounted to only 0.05 to $0.5 \mathrm{mg}$ (a few tenths of a percent or less of the platinum weights) the discrepancies will not significantly alter the conclusions from these experiments. In the later runs the results indicated that the polycrystalline EuO 

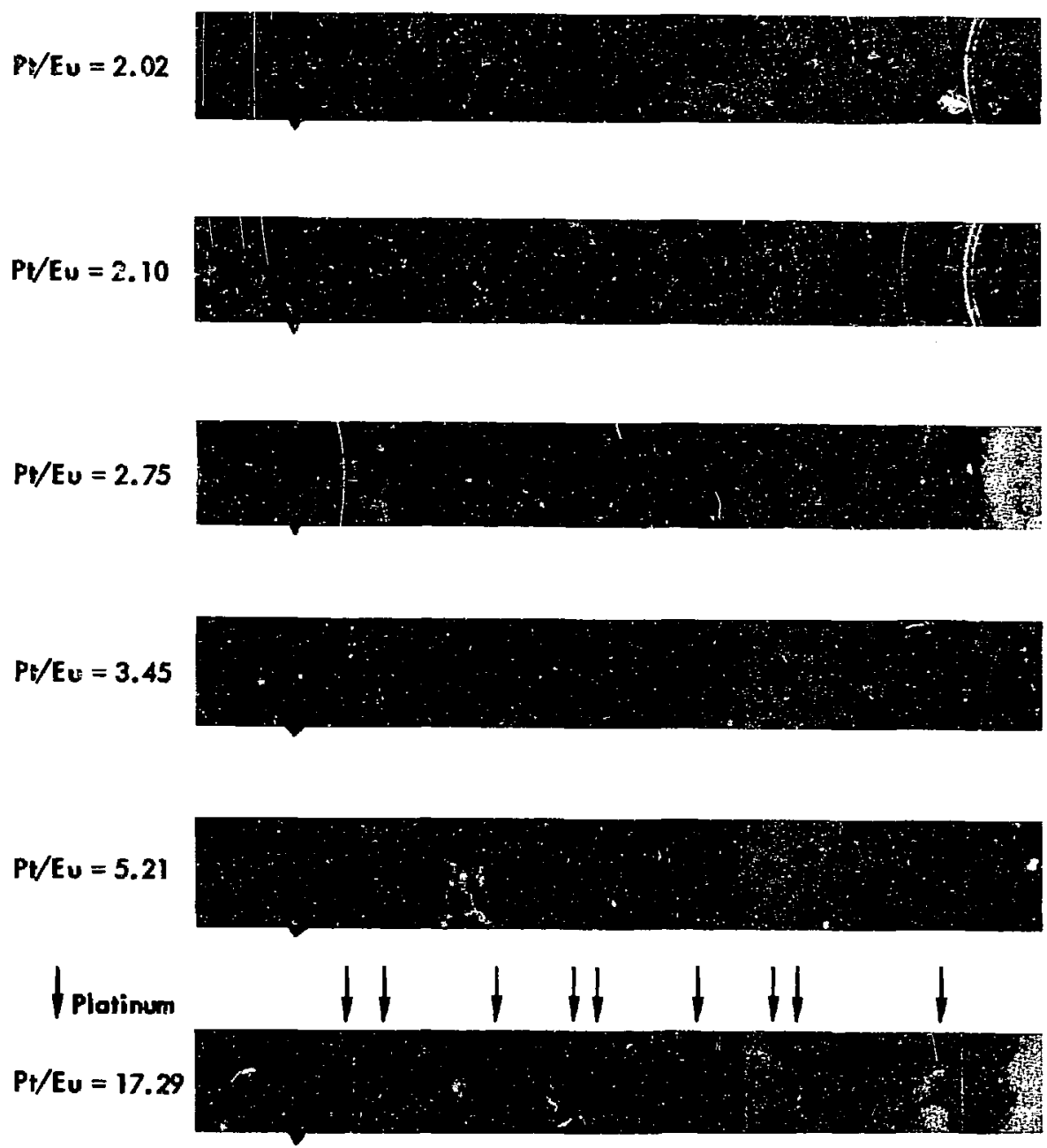

Fig. I-3. Typical $x$-ray powder patterns of plativum-europium samples. 


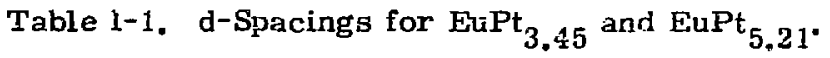

\begin{tabular}{|c|c|c|c|}
\hline \multicolumn{2}{|c|}{ Pt:EL $=3.45$} & \multicolumn{2}{|c|}{ Pt: Eir $=5.21$} \\
\hline d & I/Io & d & I/Io \\
\hline 4.55 & 15 & 4.57 & 10 \\
\hline $4.40^{2}$ & 10 & $2.66^{a}$ & 15 \\
\hline $2.8: 3$ & 5 & 2.5 & -- \\
\hline $2.69^{\mathrm{a}}$ & 10 & 2.42 & -- \\
\hline 2.53 & 5 & 2.26 & 65 \\
\hline 2. A 0 & -- & 2.19 & 100 \\
\hline 2.31 & 60 & 2.14 & -- \\
\hline $2.29^{a}$ & 100 & 2.06 & -- \\
\hline 2.22 & 15 & $1.96^{b}$ & -- \\
\hline $2.18^{\mathrm{a}}$ & 70 & 1.69 & 5 \\
\hline 2.15 & 75 & & \\
\hline 1.95 & 10 & 1.53 & -- \\
\hline $1.91^{a}$ & -- & & \\
\hline $1.75^{\mathrm{a}}$ & 7 & 1.45 & 10 \\
\hline 1.69 & 5 & $1.38 \frac{b}{3}$ & 5 \\
\hline 1.58 & -- & $1.32_{5}$ & 10 \\
\hline $1.56^{\mathrm{a}}$ & - & $1.28_{5}$ & 35 \\
\hline 1.52 & - & 1.27 & 5 \\
\hline 1.50 & - & $1.25_{5}$ & -- \\
\hline 1.47 & 7 & $1.18^{b}$ & -- \\
\hline 1.46 & 35 & $1.13 \frac{\mathrm{b}}{8}$ & 10 \\
\hline $1.43^{\mathrm{a}}$ & 10 & $1.10^{\circ}$ & 15 \\
\hline 1.42 & -- & & \\
\hline 1.36 & 7 & & \\
\hline $1.34^{\mathrm{a}}$ & 30 & & \\
\hline $1.30_{5}$ & 20 & & \\
\hline $1.28^{a}$ & I5 & & \\
\hline $1.17_{3}$ & 7 & & \\
\hline $1.14_{5}$ & 40 & & \\
\hline
\end{tabular}


Table I-2. Fesuits from equilibration of samples in the Eu- $\mathrm{Pt}-\mathrm{Eu}_{2} \mathrm{O}_{3}$ ternary system at $1500^{\circ} \mathrm{C}$.

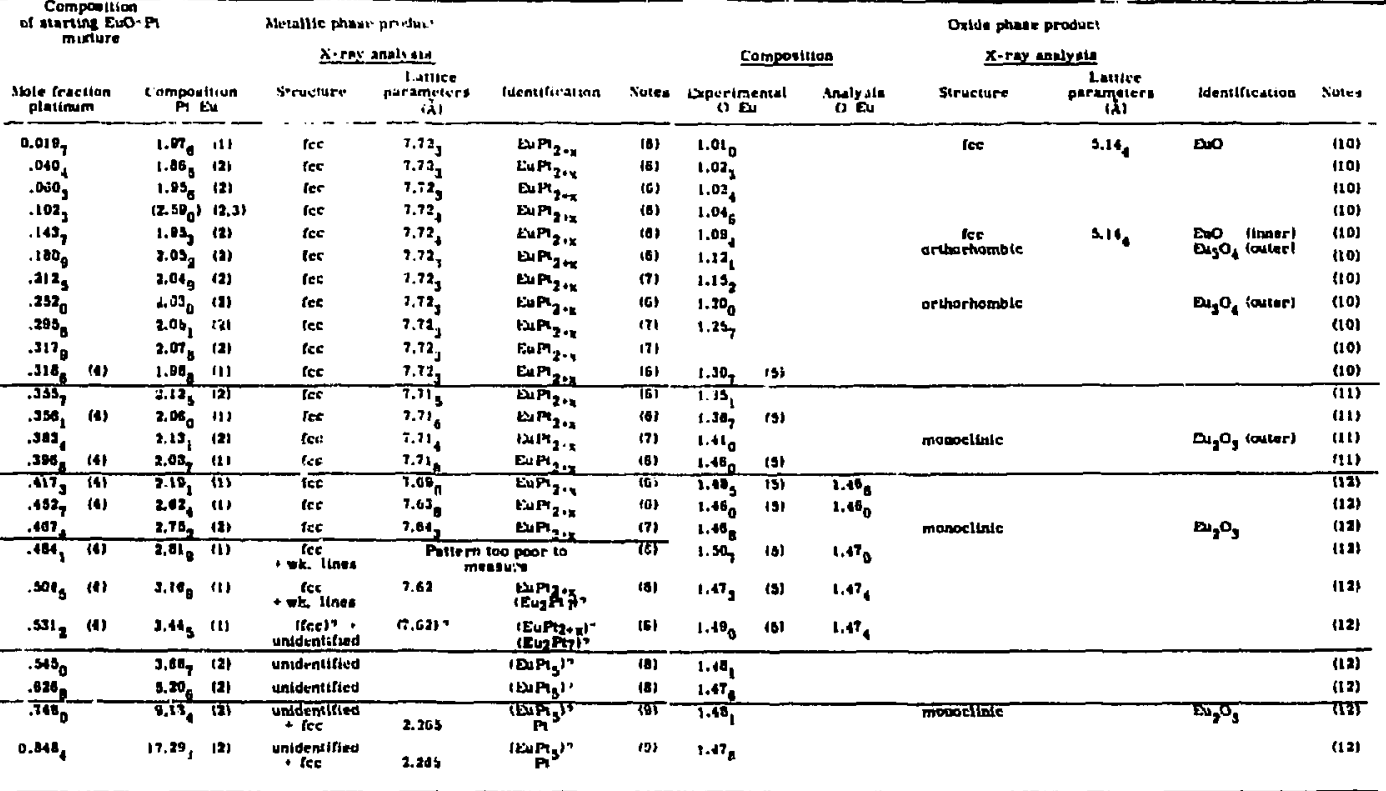

*OTES:

(1) Caleulated from weight lase of axide and weight gatn of pletinum phase.

(2) Calculated from eright loen of oxide.

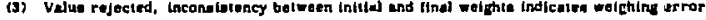

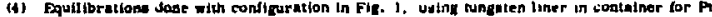

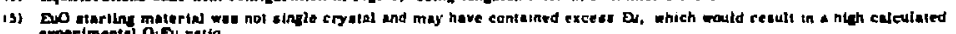

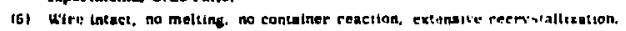

171 Wire atuck io sapeuste reall.

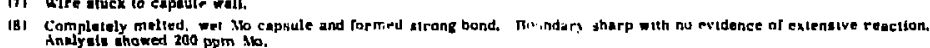

(9) Partly meired.

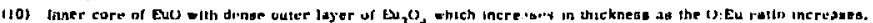

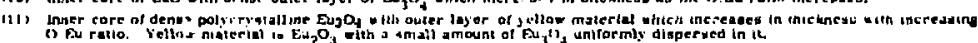

12+ 1:a, 
starting material may have contained excess Eu. For several of these runs the composition of the oxide phase product was determined by igniting the sample in air to constant weight (avout $60 \mathrm{hr}$ at 1200 to $1300^{\circ} \mathrm{C}$ ) and measuring the weight gained on oxidizing to $\mathrm{Eu}_{2} \mathrm{O}_{3}$ Weighings were made to \pm 2 micrograms.

The quantitative results of the equilibrations are illustrated in Fig. I-4, where the oxygen-to-europium ratios for the oxide phases are plotted against the platinual-to-europium ratios for the equilibrium metallic phases. The lines in Fig. I-4 were drawn using the information from optical and structural ( $x$-ray) examinations of the samples as well as the composition data. The graph represents the locus of the endpoint compositions of tie lines in the ternary diagram and facilitates finding the compositions of the binary compounds. Such a graph for a pair of binary systems with a common component, which form only binary compounds and no solid solutions or ternary compounds, would consist of vertical and horizontal line segments. Curved or sloped lines might be obtained where the equilibria involved solutions. These characteristics may be see.i by comparing Fig. I-4 with the derived ternary diagram shown in Fig. I-5. The interpretation of results presented here is based on the following assumptions: (1) compounds and solid solutions may exist in either binary system but there are no ternary phases, (2) the solubility of either of the noncommon components in any phase of the other binary system is negligible, i.e., there is negligible solubility of platinum in any of the oxide phases or of oxygen in any of the platinum-containing phases.

A vertical line is drawn in Fig. $\mathrm{I}-4$ at $\mathrm{Pt}: \mathrm{Eu}=2.02$ corresponding to the composition of the platinum phase in equilibrium with twophase mixtures of EuO and $\mathrm{Eu}_{3} \mathrm{O}_{4^{*}}$. A limit to the range of stoichiometry for single-phase EuO at $1500^{\circ} \mathrm{C}$ can be established from the run with the lowest platinum-to-EuO ratio. The starting EuO crystals were prepared in excess Eu as described above. The run with $\mathrm{Pt}: \mathrm{EuO}=0.02$ gave a product with a uniform layer of $\mathrm{Eu}_{3} \mathrm{O}_{4}$ ccvering the EuO crystal. The calculated overall composition of the oxide product (assuming a starting composition of $\mathrm{EuO}_{1.000}$ ) is $\mathrm{EuO}_{1.010^{\prime}}$ Therefore, the range of stoichiometry of $\mathrm{E}-\mathrm{O}$ at $1500^{\circ} \mathrm{C}$ is $<0.01$. This result is contradictory to the findings of Shafer. ${ }^{9}$ The lattice 


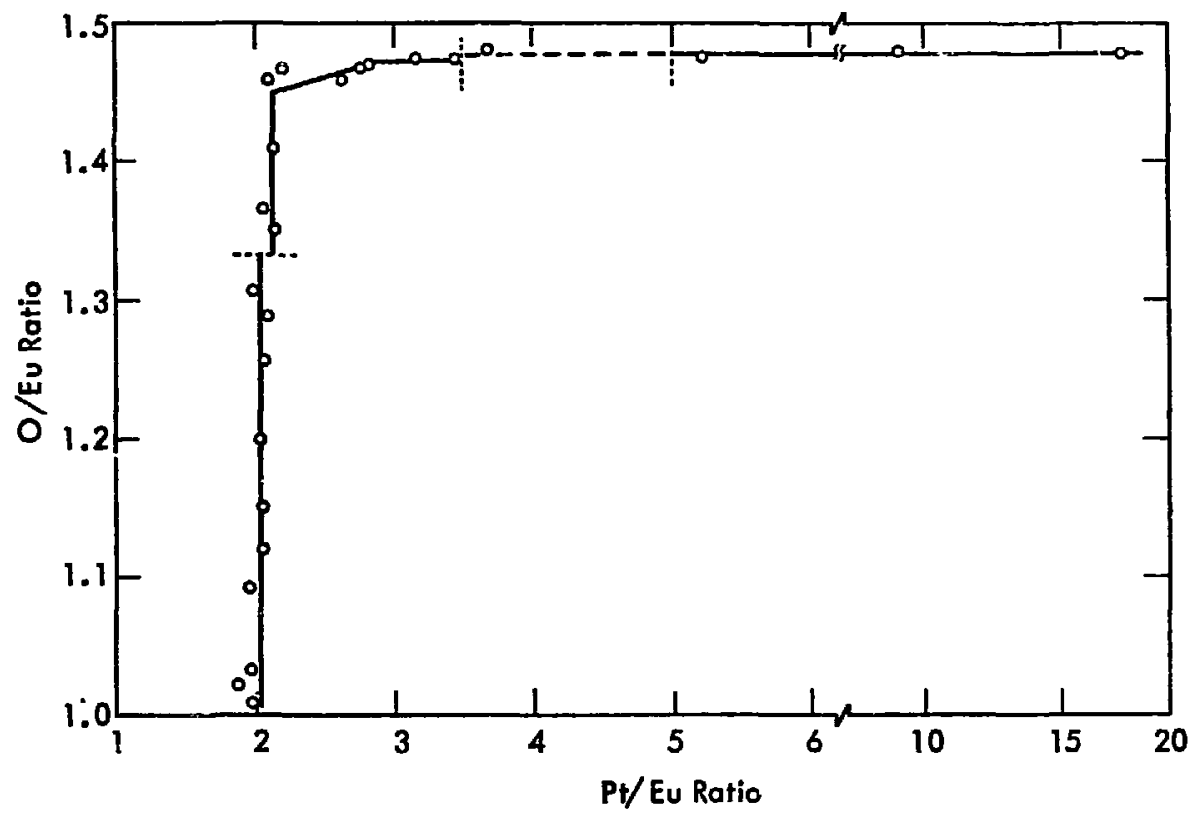

Fig. I-4. Oxygen-europium ratios vs platinum-europium ratios for samples equilibrated at $1500^{\circ} \mathrm{C}$. 


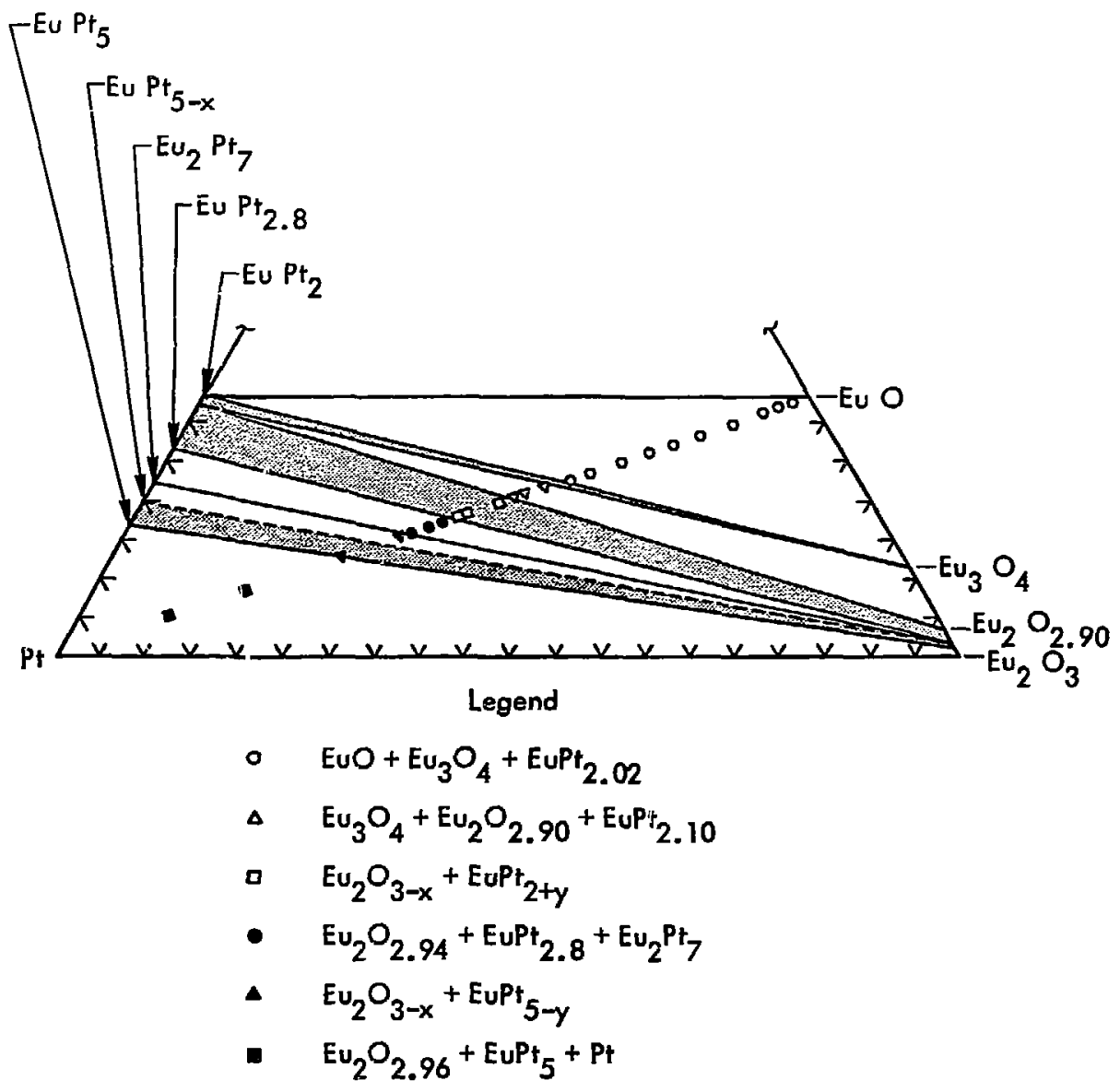

Fig. I-5. A portion of the Eu-Pt- $\mathrm{Eu}_{2} \mathrm{O}_{3}$ ternary diagram at $1500^{\circ} \mathrm{C}$. 
parameter of EuO in the equilibration products that were oxygen-rich was 5.14 , identical to the parameter for europium-rich products. The color and appearance in bulk and under the microscope were also the same for hypo- and hyperstoichiometric EuO.

Another vertical line at $\mathrm{Pt:Eu}=2.10$ corresponds to the intermetallic phase in equilibrium with two-phase mixtures of $\mathrm{Eu}_{3} \mathrm{O}_{4}$ and oxygen-deficient $\mathrm{Eu}_{2} \mathrm{O}_{3-x^{*}}$. The limits for the stoichiometry of $\mathrm{Eu}_{3} \mathrm{O}_{4}$ provided by the samples with oxide products of $0: E u=1.31$ and 1.35 are far beyond the actual values. Both of the above samples contained substantial amounts of second-phase material (either EuO or $\mathrm{Eu}_{2} \mathrm{O}_{3-\mathrm{x}}$ ). The range on the oxygen-rich side was shown to be very small by the synthetic work discussed previously. The absence of dispersed second-phase precipitates in the bulk material, after quenching from equilibrations at $1500^{\circ} \mathrm{C}$ either with EuO or with oxygen-deficient $\mathrm{Eu}_{2} \mathrm{O}_{3-x}$ indicates that the composition range is not significantly greater at temperatures up to $1500^{\circ} \mathrm{C}$ than it is at room temperatures. As with EuO, the hypo- and hyperstiochiometric materials have identical $\mathrm{x}$-ray and optical properties. I conclude that at $1500^{\circ} \mathrm{C}$ the range of stoichiometry in $\mathrm{Eu}_{3} \mathrm{O}_{4}$ is very small, and a horizontal line is drawn at $\mathrm{O}: \mathrm{Eu}=1.333$.

The sloped line from $\mathrm{Pt} / \mathrm{Eu}=2.10$ to 2.8 corresponds to equilibria between EuPt $2+x$ and $\mathrm{Eu}_{2} \mathrm{O}_{3-\mathrm{x}^{*}}$ Additional dashed lines are drawn to represent equilibria involving the unidentified phase found in this study (taken to be $\mathrm{Eu}_{2} \mathrm{Pt}_{7}$ ) and EuPt ${ }_{5}$. The final horizontal line is drawn through the data at $\mathrm{O}: \mathrm{Eu}=1.48$, which corresponds to the composition of oxide in equilibrium with two-phase mixtures of the platinum-rich intermetallic (assumed to be EuPt ${ }_{5}$ ) and platinum saturated with europium.

The ternary diagram for part of the system, $\mathrm{Pt}-\mathrm{Eu}_{2} \mathrm{O}_{3}$ - Eu at $1500^{\circ} \mathrm{C}$ constructed using the above information and assumptions, is shown in Fig. I-5.

Limiting values for the free energies of formation at $1773^{\circ} \mathrm{K}$ of EuPt $_{2+x}$ can be derived from observed equilibria with the europium oxides, We can get the partial molal free energy of europium in an intermetallic compound at a given temperature if we know the Eu(g) pressure in equilibrium with the compound. This gives a limiting 
value for the free energy of formation. Consider the following reactions:

$$
\begin{aligned}
& 4 \mathrm{EuO}(\mathrm{s})+2.02 \mathrm{Pt}(\mathrm{s})=\mathrm{Eu}_{3} \mathrm{O}_{4}(\mathrm{~s})+\mathrm{EuPt}_{2.02}(\mathrm{~s}) \\
& \mathrm{Eu}_{3} \mathrm{O}_{4}(\mathrm{~s})+\operatorname{Eu}(\mathrm{g})=4 \mathrm{EuO}(\mathrm{s}) \\
& \mathrm{Eu}(1)=\mathrm{Eu}(\mathrm{g}) \\
& 2.02 \mathrm{Pt}(\mathrm{s})+\operatorname{Eu}(1)=\mathrm{EuPt}_{2.02}(\mathrm{~s}) .
\end{aligned}
$$

Equation I-4 defines the formation of $\mathrm{EuPt}_{2.02}(\mathrm{~s})$ from the elements in their standard states. For EuPt ${ }_{2.02}(s), \Delta G_{f, 1773}^{0}=\Delta G(1)+\Delta G(2)$ $+\Delta G(3)$. Observed equilibria between the intermetallic compounds and the oxides show $\Delta \mathrm{G}(1)<0$. References 36 and 37 give free energies for Eqs. $I-2$ and $I-3$ of $\Delta G(2)=-25.1 \mathrm{kcal}$ and $\Delta G(3)=1.8 \mathrm{kcal}$.

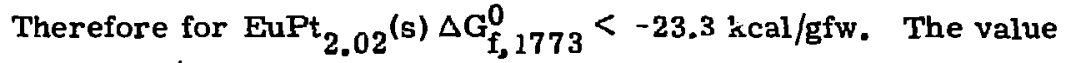
$-23.3 \mathrm{kcal} / \mathrm{g}$-atom also corresponds to the partial molal free energy of Eu in the intermetallic compound, with $\mathrm{Eu}(1)$ as the standard staie. We also know how the partial molal free energy of europium in the intermetallic compound is changing with increasing platinum content. I determined that EuPt E. $_{10}(\mathrm{~s})$ is in equilibrium with $\mathrm{Eu}_{3} \mathrm{O}_{4}(\mathrm{~s})$ $+\mathrm{Eu}_{2} \mathrm{O}_{3-\mathrm{x}}(\mathrm{s})$ at $1773^{\circ} \mathrm{K}$. Haschke and Eick determined the Eu(g) pressures for the coexistence of these two oxides. ${ }^{38}$ Consideration of a set of reactions similar to those above gives a value of $-34.4 \mathrm{kcal} / \mathrm{g}-$ atom for the partial molal free energy of Eu in EuPt $2.10^{(s)}$ at $1773^{\circ} \mathrm{K}$.

\section{The $\mathrm{Sm}-\mathrm{Sm}_{2} \mathrm{O}_{3}$ and $\mathrm{Yb}-\mathrm{Yb}_{2} \mathrm{O}_{3}$ Systems}

I attempted to prepare $\mathrm{Sm}_{2} \mathrm{O}, \mathrm{SmO}, \mathrm{Yb}_{2} \mathrm{O}, \mathrm{YbO}$ and other reduced oxides of $\mathrm{Sm}$ and $\mathrm{Yb}$. The starting materials were nominally $99.9 \% \mathrm{Sm}_{2} \mathrm{O}_{3}$ and $\mathrm{Yb}_{2} \mathrm{O}_{3}$ that had been fired in air at $1200^{\circ} \mathrm{C}$, and corresponding metal chips that had been cut from ingots of nominal $99 \%$ purity with a tungsten carbide tool. The ingots were cut under dry hexane and the material from the first cut was discarded to reduce oxide contamination. The chipg were transferred into the steel glove box and mixturea were prepared in the same way described above for EuO. The samples were sealed in molybdenum capsules by EBW.

The Sm samples vere heated to $2100^{\circ} \mathrm{C}$ and cooled quickly, with He gas used as a quenching aid. The capsules were broken open and the products recovered without the use of the glove box. All samples 
had been completely melted and cooled to a uniformly dark gray product. X-ray powder diffraction and microscopic analyses showed that the products, in all cases, were $\mathrm{Sm}_{2} \mathrm{O}_{3}$ with finely dispersed samarium metal. To check for the possible existence of $\mathrm{Sm}$ compounds stakle only at lower temperatures, the samples were again sealed in molybdenum capsules and heated for $8 \mathrm{hr}$ at $1500^{\circ} \mathrm{C}$. The products of this run were identical to the starting material.

The results indicate that at temperatures above $2100^{\circ} \mathrm{C}$, the system is ons liquid phase for compositions from Sm metal to ones with O:Sm ratios of 1.33 or higher, and that no crystalline oxide of samarium other than $\mathrm{Sm}_{2} \mathrm{O}_{3}$ exists.

The $\mathrm{Yb}$ samples were heated for several hours at $1800^{\circ} \mathrm{C}$ in sealed molybdenum capsules and allowed to cool in the furnace under vacurum (about five min to cool to $700^{\circ} \mathrm{C}$ ). The composition $\mathrm{Yb}_{2} \mathrm{O}$ had completely melted and appeared to consist of a mixture of dark red crystals and excess metal. With the other two compositions, only the metal phase melted. In these samples the oxide sintered and consisted of yery dark red crystals about $0.01 \mathrm{~mm}$ across.

Examination with the polarizing microscope showed the material to contain a mixture of dark red crystals and colorless crystals in addition to the excess metal. There was no birefringence. X-ray powder diffraction analysis showed only $\mathrm{Yb}_{2} \mathrm{O}_{3}$ (bcc) and $\mathrm{Yb}$ (fcc). By spectrographic analysis, the only metallic impurities detected in the products at levels greater than 15 ppm were La (3000 ppm) and Lu (2000 ppm).

The excess metal was dissolved from one sample with $\mathrm{HCl}$ as described by Miller and Daane. ${ }^{19}$ The loose crystalline powder from this treatment was washed in distilled water, transferred to a platinum dish, and dried in a vacuum oven at about $50^{\circ} \mathrm{C}$. The weight gain of this sample, on ignition in air at $1200^{\circ} \mathrm{C}$, was measured to assess the oxygen deficiency of $\mathrm{Yb}_{2} \mathrm{O}_{3-\mathrm{x}}$ in equilibrium with $\mathrm{Yb}$ metal at $1800^{\circ} \mathrm{C}$. The sample of $0.296211 \mathrm{~g}$ gained $112 \mu \mathrm{g}$ on ignition. The composition of the reduced sesquioxide calculated from these data is $\mathrm{YbO}_{1.495}$, which agrees well with the compositions of reduced sesquioxides of other rare earth elements reported by Miller and Daane. ${ }^{19}$ 
Since my products were obviously two-phese at room temperature, the reduced sesquioxide apparently disproportionated into $\mathrm{Yb}_{2} \mathrm{O}_{3}+\mathrm{Yb}$ as it cooled from $1800^{\circ} \mathrm{C}$. I have assumed that the metal from this reaction is dispersed within the crystalline material and is not dissolved when the bulk excess metal is removed. If some of this r.letal was lost in the $\mathrm{HCl}$ treatment, then the oxygen deficiency in $\mathrm{Yb}_{2} \mathrm{O}_{3-\mathrm{x}}$ at $1800^{\circ} \mathrm{C}$ is somewhat greater than the value I have reported.

Another sample of composition $\mathrm{YbO}$ was heated to $1450^{\circ} \mathrm{C}$ for $3 \mathrm{hr}$ and cooled slowly $\left(3 \mathrm{hr}\right.$ to $\left.1000^{\circ} \mathrm{C}\right)$. The reaction temperature for this sample was in the range used by Achard for preparations of Ybo. ${ }^{15}$ The product was a sintered pellet of oxide similar to the previous samples, but the excess metal was concentrated at the bottom of the capsule rather than dispersed through the oxide pellet.

I conclude that $\mathrm{Yb}_{2} \mathrm{O}_{3}$ is the only stable oxide of ytterbium and that the material Achard reported as YbO was probably a solid solution of oxygen in $\mathrm{YbN}$ similar to the samarium oxide-nitride that has been confused with SmO. ${ }^{17}$ Since Achard's preparations were made by reducing the sesquioxide with carbon, an oxide-carbide is also a possibility.

\section{Conclusions}

I have established that $\mathrm{EuO}$ and $\mathrm{Eu}_{3} \mathrm{O}_{\dot{1}}$ are the only stable reduced oxides of europium and that they both have very narrow ranges of composition. I have also shown that oxygen-deficient $\mathrm{Eu}_{2} \mathrm{O}_{3-\mathrm{x}}$ is stable to $\mathrm{Eu}_{2} \mathrm{O}_{2.90 \pm 0,02}$ at $1500^{\circ} \mathrm{C}$. In the Eu-Pt system, the range of stoichiometry for the fcc $\left(\mathrm{MgCu}_{2}\right)$-phase $\mathrm{EuPt}_{2+\mathrm{x}}$ has been determined to be EuPt ${ }_{2}$ to EuPt 2.8 $_{0.1}$ at $1500^{\circ} \mathrm{C}$, and two additional intermetallic phases were observed.

In contrast to the fluorides, for which there is rather close correspondence between the samarium, europium, and ytterbium systems, 35,39 there are no stable oxides of samarium or ytterbium corresponding to EuO or $\mathrm{Eu}_{3} \mathrm{O}_{4}$. This is a manifestation of the enhanced stability of the divalent oxidation states in the fluoride systems cornpared to the oxide systems. Results from two related investigations also show greater stability for divalent europium in the fluoride than in the oxides. In products from a study of the Eu-O-F ternary system 
we found $\mathrm{EuF}_{2.0}$ in equilibrium with oxygen-dificient $\mathrm{Eu}_{2} \mathrm{O}_{3-\mathrm{x}}$ (Thesis, Part II). An investigation involving the equilibration of europium fluorides with platinum-europium phases was carried out at a lower temperature than that used for the oxide equilibrations, so the results cannot be compared directly. However, the fact that EuF 2 is in equilibrium with EuPt 5 at $1260^{\circ} \mathrm{C}_{s}^{35}$ while EuO is in equilibrium with EuPt 2 at $1500^{\circ} \mathrm{C}$, indicates that the divalent state is much more stable in the fluoride, since the activity ratio of europium between EuPt $\mathrm{F}_{2}$ and EuPt $_{5}$ is not expected to change much from 1260 to $1500^{\circ} \mathrm{C}$. The factors that lead to the marked differences in stability of the divalent oxidation states of the lanthanon elements between the fluoride and the oxide systems are still not understood. 
Part II

STUDIES OF THE Eu-O-F AND Sm-O-F SYSTEMS

\section{Abstract}

I investigated a portion of the ternary system $\mathrm{Eu}-\mathrm{Eu}_{2} \mathrm{O}_{3}-\mathrm{EuF}_{3}$ by equilibrating EuO-EuF ${ }_{3}$ and EuO- EuF 2 mixtures at $1500^{\circ} \mathrm{C}$ and examining the products with a polarizing microscope and by $x$-ray diffraction. The composition at the liquid-solid boundary was not measured directly, but was estimated. A phase diagram is presented for that part of the system studied. No ternary compounds are formed with europium in an oxidation state lower than +3 in samples cooled from $1500^{\circ} \mathrm{C}$.

I examined several compositions of the $\mathrm{Eu}_{2} \mathrm{O}_{3}-\mathrm{EuF}_{3}$ and $\mathrm{Sm}_{2} \mathrm{O}_{3}-\mathrm{SmF}_{3}$ binary systems, using differential thermal analysis and $x$-ray powder diffraction. In these systems, at least one intermediate phase (and probably two or more) in addition to LnOF is stable. These additional phases all lie on the fluoride side of LnOF. At temperatures above $600^{\circ} \mathrm{C}$, solid solutions extend from approximately $\mathrm{LnO}_{0.8} \mathrm{~F}_{1.4}$ to $\mathrm{LnO}_{0.6} \mathrm{~F}_{1.8}$.

\section{Introduction}

A few years ago, anomalous magnetic behavior in $\mathrm{EuF}_{2}$ which was associated with trace impurities in the single crystals was observed. 40 The magnetic and optical properties of the inclusions in the EuF $_{2}$ crystals did not appear to correspond to any known europium compound. This prompted me to investigate the Eu-EuF ${ }_{3}-\mathrm{Eu}_{2} \mathrm{O}_{3}$ system in an attempt to identify the impurity, since oxygen seemed to be

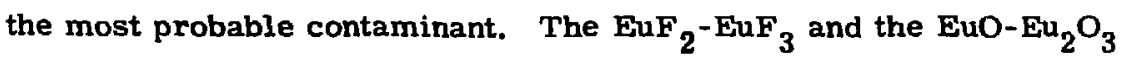
binary systems have been described in detail in Part $I$ of this thesis and elsewhere. $8,35,39$

Bevan et al. 41 discussed the lanthanon oxyfluorides and reviewed the literature on these systems. Oxyfluorides have been reported for all the lanthanon ( $\mathrm{Ln}$ ) elements and yttrium, and the structures for the stoichiometric MOF compounds at room temperature for all but Ce, $\mathrm{Tm}, \mathrm{Yb}$, and Lu seem to be established as the rhombohedral LaOF-type 
described by Zachariasen ${ }^{42}$ for LaOF and YOl . $41-50$ l'or I.a and Y, Zachariasen found tetragonal solid solutions $\mathrm{MO}_{1-\mathrm{x}} \mathrm{l}_{1+2 \mathrm{x}}(0.0 \times 0.3)$ in addition to the stoichiometric rhombohedral J.aOF and YOF. 42 Bevan et al. showed that for the Y, Sm, Gd, and Er oxyfluorides, the composition region between the stoichiometric MOF and the trifluoride is much more complicated than previously assumed. ${ }^{41}$ The continuing investigation of the intermediate composition region and the transition of stoichiometric MOF from rhombohedral to cubic (fluorite) for La, Nd, Sm, and Gd was reported by Brauer and Roether. ${ }^{49}$ Recently, Shinn and Eick published a paper on the rhombohedral-to-cubic transition for MOF compounds ( $M$ = La, Nd, Sm, Eu, Gd, Tb, Dy, Ho, Er, and $Y) .50$

Detailed investigation of the phase relationships in the extremely complex oxyfluoride systems was not attempted here, because I was primarily interested in the possible existence of a compound containing europium in the divalent state. However, differential thermal analysis (DTA) and Debye-Scherrer $x$-ray powder diffraction studies were made for several compositions in the $\mathrm{EuF}_{3}-\mathrm{Eu}_{2} \mathrm{O}_{3}$ system. These studies provide evidence for previously unknown oxyfluoride phases of Eu ${ }^{\text {[II }}$, supporting the findings of Bevan, Brauer and co-workers 41,49 that the region between stoichiometric MOF and the triflucrides for lanthanon elements and yttrium is uc: upied by a number of discrete phases that undergo transitions or dispropurtionation reactions on heating. Similar studies were attempted with the analogous samarium system, but useful quantitative information was obtained only for stoichiometric SmoF.

The present study shows no ternary cor:pounds in the Eu-EuF ${ }_{3}$ $\mathrm{Eu}_{2} \mathrm{O}_{3}$ system with europium in an oxidation state lower than +3 . The only phase in this system which resembles in any respect the impurities in the $\mathrm{EuF}_{2}$ crystals of Ref, 40 is $\mathrm{Eu}_{3} \mathrm{O}_{4^{*}}$. The color and structure of $\mathrm{Eu}_{3} \mathrm{O}_{4}$ are consistent, but the magnetic properties do not correspono to those of the impurity material. Recently, Shafer and Kuptsis published convincing evidence that the impurity in $\mathrm{EuF}_{2}$ responsible for the anomalous magnetic behavior observed in Ref. 40 and other work was a sulfide of europium. 51 


\section{The EuF 2 -EuO System}

$\mathrm{EuF}_{2}$ was prepared by hydrogen reduction of $\mathrm{EuF}_{3}$ in a molybdenum container. EuO was made by reduction of $\mathrm{Eu}_{2} \mathrm{O}_{3}$ by Eu in a sealed Mo capsule. These materials are more fully described in Ref. 39 and Part I of this thesis.

Mixtures of EuO and $\mathrm{EuF}_{2}{ }^{*}$ were sealed in molybdenum capsules by electron bombardment welding (EBW). The samples were heated to $1500^{\circ} \mathrm{C}$ in a vacuum induction furnace, held at that temperature for at least $2 \mathrm{hr}$, and cooled quickly by turning off the power and introducing argon or helium. About $2 \mathrm{~min}$ were required for the temperature to fall below $750^{\circ} \mathrm{C}$. The resulting products were examined by $\mathrm{x}$-ray powder diffraction and optical microscopy.

All the $\mathrm{EuF}_{2}$-EuO mixtures had completely melted. Microscopic examination of the products showed the composition $0.4 \mathrm{EuF}_{2}-0.6 \mathrm{EuO}$ to be very near the eutectic. Samples with larger proportions of $\mathrm{EuF}_{2}$ showed the eutectic structure in a matrix of EuF $2^{*} \mathrm{X}$-ray analysis showed the protucts of all of these runs to be EuO (cubic), a $=5.14{ }_{4} \AA$ and $\mathrm{EuF}_{2}$ (fcc), a $=5.84_{3} \AA$.

\section{The $\mathrm{EuF}_{3}-\mathrm{Eu}_{2} \mathrm{O}_{3}$ and $\mathrm{SmF}_{3}-\mathrm{Sm}_{2} \underline{\mathrm{O}}_{3}$ Systems}

Mixtures of $\mathrm{EuF}_{3}$ and $\mathrm{Eu}_{2} \mathrm{O}_{3}$ or $\mathrm{SmF}_{3}$ and $\mathrm{Sm}_{2} \mathrm{O}_{3}$ were sealed in platinum-10\% rhodium capsules by EBW and heated to $1500^{\circ} \mathrm{C}$ in an induction furnace. The products were crushed and resealed in $\mathrm{Pt}-10 \mathrm{Rh}$ capsules, again heated to $1500^{\circ} \mathrm{C}$ for $2 \mathrm{hr}$, and rapidly cooled by turning off the furnace power. Starting materials were nominal $99.9 \%$ oxides and trifluorides that had been heated in air or under HF to reduce contamination and stored in desiccaiors, as described in Ref. 39 and Part I of this thesis.

Samples frum the above preparations were examined by $x$-ray powder diffraction, optical microscopy, and D'TA. Samples of approximately $0.4 \mathrm{~g}$ for DTA were encapsuiated in $\mathrm{Yt}-10 \mathrm{Rh}$ containers by EBW at $\sim 10^{-5}$ Torr. Measurements were made $t$ heating rates of $10^{\circ} \mathrm{C} \mathrm{min}^{-1}$ from $200^{\circ}$ to $1500^{\circ} \mathrm{C}$.

\footnotetext{
The compositions are plotted in Fig. II-1.
} 


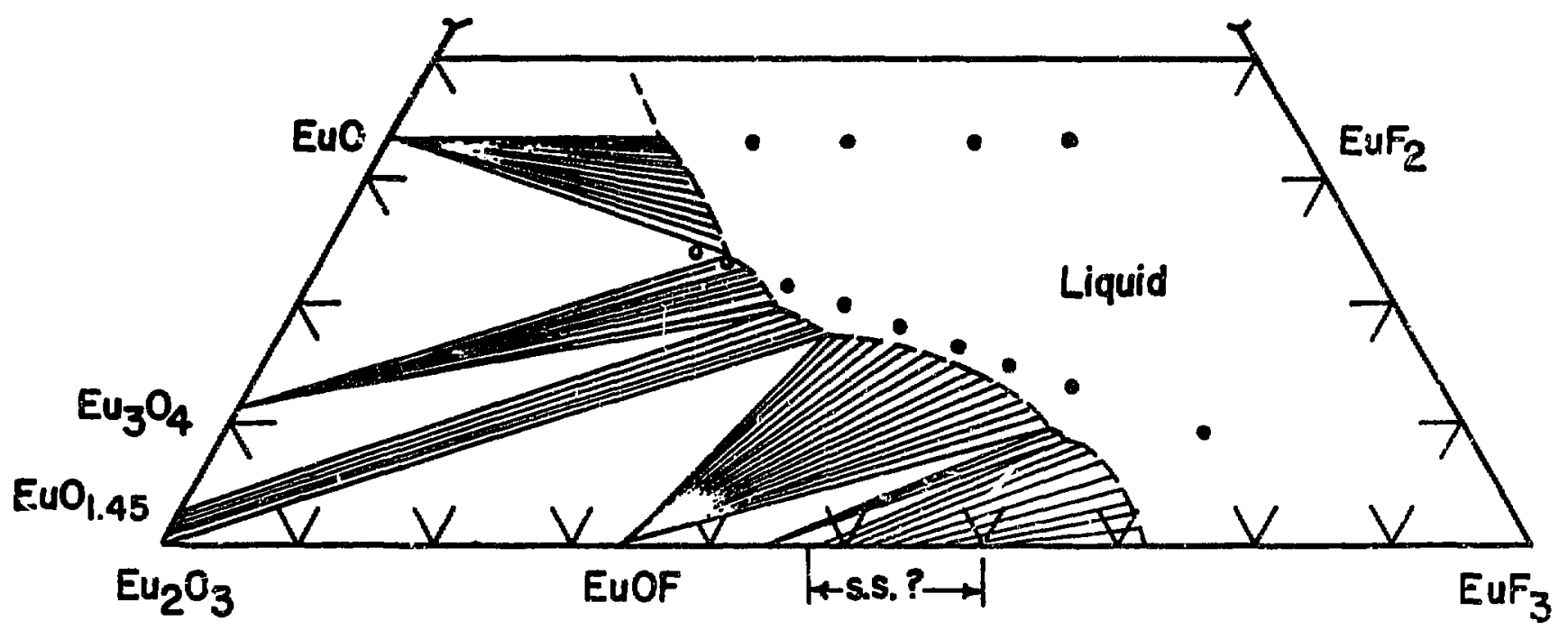

Fig. II-1. A section of th: ternary system Eu-Eu, $\mathrm{O}_{3}-\mathrm{EuF}_{3}$ at $: 5 \mathrm{CC}{ }^{\circ} \mathrm{C}$. Data points currespond $t \mathrm{~s}$ the ccmpositions listed in Table II-2 and sample EuO- KuF 2 mixtures. 
My observations on $\mathrm{EuF}_{3}-\mathrm{Eu}_{2} \mathrm{O}_{3}$ and $\mathrm{SmF}_{3}-\mathrm{Sm}_{2} \mathrm{O}_{3}$ are insufficient to provide a complete understanding of these systems. Seven compositions in each system were studied. Optical examination did not provide useful information because of the similarity of the appearance of all phases under either unpolarized or polarized light. Refractive index measurements would be required to distinguish between the various phases. Since DTA measurements were limited to temperatures below $1500^{\circ} \mathrm{C}$, melting was observed only for compositions rich in trifluorides. However, I did observe a number of effects that may help to provide a better understanding of these systems. A summary of my observations and interpretations is given in Table II- 1 , and a tentative phase diagram for the $\mathrm{Eu}_{2} \mathrm{O}_{3}-\mathrm{EuF}_{3}$ system is pres. nted in Fig. II-2. Other possible phase diagrams are consistent with the observations. Figure II-2 is presented primarily to describe the general behavior of the binary system and to define assumptions used in interpreting the $\mathrm{Eu}-\mathrm{EuF}_{3}-\mathrm{Eu}_{2} \mathrm{O}_{3}$ ternary system.

Reversible thermal effects were observed beginning at $501^{\circ} \mathrm{C}$ for SmOF and at $503^{\circ} \mathrm{C}$ for ELOF (Table II-1). The temperatures for these effects are in good agreement with those reported by Brauer ${ }^{49}$ for the rhombohedral-cubic transitions in oxyfluorides of $\mathrm{La}, \mathrm{Nd}, \mathrm{Sm}$, and Gd. Brauer found these transitions in the range from $450^{\circ}$ to $550^{\circ} \mathrm{C}$ with the value for SmOF close to $500^{\circ} \mathrm{C}$. Shinn and Eick report rhombohedralcubic transitions at $524^{\circ} \mathrm{C}$ for SmOF and $513^{\circ} \mathrm{C}$ for EuOF. ${ }^{50}$ Shinn and Eick apparently reported peak maxima rather than temperatures corresponding to the initiation of transitions on heating, which may account for some of the discrepancy between my results and theirs. Despite the higher heating and cooling rates used in my experiments, the hysteresis I observed was only about $5^{\circ}$ for SmOF and $10^{\circ}$ for EuOF, compared with the $20^{\circ}$ reported as typical by Shinn and Eick. The thermal effect beginning at $481^{\circ} \mathrm{C}$ in the sample with composition $\mathrm{EuO}_{0.9} \mathrm{~F}_{1.2}$ is probably due to the rhombohedral-cubic transition in EuOF, lowered in temperature by solution of fluoride.

$X$-ray analyses indicated that except for the sample of stoichiometric SmOF, the samarium oxyfluoride mixtures did not reach equilibrium. Samples with compositions $\mathrm{SmO}_{0.9} \mathrm{~F}_{1.2}, \mathrm{SmO}_{0.8} \mathrm{~F}_{1.4}$ and 
Table II-1. X-ray and DTA results for the $\mathrm{Eu}_{2} \mathrm{O}_{3}-\mathrm{EuF}_{3}$ system and SmOF.

\begin{tabular}{|c|c|c|c|}
\hline \multirow[b]{2}{*}{ Composition } & \multirow{2}{*}{$\begin{array}{l}\text { X-ray powder } \\
\text { diffraction analysis } \\
\text { of products }\end{array}$} & \multicolumn{2}{|c|}{ DTA results } \\
\hline & & $\begin{array}{l}\text { Temperature } \\
\text { range- }{ }^{\circ} \mathrm{C}\end{array}$ & $\begin{array}{l}\text { Peak } \\
\text { height }\end{array}$ \\
\hline EuDF & EuOF (rhomb) & $503-505$ & 5.3 \\
\hline $\mathrm{EuO}_{0.9} \mathrm{~F}_{1.2}$ & EuOF (rhomb) + wk lines & $\begin{array}{l}481-498 \\
718-734\end{array}$ & $\begin{array}{l}1.8 \\
1.5\end{array}$ \\
\hline $\mathrm{EuO}_{0.8} \mathrm{~F}_{1.4}$ & EuOF (rhomb) + wk lines & $721-734$ & 4.1 \\
\hline $\mathrm{EuO}_{0.7} \mathrm{~F}_{1,6}$ & EuOF (rhomb) + EuF $_{3}$ (orth) & $505-522$ & 1.0 \\
\hline $\mathrm{EuO}_{0.6} \mathrm{~F}_{1,8}$ & $\begin{array}{l}\text { EuOF (rhomb) }+ \text { EuF }_{3} \text { (orth) } \\
+ \text { wk lines }\end{array}$ & $553-578$ & 0.7 \\
\hline $\mathrm{EuO}_{0.3} \mathrm{~F}_{2.4}$ & EuF $_{3}$ (orth) + wk lines & $\begin{array}{c}568-588 \\
1293-1315\end{array}$ & $\begin{array}{l}(0.5) \\
8.8\end{array}$ \\
\hline $\mathrm{EuF}_{3}$ & $\mathrm{EuF}_{3}$ (orth) & $\begin{array}{c}776-806 \\
1180-1258\end{array}$ & $\sim 3.9$ \\
\hline SmOF & SmOF (rhomb) & $501-508$ & 7.7 \\
\hline
\end{tabular}

${ }^{a}$ Peak heights normalized to average sample size of $0.4 \mathrm{~g}$, assuming peak height directly proportional to mass of sample.

${ }^{b}$ Peak detectable only on cooling. 


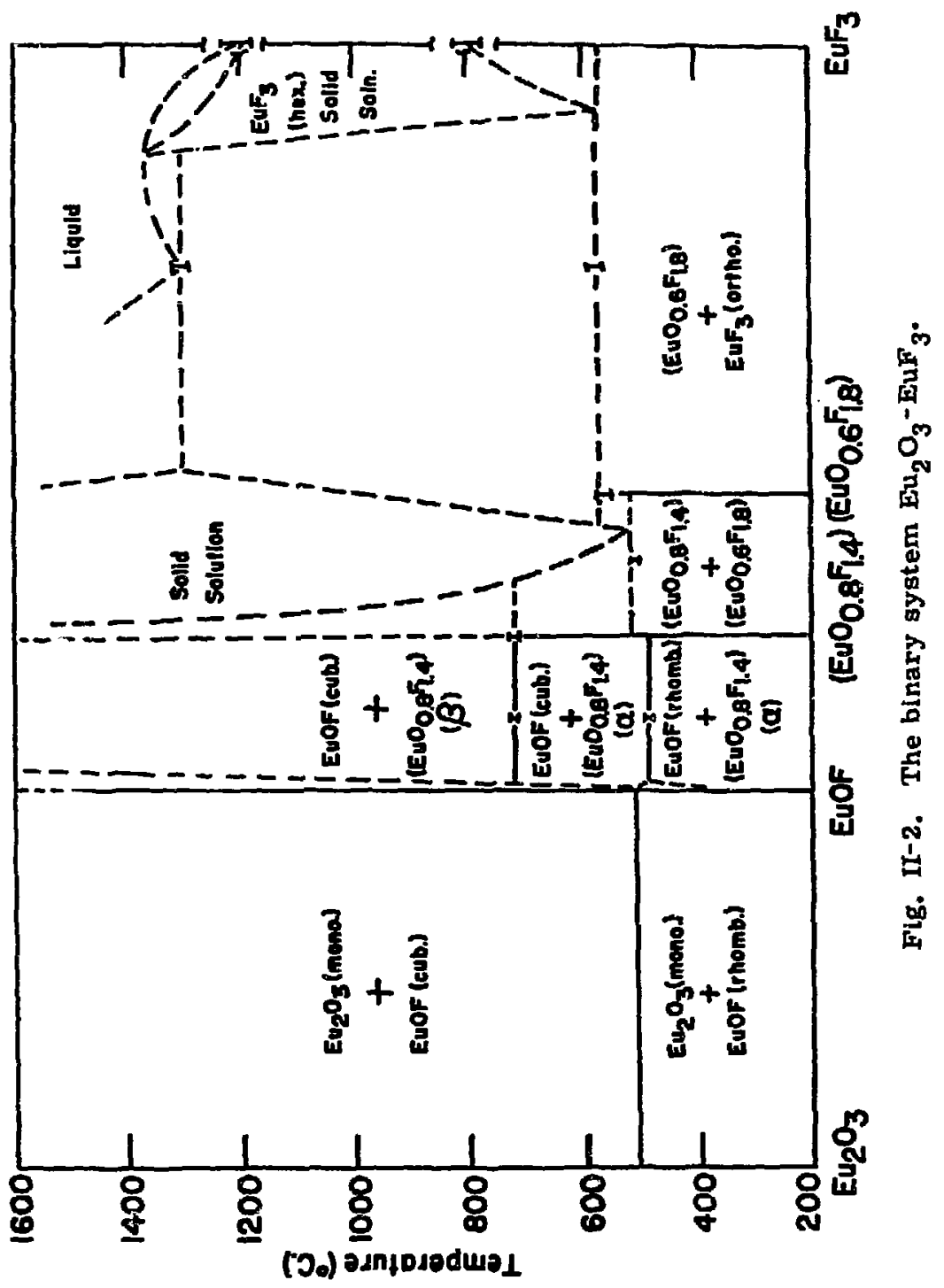


$\mathrm{SmO}_{0.7} \mathrm{~F}_{1.6}$ appedred to be mixtures of SmOF (rhombuhedrill) $+\mathrm{Sm}_{2} \mathrm{O}_{3}$ (bec) after heating at $1500^{\circ} \mathrm{C}$ as described abuve. Samples of $\mathrm{SmO}_{0,6} \mathrm{~F}_{1.8}$, and $\mathrm{SmO}_{0.3} \mathrm{~F}_{2,4}$ apleared to be mixtures "I SimoF (rhombohedral) and $\mathrm{Sm} \mathrm{F}_{3}$ (orthorhombic). I observed thermal efforts in these samples that were similar to those seen in the euripium axyfluorides but with lower intensities, wider temperature ranges, and more hysteresis. In the samarium oxyfluoride mixtures, I did not ubserve an effect corresponding to the peaks at $720^{\circ} \mathrm{C}$ in $\mathrm{F}^{\circ} \mathrm{O}_{0.9} \mathrm{~F}_{1.2}$ and $\mathrm{E}_{0.8} \mathrm{~F}_{1.4^{*}}$. Failure to achieve equilibrium in the samarium axyfluoride system is not surprising. Bevan et al. found that several hours of annealing were needed to prepare the fluorine-rich phases they identified. 41

The europium oxyfluride system was apparently bette.r lichaved than the corresponding samarium system, although it is pussible that the effects observed in both systems correspond to metastable equilibria. Observation of the thermal effect at $720^{\circ} \mathrm{C}$ for $E_{0.9} F_{1.2}$ and EuO $_{0.8} F_{1.4}$ and the absence of the rhombuhedral-cubic transition in EuO $0.8 \mathrm{~F}_{1.4}$ implies the existence of an intermediate compuund such as that reported by Brauer ${ }^{49}$ for the samarium oxyfluoride system. The thermal effect at $1293^{\circ} \mathrm{C}$ fur EuO $0.3_{2.4}$ was due to melting, as confirned by visual inspection of samples heated to $1500^{\circ} \mathrm{C}$ in sealed Pt-10 Rh containers before being loaded into the DTA capsules. The $\mathrm{SmO}_{\mathbf{6}, 3} \mathrm{~F}_{2,4}$ sample also was completely melted at $1500^{\circ} \mathrm{C}$. None of the other samples showed any evidence even of partial melting after being heated to $1500^{\circ} \mathrm{C}$. The small temperature range of the thermal effect indicates that the eutectic composition lies very close to $\mathrm{EuO}_{0.3} \mathrm{~F}_{2.4}$

The disappearance of the thermal effect corresponding to the rhombohedral-to-cubic transitions of the stoichiometric oxyfluorides in samples of higher fluoride concentration is at variance with $x$-ray results indicating the presence of LnOF (rhombishedral) at roum temperature for all compositions down to $\mathrm{LnO}_{0.6} \mathrm{~F}_{1.8}$ in both the samarium and europium systems. A possible explanation for this discrepancy is that phases identified as SmOF (rhombohedral) and EuOF (rhombohedral) in the fluoride-rich samples were actually compounds with closely related structures in the composition range $\mathrm{LnO}_{0.9} \mathrm{~F}_{1.2}$ 
to $\mathrm{LnO}_{0.6} \mathrm{~F}_{1.8^{\circ}}$. The structures of all of these phases reported by Brauer 49 are closely related to the fluorite structure. My specimens could also be composed of phases quenched in from solid-solution regions at higher temperatures.

An attempt to prepare an oxylluoride $\mathrm{Eu}_{3} \mathrm{O}_{4} \mathrm{~F}$ analc rous to the phase $\mathrm{Eu}_{3} \mathrm{O}_{4} \mathrm{Br}$ reported by $\mathrm{Barnighausen}{ }^{8}$ was unsuccessful. A sample of this composition prepared from $\mathrm{EuF}_{3}$ plus $\mathrm{Eu}_{2} \mathrm{O}_{3}$ yielded EuOF (rhombohedral) plus $\mathrm{Eu}_{2} \mathrm{O}_{3}$ (bcc, $\mathrm{a}=10.86_{9} \AA$ ) when annealed at $1500^{\circ} \mathrm{C}$ and quickly cooled. 'In only four cases have $\mathrm{I}$ seen $\mathrm{Eu}_{2} \mathrm{O}_{3}$ in the cubic form after it was heated above $1300^{\circ} \mathrm{C}$ : in this preparation, in a ternary mixture described in Table II-2, and in the products of two preliminary runs in which mixtures of $\mathrm{EuO}_{+} \cdot \mathrm{EuF}_{3}$ and $\mathrm{EuF}_{2}+\mathrm{EuF}_{3}$ $+\mathrm{Eu}_{2} \mathrm{O}_{3}$ were heated to $1800^{\circ}$ in tantalum containers, cooled slowly to $1500^{\circ} \mathrm{C}$, and then quenched. The products of the runs in tantalum were $\mathrm{EuF}_{2.26}$ (fcc, $a=5.80_{5} \AA$ ) $+\mathrm{Eu}_{2} \mathrm{O}_{3}$ (bcc). These results have not been included in the discussion of the ternary system because the samples reacted with the tantalum containers.

The similarity between the oxyfluoride systems and the reduced fluoride systems is worthy of some attention. Solid solutions and nonstoichiometric compounds in both the $\mathrm{LnO}_{1-\mathrm{x}} \mathrm{F}_{1+2 \mathrm{x}}(0 \leq \mathrm{x} \leq 0.4)$ (see Refs. 41, 42, and 49) and the $\operatorname{LnF}_{2+x}(0 \leq x \leq 0.45)$ (see Refs. 35 and 39) systems have structures based on an fcc fluorite lattice. The predominant lattice defects in a number of nonstoichiometric oxides, fluorides, and oxyfluorides based on the fluorite structures are interstitial anions or anion vacancies. 52 Interstitial anions have been shown to be the primary lattice defect in several such solid solutions involving a lanthanon trifluoride in a difluoride or an oxyfluoride. $39,52-55$ The cation sublattice in these systems is essentially ideal.

Because of the energy involved in anion-cation separation, it is unlikely that configurations that do not satisfy local rharge compensation will. be significant in these systems. In LnOF (inucite), the oxide and fluoride ions are randomly distributed on the anion lattice sites, satisfying the condition that unit cells with excess oxide ions contain corresponding anion vacancies and cells with excess fluoride ions contain corresponding interstitial ions. For solid solutions containing 
Table II-2. Analysis of compositions in the ternary system Eu- $\mathrm{Eu}_{2} \mathrm{O}_{3}-\mathrm{EuF}_{3}$ prepared by equilibrating EuO- $\mathrm{EuF}_{3}$ mintures at $1500^{\circ} \mathrm{C}$.

\begin{tabular}{|c|c|c|c|c|c|c|c|c|}
\hline \multirow[b]{3}{*}{$\begin{array}{l}\text { Mol ratio } \\
\text { EuO/EREF }\end{array}$} & \multirow[b]{3}{*}{$\begin{array}{l}\text { Optical observations } \\
\text { (transmitted light) }\end{array}$} & \multirow{3}{*}{$\begin{array}{l}\text { X-ray } \\
\text { sample } \\
\text { No. }\end{array}$} & \multicolumn{6}{|c|}{ X-ray powder pattern observations (wilh intengity and quality) } \\
\hline & & & \multicolumn{3}{|c|}{ Ice nuoride phase ${ }^{+}$} & \multicolumn{2}{|c|}{ Additional phases $*$} & \multirow[b]{2}{*}{ Comments } \\
\hline & & & $\begin{array}{c}\text { Lattice } \\
\text { parameter-A }\end{array}$ & Pattern & $\begin{array}{c}\text { Composition- } \\
\text { EuF }_{2+x}\end{array}$ & Fadditior & $\frac{\text { al phases }}{\text { Composition }}$ & \\
\hline \multirow[t]{3}{*}{$2.70^{5}$} & $\begin{array}{l}\text { 1st phase dark red, trangparent, } \\
\text { and brightly blrefringent }\end{array}$ & 1 & $5.84_{0}$ & $\mathbf{s . 8}$ & EuF $_{\mathbf{2 . 0 0}}$ & $\begin{array}{l}\mathrm{s}, \mathrm{g} \\
\mathrm{m}, \mathrm{f}\end{array}$ & $\mathrm{EuO}_{3} \mathrm{O}_{4}$ & - \\
\hline & $\begin{array}{l}\text { 2nd phase colorless, tranoparent, } \\
\text { and non-birefringent }\end{array}$ & 2 & $5,80_{5}$ & $\mathbf{m}, \mathbf{p}$ & EuF $_{2.26}$ & $\begin{array}{l}\mathbf{8 , 8} 8 \\
\mathbf{8 , 8}\end{array}$ & $\mathrm{EuO}_{3} \mathrm{O}_{4}$ & - \\
\hline & $\begin{array}{l}\text { 3rd phase apaque } \\
\text { (1st phase is major component; } \\
\text { 2nd phase minor; } 3 \text { rd phase } \\
\text { very gmall amounts.) }\end{array}$ & & & & & & & \\
\hline $2.33^{5}$ & $\begin{array}{l}\text { 1st phase dark red, transparent, } \\
\text { and brightly birefringent } \\
\text { 2nd phase colorless, transparent, } \\
\text { and non-birefringent } \\
\text { 3rd phase colorless, transparent, } \\
\text { and brightly birefringent } \\
\text { (1st and and phases about equal } \\
\text { in amount; 3rd phage very } \\
\text { amall amounts.) }\end{array}$ & I & $5.83_{8}$ & $\mathbf{8}, \mathbf{B}$ & EuF $_{2.02}$ & $\mathbf{w}, \mathbf{p}$ & $\mathrm{Eu}_{3} \mathrm{O}_{4}$ & - \\
\hline $1.86^{5}$ & Same as previous sample & 1 & $5.83_{8}$ & 8,8 & $\mathrm{EuF}_{2,02}$ & $\mathrm{~m}, \mathbf{l}$ & $\mathrm{Eu}_{3} \mathrm{O}_{4}$ & - \\
\hline \multirow[t]{2}{*}{$1.50^{5}$} & $\begin{array}{l}\text { 1st phase colorless, transparent, } \\
\text { and non-birefringent }\end{array}$ & l & $5.83_{8}$ & B, $\mathbf{g}$ & EuF $_{2,02}$ & $\mathbf{8 , 8}$ & $\begin{array}{l}\quad \mathrm{Eu}_{2} \mathrm{O}_{3} \\
\text { (monocilinic) } \\
\text { + additional } \\
\text { weak lines, }\end{array}$ & - \\
\hline & $\begin{array}{l}\text { 2nd phase light tan, trangparent, } \\
\text { with moaalc-like birefringence } \\
\text { (Both pheses about equal in amount.) }\end{array}$ & 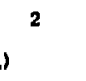 & 5.840 & s, g & $\mathrm{EuF}_{2.00}$ & $\mathbf{s , g}$ & $\underset{\text { (monoclinic) }}{\mathrm{Eu}_{2} \mathrm{O}_{3}}$ & - \\
\hline \multirow[t]{2}{*}{$1.50^{55}$} & $\begin{array}{l}\text { 1st phage light tan, transparent, } \\
\text { and non-birefringent }\end{array}$ & 1 & $5.80_{5}$ & 8,8 & $\mathrm{EuF}_{2,26}$ & $m, t$ & $\mathrm{Eu}_{2} \mathrm{O}_{3}$ (bcc) & $\begin{array}{l}\text { Cooled slowly, } \\
\text { see discussion } \\
\text { under section } 3 .\end{array}$ \\
\hline & $\begin{array}{l}\text { 2nd phase colorless, transparent, } \\
\text { and brightly birefringent (Both } \\
\text { phases about equal in amount.) }\end{array}$ & & & & & & & \\
\hline \multirow[t]{2}{*}{$1.22^{5}$} & $\begin{array}{l}\text { 1gt phase light tan, transparent, } \\
\text { with mosalc-like birefringence }\end{array}$ & 1 & $5.83_{8}$ & B, $\mathbf{g}$ & $E_{2.02}$ & $w, p$ & \multirow{2}{*}{$\begin{array}{l}\text { EuOF + sev- } \\
\text { eral extru } \\
\text { weak lines } \\
\text { EuOF + sey- } \\
\text { eral extra } \\
\text { weak tines }\end{array}$} & \\
\hline & $\begin{array}{l}\text { 2nd phase colorless, trangparent. } \\
\text { and non-birefringent } \\
\text { (Ist phase is major component.) }\end{array}$ & 2 & $5.80_{5}$ & s, g & $E_{2 u} F_{2.26}$ & B, g & & \\
\hline
\end{tabular}


Table II-2 (continued)

\begin{tabular}{|c|c|c|c|c|c|c|c|c|}
\hline \multirow[b]{2}{*}{$\begin{array}{l}\text { Mol ratio } \\
\text { EuO/Eu F }\end{array}$} & \multirow[b]{2}{*}{$\begin{array}{l}\text { Optical observations } \\
\text { (transmitted light) }\end{array}$} & \multirow[b]{2}{*}{$\begin{array}{l}\text { X-ray } \\
\text { sample } \\
\text { No. }\end{array}$} & \multicolumn{6}{|c|}{$X$-ray powder paltern observations (with intens lly and quality) - } \\
\hline & & & $\frac{\text { lcc \&I }}{\text { Lattice }}$ & $\begin{array}{l}\text { luoride ph } \\
\text { Pattern }\end{array}$ & $\begin{array}{l}\text { ange } \\
\text { Composition" } \\
\text { Euf }_{2+x}\end{array}$ & \multicolumn{2}{|c|}{ Additional phases" } & Commente \\
\hline $1.00^{8}$ & $\begin{array}{l}\text { lat phase tan, trangparent, and } \\
\text { none-birefringent }\end{array}$ & 1 & $5.80_{B}$ & $\mathrm{~m}, \mathrm{t}$ & EuF $_{2.28}$ & 8.8 & EuOF & - \\
\hline & $\begin{array}{l}\text { 2nd phase colorless, tranaparent, } \\
\text { and blrefringens }\end{array}$ & 2 & $5.83_{0}$ & 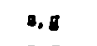 & EuF $_{2.00}$ & $m, p$ & EuOF & - \\
\hline & & 3 & $5,81_{4}$ & 8,6 & $E u F_{2.20}$ & .8 & EuOF & - \\
\hline 0.82597 & $\begin{array}{l}\text { 1st phase colorless, transparent, } \\
\text { and non-birefringent } \\
\text { and phase light tan, transparent, } \\
\text { and birefringent (Boih phases } \\
\text { about equal in amount]. }\end{array}$ & 1 & $5.78_{5}$ & n. 1 & EuF $_{2.27}$ & 8. 8 & EuOF & - \\
\hline $0.818^{5}$ & $\begin{array}{l}\text { Same as prevlous sample but with } \\
\text { opaque melallic inclusions } \\
\text { (Mo contamisation) }\end{array}$ & 1 & $5.78_{3}$ & m, $\mathbf{l}$ & EuF $_{2.28-2.43}$ & $\Delta .8$ & EuOF & $\begin{array}{l}\text { Interior of } \\
\text { cructble corroded }\end{array}$ \\
\hline $0.667^{15}$ & $\begin{array}{l}\text { 1st phase colorleas, transparent. } \\
\text { ond brighily birefiringent } \\
\text { and phase tan, traneparent with } \\
\text { oome optical denulity, and } \\
\text { birefringent }\end{array}$ & $\mathbf{t}$ & $5.18_{3}$ & s, 8 & $E_{2,28-2,43}$ & $\begin{array}{l}\text { Pattern } \\
\text { Hlar to E }\end{array}$ & 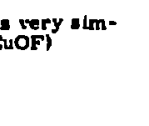 & \\
\hline $0.667^{5}$ & $\begin{array}{l}\text { Same as previous sampie but with } \\
\text { opaque metallic incluatons } \\
\text { (Mo contamination) }\end{array}$ & $\mathbf{I}$ & $5.18_{3}$ & $\mathbf{m}, t$ & $E_{2 u F_{2.28-2.43}}$ & $m_{1} \mathbf{l}$ & EUOF & $\begin{array}{l}\text { Interlor of } \\
\text { cructble corroded }\end{array}$ \\
\hline $0.400^{51}$ & $\begin{array}{l}\text { A! least two colorleds, trensparent } \\
\text { phated, with some birofringence }\end{array}$ & 1 & $5.78_{2}$ & 8.8 & $E u F_{2.28-2.43}$ & $\begin{array}{l}\text { Patterna } \\
\text { EuOF but } \\
\text { lattice pa: }\end{array}$ & $\begin{array}{l}\text { oimilar to } \\
\text { with different } \\
\text { ramelers. }\end{array}$ & $\begin{array}{l}\text { (Sample perhaps not } \\
\text { completely' melied }\end{array}$ \\
\hline $0.389^{118}$ & $\begin{array}{l}\text { Ist phase brown, Iranaparent. and } \\
\text { weakly birefringent } \\
\text { and phase colorless, transparent, and } \\
\text { and non-birefringent }\end{array}$ & d & $5.78_{3}$ & 1.8 & EuF $_{2.28-2.43}$ & $\begin{array}{l}\text { (Several u } \\
\text { lines)! }\end{array}$ & inidentified & Cooled slowly \\
\hline
\end{tabular}

Powder paltern observetions rated at follows:

- Iar: p - poor

"EuF $F_{9+x}$ solid solution: compositionu derived from latisce parameter, Ret. \{2|.

"Phases identified from patterna corresponding to the following atructurea:

EuO $(f(c))_{-a} \cdot 3.14 \mathrm{~s} A$

Eu, o, (orthorhombic)-e = 10,09 $\dot{A}_{\text {: }} b=12,07 \dot{A}_{i} c=3.50 \dot{A}$

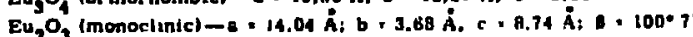

Eu, $\mathrm{O}_{3}$ (bec) - $=10.88_{\mathrm{B}} \dot{A}$

EuOF (rhombohedral, hexagonal representalion)- $=3.88_{4} A_{i}=18.34 \mathrm{~g}$

Container: Mo

IS Contatner: P-100, th 
excess $\mathrm{LnF}_{3}$ that have either the nuorite or a clusely related structure, the extra fluoride ions are introduced as pairs, one substituting for an oxide ion and the other as an associated interstitial ion. Changes in structure involving ordering of these "defects" require interdiffusion of the anions. As pointed out by Brauer, ${ }^{49}$ dimorphic transitions become more difficult in these syatems as the interstitial sites are filled.

In the reduced fluoride systems with compositions $\mathrm{LnF}_{2+x^{\prime}}$ the excess $\mathrm{F}^{-}$ions are introduced as associated pairs of interstitial $\mathrm{F}^{-}$ ions and trivalent cations. Phase changes in these systemc should occur more readily because they require only local rearrangements of anions and electron transfers. In fact, the manifestation of this behavior is observed in the difference between DTA thermograms for the difluoride-trifluoride, ${ }^{35}$ and the oxide-Ruoride sysiems. The hysteresis for nonstoichiometric samples is much more pronounced for the oxyfluoride material.

\section{The Ternary Sygtem in the Region Bounded}

by the Composition EuF $2-$ EuF $_{3}-\mathrm{Eu}_{2} \mathrm{O}_{3}-\mathrm{EnO}_{1}$

Compositions within the ternary fleld were prepared by equilibrating mixtures of $\mathrm{EuF}_{3}$ and EuO. The mixtures were encapsulated in either Mo or $\mathrm{Pt}-10 \mathrm{Rh}$ crucibles and sealed by $\mathrm{r}: \mathrm{BW}$. Starting materiais were the $\mathrm{EuF}_{3}$ and EuO already described. Mulybdenum crucibles were used for mixtures for which the EuO/EuF mole ratio ex $_{3}$ ceeded 0.67 and Pt-10Rh crucibles for mixtures with EuO/EuF $3 \leq 1.50$. Several intermediate compositions were heated in both kinds of containers. The samples were held at $1500^{\circ} \mathrm{C}$ in an induction furnace for at least $2 \mathrm{hr}$ before being cooled rapidy. Two samples were couled slowly after annealing at $1500^{\circ} \mathrm{C}$.

The products of the equilibrated mixtures of $\mathrm{EuF}_{3}$ and EuO were examined by $x$-ray powder diffraction and optical microscopic techniques. (See Table $11-2$. )

Optical identification of EuO and $\mathrm{Eu}_{3} \mathrm{O}_{4}$ is unambiguous because no other phases in this $5 y$ stem appeas yimilas to eiurier of these materials. Fiuorides on the divalent side of $\mathrm{EuF}_{2.1}$ are transparent, nearly 
colorless, and nonbirefringerit. Fluorides from EuF $\mathrm{F}_{2.1}$ to $\mathrm{JuF}_{2.3}$ are transparent, light brownish-yellow, and weakly birefringent. Compositions from EuF 2.3 to $\mathrm{EuF}_{3}$ are transparent, nearly colurless, and brightly birefringent. ${ }^{39}$ it is difficult to detect small concentrations of EuO in $\mathrm{Eu}_{3} \mathrm{O}_{4}$ or of $\mathrm{EuF}_{2+x}$ in one of the other transparent culorless phases. It is not possible to distinguish between EuF, EuOF, and $\mathrm{Du}_{2} \mathrm{O}_{3}$ without using more sophisticated techniques than those applied in this study. However, very small amounts of EuO can be detected in phases other than $\mathrm{Eu}_{3} \mathrm{O}_{4^{*}}$. It is also easy to detect very small amounts of onc of the trivalent species or of $\mathrm{Eu}_{3} \mathrm{O}_{4}$ in any of the other phases.

The compositions of the nuor ides found in the products were obtained from $x$-ray lattice parameters by using data reported in Ref. 39. In a number of runs, microscopic examination indicated the presence of more than one fuoride composition. For these cases, $x$-ray powder diffraction patterns were taken for several samples. The $x$-ray data confirmed that two different nuoride compositions were present in some of the products, and three nuoride compositions were found in one sample. The composition of crystalline products in rapidly cooled samples depends upun the phase boundary surfaces in the system and the crystallization paths. Since my samples were coolcd rapidly, equilibrium was not necessarily maintained, and more than three phases were found in some of the products.

The interpretation most consistent with the ternary equilibration data, the $\mathrm{Eu}_{2} \mathrm{O}_{3}-\mathrm{EUF}_{3}$ pseudo-binary shown in Fig. II-2, and the EuO- Eu ${ }_{2} \mathrm{O}_{3}$ binary system (see Ref. 8 and Part I of this thesis) is illustrated in Fig. II-1.

\section{Conclusions}

The ternary equillbria in the Eu-O-F systems are well established at $1500^{\circ} \mathrm{C}$, with the following exceptions. The number, compositions, and structures of the oxyfluoride phases in the range $\sim$ EuO $_{0,6} \mathrm{~F}_{1,8}$ to EuO $0,8 \mathrm{~F}_{1.2}$ are uncertain. The phase diagram (Fig. II- I) is drawn on the assumption that the $\mathrm{EuF}_{3}-\mathrm{Eu}_{2} \mathrm{O}_{3}$ system is binary and correctly represented in Fig. II-2. The liquidus points on 
the $\mathrm{EuF}_{3}-\mathrm{Eu}_{2} \mathrm{O}_{3}$ and $\mathrm{EuF}_{2}-\mathrm{EuO}$ joins can be estimated with fair reliability, but the liquid-solid phase boundaries in the intermediate region are pure speculation. The products of the $\mathrm{EuF}_{3}$-Eu() r(actions all appeared to have been completely melted; but since the samisles were not crushed and reheated nor analyzed by DTA, the pnssibiiity that sone of these compositions could have been only partially liquid at $1500^{\circ} \mathrm{C}$ cannot be excluded. The diagram in Fig. $11-1$ is drawn as if there were only une liquid phase, but there is no direct evidence for this interpretation. A miscibility gap may exist between aniun-rich and metai-rich liquids similar to the gaps found in other lanthanonlanthanon-halide systems. ${ }^{56-62}$ The region of the system on the metal-rich side of EuO-EuF ${ }_{2}$ has not been investigated.

There is clearly no evidence for a ternary compound in this system other than those between $\mathrm{EuF}_{3}$ and $\mathrm{Eu}_{2} \mathrm{O}_{3}$. It is possible that une or more other ternary compounds may exist; but I think this unlikely, as yo such phase was evidenced in any of the preparations - neither in those cooled rapidly nor in those cooled slowly.

The optical and $x$-ray properties of the three uxide phases prepared in the uresence of fluorides are identical tu thrse ubserved for samples in which no fluoride was present. Also, the properties of the Iuorides forned in the presence of oxides or axyfluorides are identical to those of nuorides for which analysis indicates negligible oxygen content. Therefore, I believe that the solubility of fluorides in any of the uxide phases or of axide in the fluorides is very small in the crystalline state. Since there were no color changes in the uxyfluoride samplies equilibrated with reduced fluorides similar to the color changes observed when lanthanon segquioxides are partially reduced (see Ref. IS and Part I of this thesis), partially reduced or aniondeficient lanthanon oxyfluorides may not be stable. One would have expected to ubserve partially reduced solid solutions based on the fiuorite structure $w$ ith anion vacancies, particularly in the eurupium oxyfluoride system. 
VAPORIZATION STUDIES

Part III

A MASS SPECTROMETRIC INVESTIGATION OF THE SUBLIMATION OF HAFNIUM AND ZIRCONIUM FROM A DILUTE HAFNIUM ALLOY

\section{Abstract}

The vaporization of hafnium and zirconium from a hafnium alloy filament with an initial zirconium content of 5 at.\% was studied over the temperature interval 1800 to $2300^{\circ} \mathrm{K}$, using a mass spectrometer. Least-squares analyses of hafinium ion intensity vs temperature data by the second-law method gave a standard enthalpy of sublimation at $298.15 \times, \Delta \mathrm{H}_{298}^{0}$, of $1: 33.6 \pm 3.0 \mathrm{kcal} / \mathrm{g}$ atom. Similar analyses of zirconium ion intensity data gave a standard partial molar enthalpy of sublimation, $\overline{\Delta H}_{298}^{0}$, of $148.8+3.4 \mathrm{kcal} / \mathrm{g}$ atom, which is in agreement within the estimated experimental errors with the standard enthalpy of sublimation of pure zirconium. The hafnium data were also analysed by the second-law and the third-law methods, with zirconium used as a reference, assuming the alloy to be an ideal solution. Second-law evaluation of the intensity ratio data gave $\Delta \mathrm{H}_{298}^{0}=150.04 \pm 2.3 \mathrm{kcai} / \mathrm{g}$ atom, and the third-law treatment gave an average value of 148.5 $+2.5 \mathrm{kcal} / \mathrm{g}$ atom, for the entha!py of sublimation of hafnium.

\section{Introduction}

Experimental values for the enthalpy of sublimation of hafnium were unavaiiable when this investigation was started. Stull and Sinke ${ }^{63}$ estimated $\Delta \mathrm{H}_{298}^{0}=168 \mathrm{kcal} / \mathrm{g}$ atom, using a reported normal boiling point, and Krikorian ${ }^{64}$ estimated $\Delta \mathrm{H}_{298}^{0}=145 \mathrm{kcal} / \mathrm{g}$ atom by correlating properties of neighboring elements of the periodic table.

Subsequently, the vaporization of hafnium was studied by several investigators using Langmuir vaporization techniques ${ }^{65-68}$ and a mass-spectrometric Knudsen vaporization method. ${ }^{69}$ The results of these investigations were evaluated and reduced by use of a consistent set of thermodynamic functions. ${ }^{68,70}$ The value recommended by Fiultgren et al., ${ }^{70}$ based on Refs. $65-67$, is $\Delta H_{298}^{0}=148.0 \pm 1.0 \mathrm{kcal} / \mathrm{g}$ atom, and the results of Koch et al. ${ }^{68}$ for liquid hafnium are in 
agreement with that value. My results are slightly higher than these and are in accordance with Blackburn ${ }^{67}$ and Trulsen and Goldsteins ${ }^{69}$ results. Longfellow and wood ${ }^{71}$ reported the results of an investigation on the cohesive energy of hafnium in which they compare the cohesive energies of two materials by measuring the wear-rate ratios of the materials during a spark erosion process. Their result for hafnium was $185.5 \pm 8.5 \mathrm{kcal} / \mathrm{g}$ atom. Longfellow and Wood expressed concern about uncertainties in the thermodynamic properties of hafnium. Certainly, the properties must be reliably known in order to properly assess the significance of the anomalous wear-rate ratios observed with this element.

Work described in this thesis confirms the previously reported experimental determinations of the enthalpy of sublimation of hafnium and introduces a somewhat novel technique for using mass spectrometry to study vaporization phenomena.

A sensitive technique is required to study the vaporization of solid hafnium, since it has such a low vapor pressure (about $10^{-6}$ atm at the melting point, $2500^{\circ} \mathrm{K}$ ). The evaporation process may be complicated by reaction of hafnium with oxygen, in the environment or dissolved in the metal, to form a volatile oxide, even at low oxygen artivities. A mass spectrometer is both sensitive and selective. With such an instrument one can study individually each of the species vaporizing from a sample. And they can be studied even at very low partial pressures. Vapor species could be detected at vaporization rates corresponding to pressures as low as $10^{-12}$ atm in the system used for these experiments. This sensitivity refers to condensible species; the sensitivity for noncondensible gases is greater because of multiple passes through the ionizing region of the ion source made by noncondensible gas molecules. This high sensitivity permitted measurements to be madie over a temperature range greater than $500^{\circ} \mathrm{K}$, with a corresponding range in hafnium vapor pressure of four orders of magnitude from $\sim 10^{-11}$ atm at $1800^{\circ} \mathrm{K}$, to $\sim 10^{-7}$ atm at $2300^{\circ} \mathrm{K}$. The only detectable hafnium-containing species in the vapor emanating from the hafnium-zirconium alloy filaments were $\mathrm{Hf}(\mathrm{g})$ and $\mathrm{HfO}(\mathrm{g})$. The other important vapor species observed were $\mathrm{Zr}_{\mathrm{r}}(\mathrm{g})$ and $\mathrm{ZrO}_{\mathrm{r}}(\mathrm{g})$. 
In my experiments I used a metal filament inside the ion source, heated by self-resistance, as a vaporizing sample in order to obtain higher sensitivities than are ordinarily available with furnace sources.

I used a novel technique for determining the relationship between experimental ion intensities and vapor concentrations in which the reference element is dissolved in the sample material. This guarantees that geometrical effects will not introduce errors, since both reference and sample species originate at the same place.

My results indicate that the assumption of an ideal solution for the alloy is valid. Kubaschewski ${ }^{72}$ has also shown that the experimental phase diagram for the hafnium-zirconium system is consistent with the assumption of ideal solutions for both the solid and liquid phases.

\section{Equipment}

The mass spectrometer used was a 60-deg sector magnetic deflection instrument with a radius of curvature of $30.5 \mathrm{~cm}$. The instrument was described in a previous publication. ${ }^{73} \mathrm{~A}$ fast magnetic sweep $^{74}$ was used in these studies rather than the ion-accelerating voltage sweep. The magnetic field was swept in synchronization with a 256-channel, multichannel scaler, and signals were accumulated as described in Refs. 73-75 to obtain signal-to-noise enhancement. The field sweep was linear over the portion of the spectrum used for quantitative measurements. ${ }^{74}$ An ion-accelerating potential of $10,000 \mathrm{~V}$ was used for all measurements. An additional $4000-\mathrm{V}$ accelerating potential was provided between the analyser exit slit and the Dumont SP-172 electron multiplier used as an ion detector. The window of the photo multiplier was removed, and a nickel wire grid of about $97 \%$ transmission mounted over the first dynode was used as an electrostatic shield. The ion source is illustrated in Fig. III-1. The electron beam ionizer and sample filament were mounted inside a stainless steel box that was supported by a fused silica insulator plate in a carriage of an airlock system similar to the one described by Stevens. 76 Electrical leads were brought into the vacuum system through tungstenin-glass seals in the core of the carriage. Components of the ion source were supported on nickel-through-alumina feedthroughs to which the electrical connections were made. A rhenium filament was 


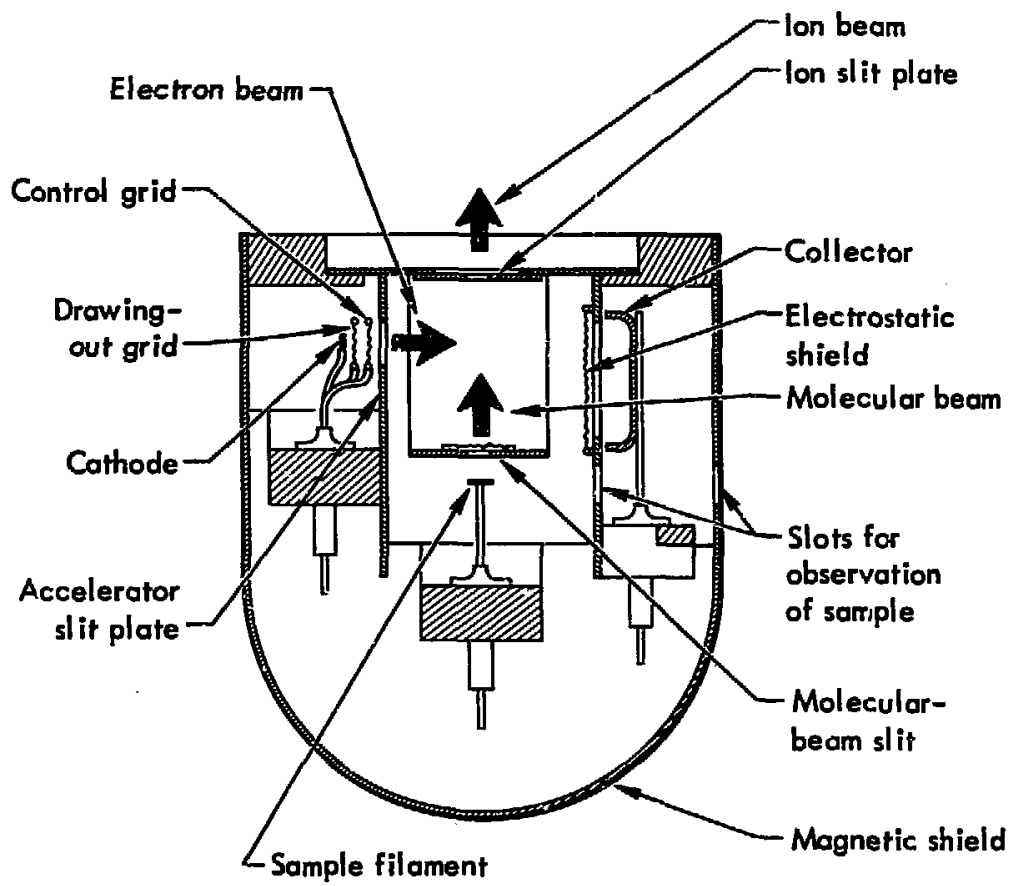

Fig. III-1. Schematic diagram of ion source. 
used as a cathode. Magnetic field and electrostatic field shielding was provided by a sheet of an iron alloy ( $\mu$-metal) wrapped around the outside of the source box. Tungsten or nickel mesh of about $97 \%$ transmittance was used for the grids and over all openings to the ion source, except for apertures used for temperature measurement. The cathode potential was adjustable from -5 to $-80 \mathrm{~V}$, and the collector was operated at $+75 \mathrm{~V}$, relative to the steel box. The control grid voltage was determined by the collector current to $\pm 0.3 \%$. A potential of $+10,000 \mathrm{~V}$ was applied to the ion source. Molecules and atoms in the molecular beam were ionized by electron bombardment. Positive ions were extracted from the source box by the field that "leaked" through the source ion slit and then were accelerated into the analyser. The ion beam was aligned and focused by rotating the carriage and adjusting the potentials on a set of crossed field electrostatic alignment and focus plates in front of the analyser entrance slit.

Samples used were in the form of filaments spot-welded to 0.1by $10-\mathrm{mm}$ tantalim electrodes that were folded to put the sample under slight tension in order to maintain alignment as the filament expanded on heating. The filaments were heated resistively with a 12-V, 20-A, regulated d.c. power supply. Preliminary measurements with zirconium and hafnium filaments and the first series of data reported for hafnium were made without using the molecular beam slit plate shown in Fig. III-1 to isolate the sample from the ionizing region.

An ion-pump vacuum system maintained the residual gas pressure at $2 \times 10^{-8}$ to $1 \times 10^{-7}$ Torr in the ion source region during the measurements. Temperatures were measured with a disappearing filament optical pyrometer that had been calibrated to the International Practical Temperature Scale of 1948. Pyrometric lamps calibrated by the National Bureau of Standards were used as stcondary standards. The specimen was observed through a $0.5-$ by $1.0-\mathrm{cm}$ slot in the ion source box and a window in the vacuum chamber from a distance of $15 \mathrm{~cm}$. A correction factor for absorption and reflection by the window was determined before it was installed on the spectrometer. The window was protected by a shutter except during observations. 
Since this was the first investigation of this nature conducted with this apparatus, a preliminary experiment was carried out with zirconium, an element similar to hafnium, for which the enthalpy of sublimation was known.

\section{Zirconium}

Experimental

The zirconium filament was made from a strip of foil 45 by 7 by $0.025 \mathrm{~mm}$. The principal impurities determined by spectrographic analysis were $5000 \mathrm{ppm}$ iron and $200 \mathrm{ppm}$ chromium. No other metallic impurity exceeded $20 \mathrm{ppm}$. This strip was iolded into a tube of triangular cross section $2.5 \mathrm{~mm}$ on a side. A gap was left between the edges of the strip, forming a slit down the center of one side of the tube about $0.3 \mathrm{~mm}$ wide. This sample filament was spot-welded to the tantalum electrodes in the ion source so that one flat side faced the ion slit and the side with the $0.3-\mathrm{mm}$ gap faced the window of the vacuum system.

After the system was degassed for several hours with the sample at about $1350^{\circ} \mathrm{C}$, the temperature was increased to about $1600^{\circ} \mathrm{C}$ and the spectrum was surveyed by sweeping the magnetic field slowly while observing the ion intensitic.s with a count-rate meter and oscilloscope as described in Ref. 73. Peaks from the sample were found only at mass-to-charge ratios, $\mathrm{m} / \mathrm{e}$, corresponding to $\mathrm{Zr}, \mathrm{ZrO}$, and alkali metal ions. Peaks from residual geses and organic materials were also present. The ionization voltage for the survey was $30 \mathrm{~V}$.

The magnetic field sweep was then set to give a spectrun including $\mathrm{m} / \mathrm{e}=89$ to 91 in the linear range. The slits were adjusted and the instrument tuned to give trapezoidal-shaped mass peaks with half widths of about 20 channels on the 256-channel scaler. Hesolving power was about 200, giving separations between adjacent mass peaks about equal to the peak widths. The spectrum for increasing magnetic field was collected in the first 128 channels and that for decreasing field in the remaining 128 channels of the scaler. Spectra were accumulated at a sweep frequency of about 2 sweeps per second for 
times from about 1 to $20 \mathrm{~min}$. Intensities were normalized to $1.92 \mathrm{~min}$, the summing time used for most of the measurements.

The emission regulatcr was set for an ionizing voltage of $11.5 \mathrm{~V}$ and a collector current of $25 \mu \mathrm{A}$. Ion intensities were measured with the filament at temperature and the electron bombardment current turned off, to determine the background due to therinal ions from the sample filament. Intensities were measured with the electroijbombardment ionizer on immediately after turning the sample temperature down to obtain the background due to residual vapors in the system.

Tempurature measurements were made by observing the $0.3-\mathrm{mm}$ slit and the surface next to the slit. Temperatures used were the average of three measurements, one each before and after counting the gross intensities and one after the thermal-background determination. The spread between extremes for a given run was usually less than $5^{\circ} \mathrm{C}$. Intensity measurements were also made for $\mathrm{m} / \mathrm{e}=105$ to 107 , corresponding to ŻrO ${ }^{+}$, at an ionizing voltage of $17.5 \mathrm{~V}$.

\section{Calculations}

Ion intensity data were printed out as sums of accumulated counts in the multichannel scaler over a number of channels fewer than the number across the flat tops of the peaks. The gross observed intensity of a given ion was taken as the largest sum of counts in the channels across the tops of the increasing magnetic field peak and the decreasing field peak, and was normalized to $1.92 \mathrm{~min}$. For the zirconium experiments, the data were printed out as running sums of 8 channels, so the intensities are the total number of counts accumulated in 16 channels corresponding to the tops of the peaks in $1.92 \mathrm{~min}$. The gross observed intensity for $\mathrm{m} / \mathrm{e}$ is referred to as $\mathrm{N}_{0}^{\mathrm{m}}$. The corresponding thermal ion background $\left(B_{t}^{m}\right)$ was taken as the sum of counts in the same channels with the bombardment current off, and the sum in these channels with the sample cool and the bombarament current on was used for the background due to residual vapors $\left(B_{r}^{m}\right)$. The positions of the background peaks were generally displaced from the principal spectra, so the background values did not usually correspond to the tops of the background peaks. 
Coincidence corrections were applied as described i:1 Ref. 73. The "saturation counting rate" $\left(\mathrm{N}_{\mathrm{S}}\right)$, an instrumental constant, was determined by plotting the $\mathrm{N}_{0}^{185} / \mathrm{N}_{0}^{187}$ ratio vs $\mathrm{N}_{0}^{185}$ for several spectra from a thermal ionization source with a rhenium filament. At this mass with a thermal source, the background was negligible. $N^{185} / N^{187}$ is a linear function of $\mathrm{N}^{185}$, and $\mathrm{N}_{\mathrm{S}}$ is the intercept on the $\mathrm{N}^{185}$ axis where $\mathrm{N}^{185} / \mathrm{N}^{187}$ extrapolates to 1.0 . The intensity of a given peak due to neutral atoms or molecules evaporating from the sample is $I^{m}=N_{o}^{m} /\left(1-N_{o}^{m} / N_{s}\right)-B_{t}^{m} /\left(1-B_{t}^{m} / N_{s}\right)-B_{r}^{m} /\left(1-B_{r}^{m} / N_{s}\right)$.

A CDC-6600 computer was used to calculate standard enthalpies of sublimation, $\Delta \mathrm{H}_{298}^{0}$, from the intessity-vs-temperature data by the method of least-squares, using the second iaw of thermodynamics. If one has pressure-vs-temperature data, it can be analysed by the second-law and third-law methods, both, using the equation

$$
-R \ln P^{0}-\Delta\left(\frac{G_{T}^{0}-H_{298}^{0}}{T}\right)=\Delta H_{298}^{0} 1 / T+\delta,
$$

where $R$ is the gas constant, 1.98717 gibbs/mole. $P^{0}$ is the pressure of the pure substance in atmosphere at temperature $\mathrm{T}^{\circ} \mathrm{K}$;

$$
\Delta\left(\frac{\mathrm{G}_{\mathrm{i}}^{\mathrm{i}}-\mathrm{H}_{298}^{0}}{\mathrm{~T}}\right)
$$

is the difference between the iree energy functions (fef) for the gas and condensed phases, and $\delta$ is the difference between the entropy of sublimation implicit in the free energy functions and the value consistent with the temperature dependence of the vapor pressure. In third law calculations, $\delta$ is taken to be 0 .

The mass spectrometry data do not give pressures directly, but the intensity of a given ion is proportional to the concentration of the species from which it was formed, $C^{\mathbf{z}}: F^{\mathbf{z}} \mathbf{I}^{\mathbf{m}}$, where $\mathrm{C}^{\mathbf{z}}$ is the concentration of atoms or molecules from which ions of $\mathrm{m} / \mathrm{e}$ are formed and $F^{z}$ is the sensitivity factor of the mass spectrometer for species $z$, including isotope abundance, ionization efficiency, ion extraction 
efficiency, transmission and detector efficiency. We can then relate ion intensity to pressure by using the ideal gas law:

$$
P_{(z)}=R C^{\mathbf{z}} T=R F^{z I^{m}} T .
$$

Our mass spectrometric data were analysed by using a variation of Eg. III-2 in the form

SIGMA $=-R \ln I^{m} T-\Delta\left(\frac{G_{T}^{0}-H_{298}^{0}}{T}\right)=\Delta H_{298}^{0} 1 / T+K$,

where $K \cdot \delta+R$ ln $R^{z}$. The free energy' functions were taken from Hultgren et al. 77

\section{Results}

Emittances for the zirconium filament were calculated from the temperature observations of the slit and surface adjacent to the siit, assuming the slit to be a blackbody. The effective wavelength for the pyrometer was assumed to be $0.65 \times 10^{-4} \mathrm{~cm}$, and $1.4380 \mathrm{~cm}^{\circ} \mathrm{K}$ was used for the radiation constant, $C_{2}$. The results are listed in Table III-1. The average value for the emittance of $\beta \mathrm{Zr}, \epsilon .65$, over the temperature range $1660^{\circ}$ to $2040^{\circ} \mathrm{K}$ was $0.439 \pm 0.024$. The emittance was independent of temperature within our precision. These results are in agreement with published values for the emissivity of zirconium. Bradshaw reports $\epsilon_{0.655}=0.426 \pm 0.013$ for $\beta Z$ r, essentially independent of temperature from 1300 to $1810^{\circ} \mathrm{K} .{ }^{78} \mathrm{Zwikker}$ gives $\epsilon_{0.65}=0.43$ for $\beta Z r .{ }^{79}$ Our results might be expected to be high because the surface was not polished and the slit might not have been a perfect blackbody. Color matching of the zirconium filament or blackbudy slit to the pyrometer filamert was poor because of interference bv grid wires of the electrostatic shield, which extended across the observation slot and were too closely spaced. This problem was eliminated by cutting away part of the grid before starting the hafnium studies.

The ion intensities vs temperature are listed in Table III-1 and graphs of. -sigma vs l/'T are shown in Fig. III-2. Residual gas 
Table III-1. The sublimation of zirconium as a function of temperature measured by ion intensity, using a mass spectrometer, and the spectral emittance of a zirconium filament.

\begin{tabular}{|c|c|c|c|c|c|}
\hline $\begin{array}{l}\text { Run } \\
\text { No. }\end{array}$ & $\begin{array}{c}\text { Termperature } \\
\left({ }^{\circ} \mathrm{K}\right)\end{array}$ & $\begin{array}{c}\text { Emittance } \\
\left(0.65 \times 10^{-4} \mathrm{~cm}\right) \\
\end{array}$ & $\begin{array}{l}-\mathrm{R} \ln (\mathrm{IT}) \\
\text { gibbs/mole } \\
(\mathrm{m} / \mathrm{e}=90)\end{array}$ & $\begin{array}{l}\text { - R In (IT) } \\
\text { gibbs/mole } \\
\text { (m/e }=91)\end{array}$ & $\begin{array}{c}-\Delta \text { (fef) } \\
\text { gibbs/mole }\end{array}$ \\
\hline 353 & 1662 & 0.436 & -29.110 & & 33.164 \\
\hline 350 & 1714 & 0.443 & $-3 i .647$ & $-28,745$ & 33,121 \\
\hline 358 & 1751 & 0.459 & -33.192 & -30.310 & 33.093 \\
\hline 361 & 1780 & 0.456 & -35.317 & -32.400 & 33.070 \\
\hline 366 & 1817 & 0.430 & -36.281 & -33.277 & 33.045 \\
\hline 369 & 1818 & 0.439 & -36.877 & & 33.045 \\
\hline 374 & 1838 & 0.454 & -37.935 & -34.964 & 33.033 \\
\hline 377 & 1865 & 0.445 & -39.197 & -36.203 & 33.017 \\
\hline 382 & 1899 & 0.437 & -40.082 & -37.091 & 32.997 \\
\hline 385 & 1935 & 0.416 & -41.480 & -36.455 & 32.969 \\
\hline 391 & 1955 & 0.436 & -42.386 & -39.370 & 32.953 \\
\hline 394 & 2004 & 0.424 & -43.925 & -40.892 & 32.914 \\
\hline 399 & 2043 & 0.430 & $-45,350$ & -42.325 & 32.891 \\
\hline
\end{tabular}




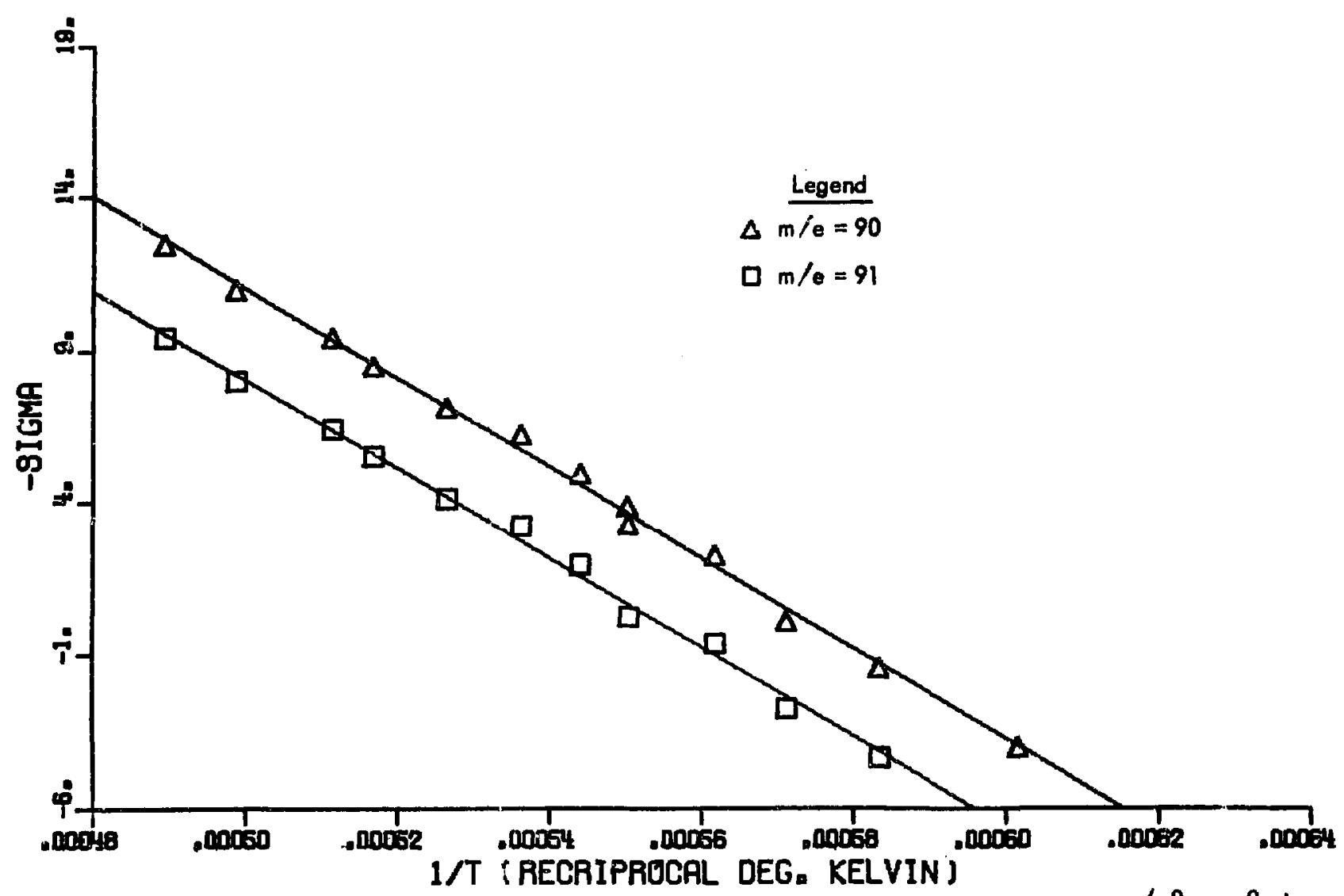

Fig. III-2. Sigma glot for the sublimation of zirconium. -Sigma $=R$ In $(I T)+\Delta\left(\frac{G_{T}^{0}-H_{298}^{0}}{T}\right)$. 
backgrounds, $B_{r}^{m}$, were 283 for $m / e \quad 90$ and 140 for $m / e=91$. $B_{t}^{m}$ ranged from $2.2 \times 10^{2}$ to $7.974 \times 10^{4}$ for $\mathrm{m} / \mathrm{e} \quad 91$ and from $4.0 \times 10^{2}$ to $1.368 \times 10^{5}$ for $\mathrm{m} / \mathrm{e}=90$. At temperatures above $1900^{\circ} \mathrm{K}$ the experimental isotope ratios $\mathrm{I}^{90} / \mathrm{I}^{91}$ agreed within $1 \%$ with the literature value of 4.582. 80 The apparent isotope ratios decreased with decreasing temperature to a value of 4.30 at $1714^{\circ} \mathrm{K}$, indicating a sys . tematic error in background corrections. The results are represented by the equations

$$
\text { Sigma }(90)=(148.2 \pm 5.0) \times 10^{3} / \mathrm{T}-85.1 \pm 2.8
$$

and

$$
\text { Sigma }(91)=(146.6 \pm 6.6) \times 10^{3} / T-81.3 \pm 3.6 \text {, }
$$

where the uncertainties include only the statistical variations in the intensity vs temperature data. Throughout this report uncertainties indicated that te represent two standard deviations as recommended by Rossini. ${ }^{81}$ The value for $\Delta \mathrm{H}_{298}^{0}$ obtained by combining the two results, weighting them inversely as their variances, as described in Ref. 81 , is $147.6 \pm 4.0 \mathrm{kcal} / \mathrm{g}$ atom. Hultgren et al. list $\Delta \mathrm{H}_{298}^{0} \cdot 145.5$ $\pm 1.0 \mathrm{kcal} / \mathrm{g}$ atom.

\section{Conclusions}

The enthalpy of sublimation measured in the preliminary study was slightly higher than the accepted value for zirconium, and the precision was not as good es hoped. However, the shortcomings seemed to result from three sources that could be corrected: the partial collimation of the optical path for temperature measurements; background errors mentioned previously; and a problem in the ion source, described below. The background errors could be reduzed by more extensive baking of the ion source before the measurements are made, in order to decrease the total background corrections.

After concleting the ion intensity-vs-temperature measurements, I observed that the ion intensity of a given species was a linear function of the collector current only up to a critical value that depended on the ionization voltage. At $11.5 \mathrm{~V}$, the voltage used for these measure = mests, the ion intensities were linear functions of collector current 
only up to asout $10 \mu \mathrm{A}$. I believe that the nonlinearity is a result of electron-beam geometry changes with field variations within the source, as the control-grid potential changes. In the nonlinear region, the electron-beam geometry is likely to be more susceptable to variations in magnetic field resulting from changes in current through the sample filament. This problem was alleviated by installing the drawing-out grid. Placing a positive voltage on this grid allowed me to achieve ion intensities that were linear functions of collector current to collector currents of $20 \mu \mathrm{A}$ at $11.5 \mathrm{~V}$. All intensity measurements for the subsequent studies were made under conditions where the ion intensities were linear with collector current.

Since I believed that the problems discussed above accounted for the excessive scatter and any major systematic errors, the hafnium experiments were started without further preliminary tests with zirconium.

\section{Hafnium}

\section{Experimental}

The hafnium filaments were made from 0.25 - by 2.54- mm ribbon (obtained from the Wah Chang Corporation, Albany, Oregon, in 1961).*

The ion source was modified as discussed in the previous section and, in addition, after the first run with hafnium tine molecular beam slit shown in Fig. III- 1 was added. This allowed a bias voltage to be applied to the sample, reducing the thermal ion background substantially.

The data register and sweep signal systems : re modified to compensate for the dead time by extending the court.ug time in each channel by an appropriate amount. Each time a pulse was counted, the pulses that drive the multichannel scaler were gated-off for a period of time equal to the dead time of the system. Data were taken for a tixed number of sweeps rather than for a constani total elapsed time. Since the magnet sweep signal was generated by the same pulses that stepped the

\footnotetext{
This was part of the same material used in the high-temperature electrical resigtivity and allotropic transformation studies reported in Ref. 82.
} 
scaler, the field was still a linear function of channel pusition, and the position of the spectral features were not affected by intensity changes. The gate time could not be adjusted to completely eliminate the dead time corrections. For the first few runs the delay was too short, and for the subsequent muns it was too long, leading to negative effective dead times. The coincidence correction factor was measured each day a zun was made, either by using the rhenium filament thermal ion source or by plotting ion intensity ratios from the hafnium filament, $I^{180} / I^{179}$ vs $I^{180}$. When both methods were used, they were in agreement. Although modifying the system did not entirely eliminate the necessity for coincidence corrections, the magnitude of the corrections was reduced by factors of 0.1 to 0.01 .

After the system was baked-out with the sample at about $1500^{\circ} \mathrm{C}$ for several days, a survey of the spectrum was made with an ionizing voltage of $20 \mathrm{~V}$ and the sample at about $1650^{\circ} \mathrm{C}$. The only important vapor species from the sample were $\mathrm{Hf}(\mathrm{g}), \mathrm{HfO}(\mathrm{g}), \mathrm{Zr}(\mathrm{g}), \mathrm{ZrO}(\mathrm{g})$ and alkali metals. The intensity ratios of mass peaks for each species were determined by sweeping the appropriate mass ranges. Currected relative intensities agreed with the isotope ratios given by Strominger et al. 80

Several attempts were made to relate the intensity ratios of $\mathrm{HFO}^{+} / \mathrm{Hf}^{+}, \mathrm{ZrO}^{+} / \mathrm{Zr}$, and $\mathrm{HfO}^{+} / \mathrm{ZrO}^{+}$to temperature and oxygen partial pressure. Only approximate values were obtained, because cunstant oxygen pressures could not be maintained in the system long enough to achieve sieady state. The magnitude of the $\mathrm{MO}^{+}$intensities are of interest, as they indicate the extent of the reaction between the filament and oxygen in the system. With the filament heated to about $2000^{\circ} \mathrm{K}$, the $I^{196} / \mathrm{I}^{180}$ ratio was 0.015 when the total pressure in the source region of the spectrometer was $3 \times 10^{-8}$ Torr. The residual gas spectra indicated the presence of $\mathrm{CO}$ and $\mathrm{N}_{2}, \mathrm{H}_{2} \mathrm{O}$, and $\mathrm{Ar}$ in order of decreasing importance with traces of other species. At a source manifold pressure of $1 \times 10^{-7}$ Torr, with residual gases $\mathrm{N}_{2}$ and $\mathrm{CO}, \mathrm{H}_{2} \mathrm{O}$, $\mathrm{O}_{2}$, Ar, and $\mathrm{CO}_{2}$, plus traces of other species, the $\mathrm{I}^{196 / \mathrm{I}^{180}}$ ratio was 0.5. The $\mathrm{I}^{106}$ intensities from $\mathrm{ZrO}$ were too low and variable to be even qualitatively useful at a source pressure of $3 \times 10^{-8}$ Torr. At $\sim 1 \times 10^{-7}$ Torr, the $I^{106 / I^{90}}$ ratio seemed to be somewhat greater than 
the $I^{196} / I^{180}$ ratio. The data wer'e taken with an ionizing energy of $12.5 \mathrm{~V}$. Studies of this type with a reliable oxygen gas inlet system could yield interesting results concerning the thermodynamics and kinetics of reacticons involving hafnium, zirconium, and oxygen, or similar systems.

During the course of these experiments and some ionization efficiency measurements to be discussed later in the paper, the $\mathrm{Zr}^{+} / \mathrm{Hf}^{+}$, $I^{90} / I^{180}$, ratio had desreased significantly. Before the experiments were continued, the filament was replaced by a new one and instrumental adjustments were made to obtain optimum sensitivity and resolution.

Specimens cut from the ends of the sample filaments during fabrication and from the center section of the used filament were analysed by the chemical methods described in Ref. 82 ; they contained $2.25 \pm 0.1$ and $1.70 \pm 0.1 \mathrm{wt} \%$ zirconium, respectively. The filament used for the remaining experiments also exhibited a decreasing $\mathrm{I}^{90} / \mathrm{I}^{180}$ ratio as the studies progressed. The filament burned out at the end of the final experiments, so a post-mortem analysis of the center section was impossible. The residue from the ends of this filament was analysed and found to contain $2.9 \mathrm{wt} \%$ zirconium. These results indicate that zirconium depletion of the sample occurs primarily due to diffuzion of zirconium to the cooler ends of the filament. From the analytical results or the first filament, I was able to estimate the rate of zirconium depletion of the samples and found that they were in agreement, within random errors to the changes in intensity ratios.

After the system was baked again for several days to reduce the residual gas backgroind, measurements of intensity as a function of temperature were made for $\mathrm{Hf}^{+}(\mathrm{m} / \mathrm{e}=179$ to 181$)$ at $11.0 \mathrm{~V}$ ionization energy and for $\mathrm{Zr}^{+}(\mathrm{m} / \mathrm{e}=89$ to 91$)$ at $12.0 \mathrm{~V}$. The energy used for $\mathrm{Zr}^{+}$ was as high as possible to give maximum sensitivity. The energy was maintained below the second ionization potential of hafnium to eliminate the contribution of $\mathrm{Hf}^{++}(180)$ to the $\mathrm{m} / \mathrm{e}=90$ peak. The second ionization potential of hafnium is estimated to be about the same as for $\mathrm{Zr}$, 13.13 V. 83 Intensities of $\mathrm{HfO}^{+}(\mathrm{m} / \mathrm{e}=195$ to 197$)$ and $\mathrm{ZrO}^{+}(\mathrm{m} / \mathrm{e}-105$ to 107) were measured at an ionizing energy of $17.5 \mathrm{~V}$, to establish that the gaseous oxide concentrations were not high enough to interfere with 
the metal ion intensity measurements. The maximum intensity ratios observed during any of the vaporization measurements wrere $I^{196} / \mathrm{I}^{180} \sim 0.015$, and for most runs the ratio was less than $10^{-3}$.

All intensities are given as the sum of counts in a selected number of channels-constant throughout a given series and fewer than the number across the flat tops of the peaks - for $; 00$ sweeps, and increasing and decreasing field scans were added together. In diffierent series of measurements, data were summed over 4 to 16 channels. In series 540, all data were summed over 8 channels. In subsequent runs, twice as many channels were used in peaks for $\mathrm{m} / \mathrm{e}$ in the range 180 to 200 as for $\mathrm{m} / \mathrm{e}=90$ to 110 , because of the increase in peak width with $\mathrm{m} / \mathrm{e}$. This gave sums over corresponding parts of the peaks. The intensities were normalized to equivalent counting times. Ionization efficiencies as functions of ionizing energy were determined for $\mathrm{Hf}, \mathrm{Zr}$, and HfO. The measurements were made at different times and under a variety of conditions. The results normalized to maximum net intensities are shown in Figs. III-3 through III -5 . Voltages were read from a $1 \%$ meter on the emission regulator, which had been standardized with a calibrated meter. Readings were corrected for voltage drops across the current-carrying conductors between the points of meter connections and the center of the filament. The voltage scale was checked by measuring the ionization efficiency curve of argon, $m / e=40$, and no normalization factor was necessary. The energy distribution of the electron beam was the normal thermal distribution at about $2200^{\circ} \mathrm{K}$, plus a linear gradient of about $1 \mathrm{eV}$ across the ionization region due to the voltage drop across the effective part of the cathode. The appearance potential obtained for $\mathrm{Zr}^{+}$of $7.0 \pm 0.8 \mathrm{~V}$ agrees with the spectroscopic ionization potential given by Moore. ${ }^{83}$ My appearance potential of $6.0 \pm 0.8 \mathrm{~V}$ for $\mathrm{Hf}^{+}$is somewhat lower than Moore's estimate of 7.0 V. The appearance potential of $\mathrm{HfO}^{+}$was found to be $6.3 \pm 0.8 \mathrm{~V}$.

Most of the ionization efficiency measurements were made by scanning three adjacent peaks, as in the intensity-vs-temperature experiments. A number of spectra were taken at different ionizing voltages, holding the sample temperature and electron beam collector current constant. Intensity ratios were compared to isotope 


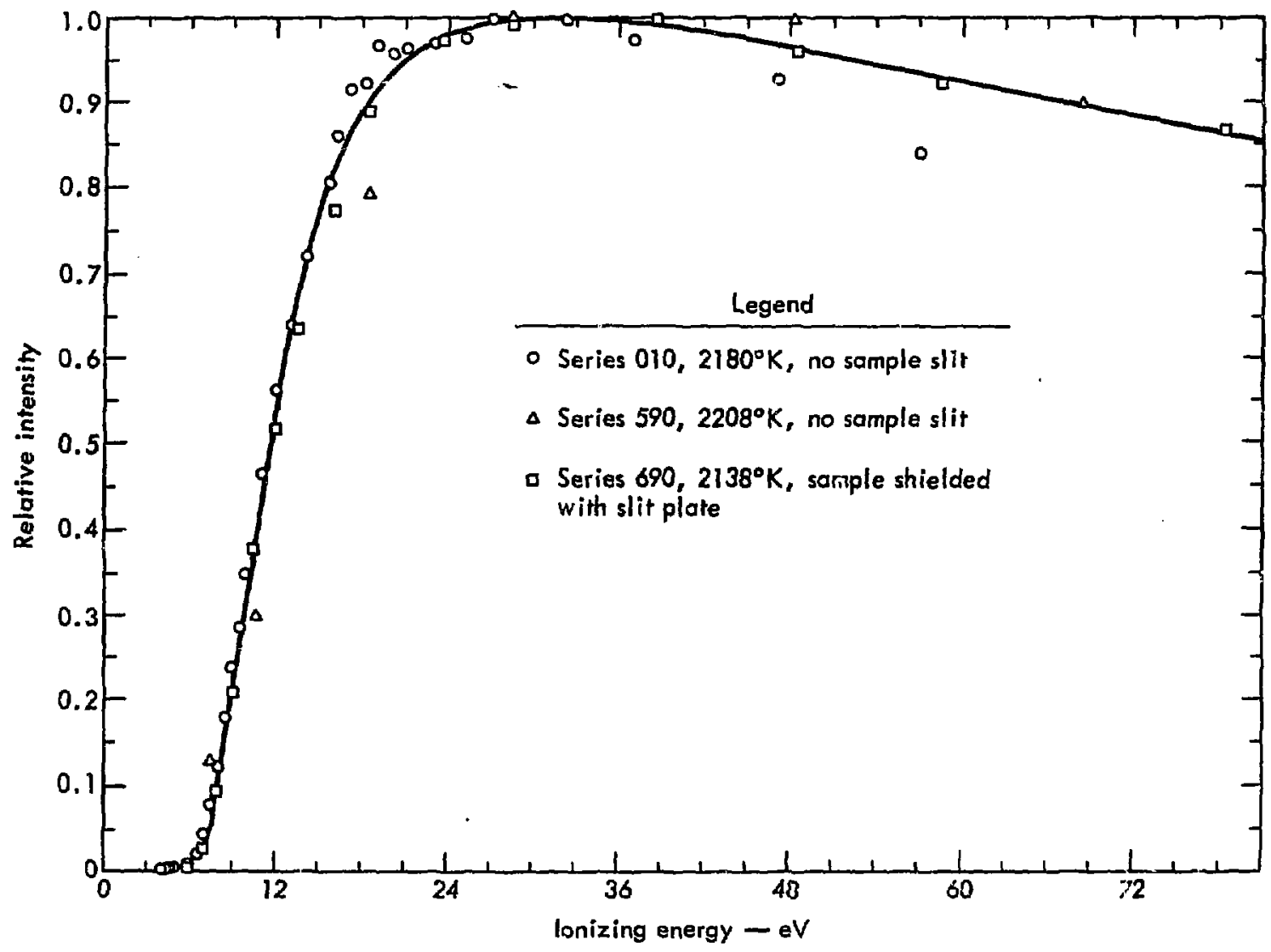

Fig. III-3. Ionization efficiency vs ionizing voltage for hafnium. 


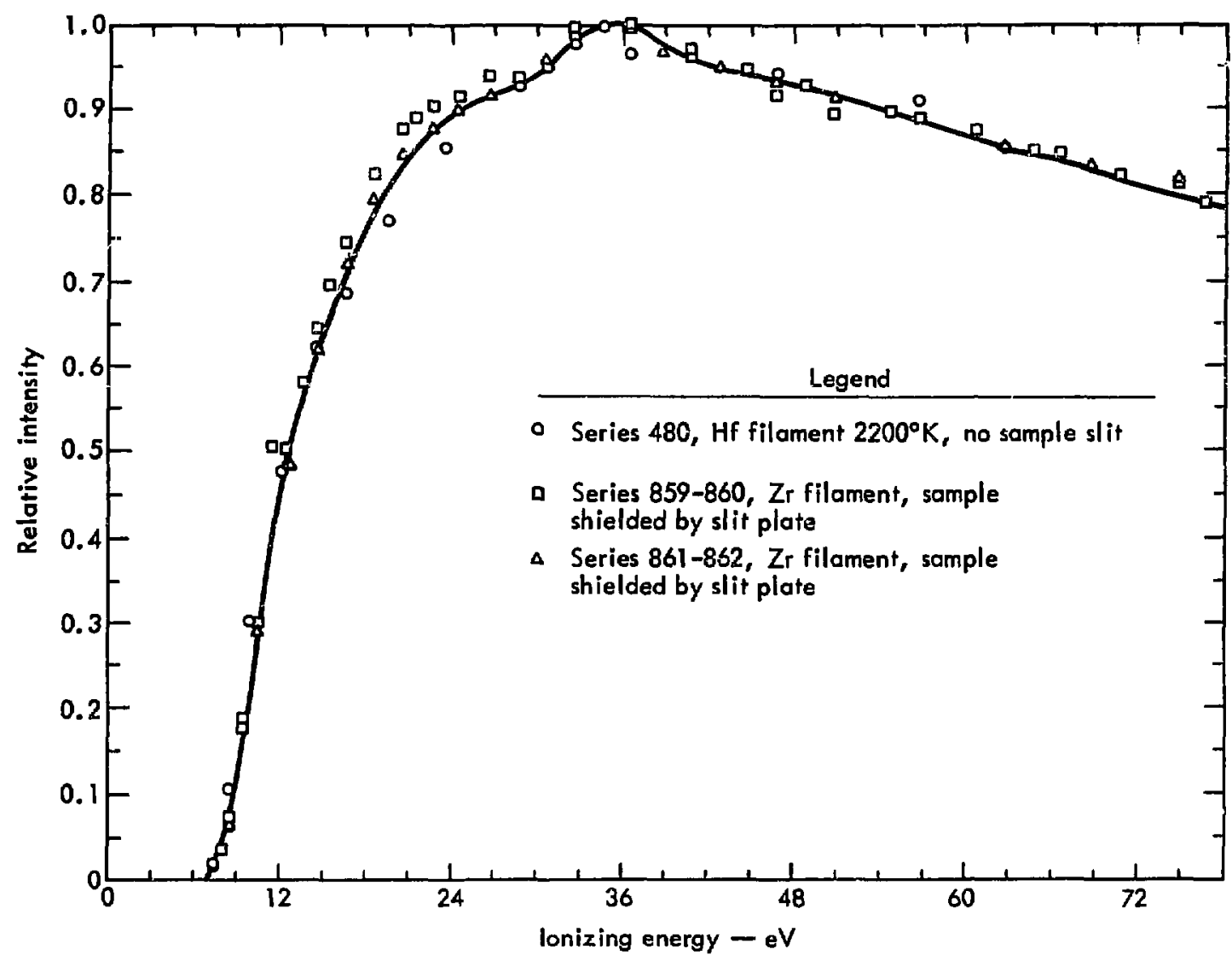

Fig. III-4. Ionization efficiency vs ionizing voltage for zirconium. 


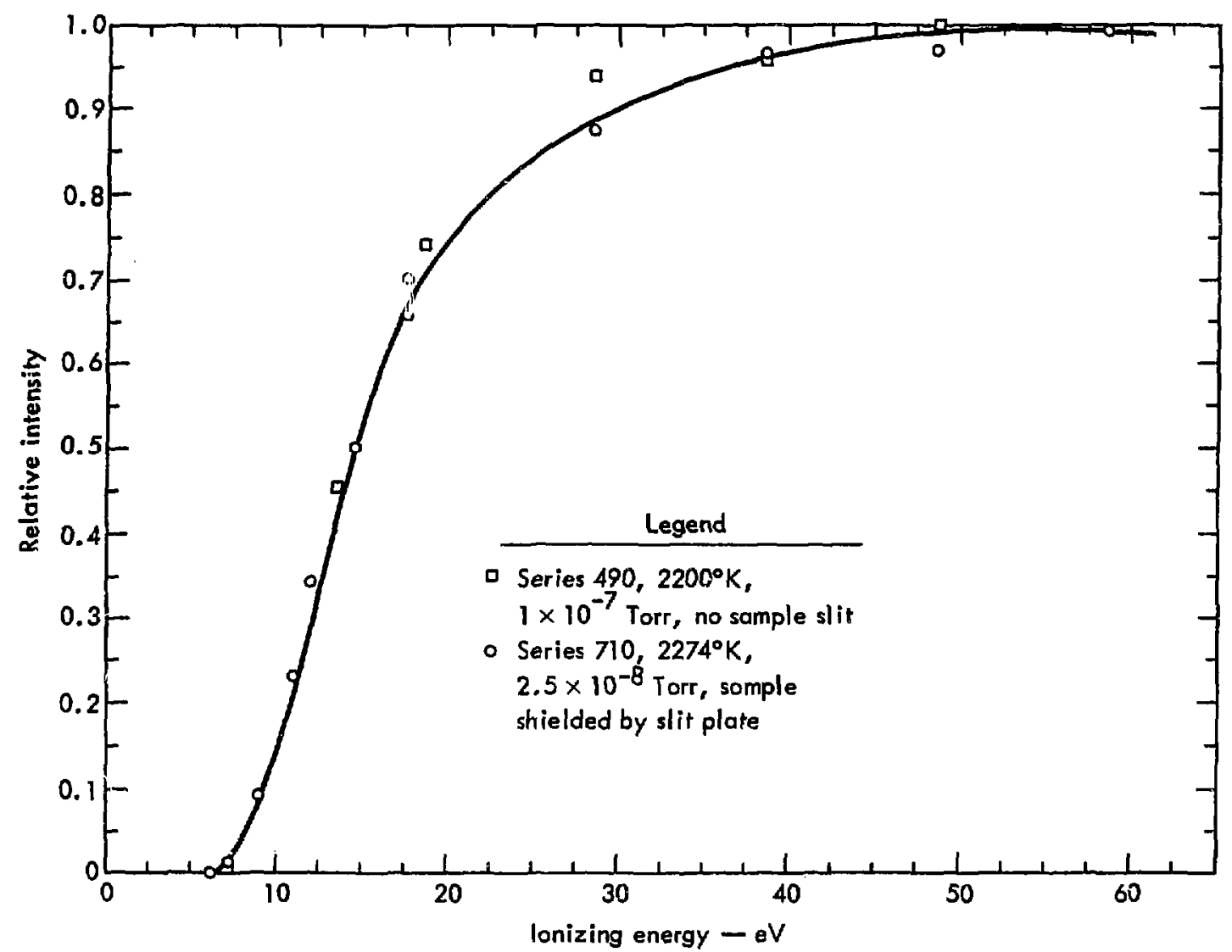

Fig. III-5, Ionization efficiency vs ionizing voltage for HfO. 
abundances, and data that did not agree within statistical limits with Ref. 80 were discarded.

The final two runs for zirconium, for which a zirconium metal filament was placed in the source afier the hafnium runs were finished, were done by a different technique. After several preliminary scans at different voltages to confirm that the relative ion intensities corresponded to the isotope abundances of zirconium, i. e., resic 1 al background was low enough, the magnetic field was locked at a value that focused $\mathrm{m} / \mathrm{e}=90$ on the detector slit.

The multichannel scaler was stepped at a rate of about 256 channels per 5 to $10 \mathrm{~min}$ for one sweep, while the ionizing voltage was changed manually to a new value every 10 channels. The data were printed out digitally; no running sum was made. Intensities were taken as the average number of counts per channel in consecutive channels for which the data were fairly constant, usually 7 or 8 channels. Thermal ion background corrections were applied, and residual gas backgrounds were negligible. There was gentrally good agreement between the ionization efficiency curses for $\mathrm{Zr}$ taken from the hafnium alloy filament and those taken from a zirconium metal filament after the final hafnium experiments. We could not resolve an effect due to the second ionization potential of hafnium. The peculiar hump in the curve that we at first attributed to that effect was also seen in runs with the zirconium filament.

Measurements of ion intensity as a function of collector current were made for $\mathrm{Hf}^{+}$. The spectrum from $\mathrm{m} / \mathrm{e}=179$ to 181 was counted for each value of the current at constant sample temperature and ionizing vol+age. Some of the results are illustrated in Fig. III-6. The deviation from linearity of these curves of ion intensity vs collector current must result from changes in the ionization efficiency, the ion extraction efficiency, or the transmission. The deviations from linearity occurred when the control grid potential approached the electron acceleration voltage. Changes in control grid potential would be expected to change the electron beam geometry and therefore to alter the spacial distribution of the ions produced. As a result, the ion extraction efficiency would change, and small changes in transmission could occur because of variations in ion focusing. Changes in the field. 


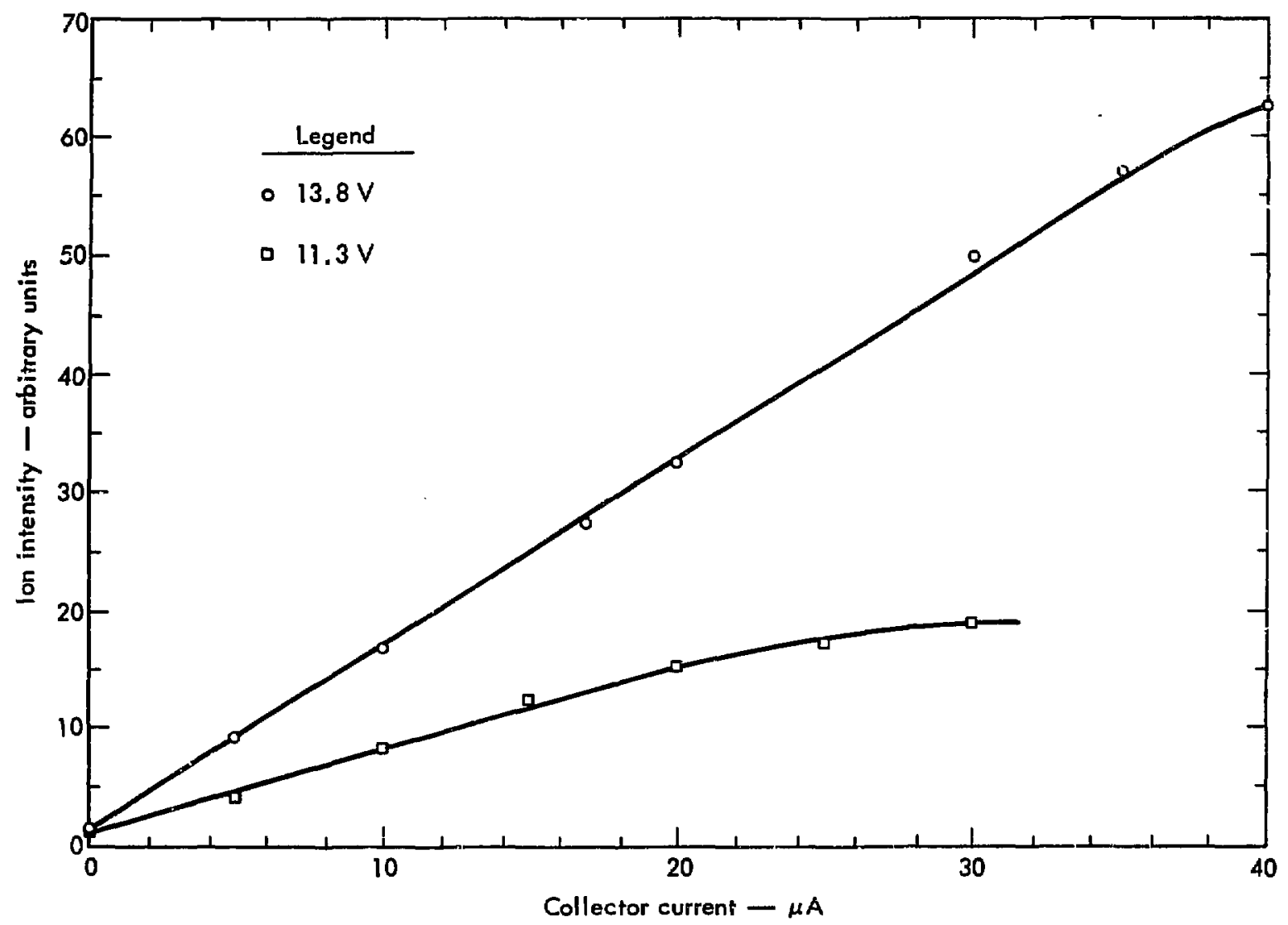

Fig. III-6. Ion intensity vs collector current at constant ionizing voltage and ample ternperature. 
distribution within the ionization region as the control grid voltage changes could lead to variations in the effective ionization energy and thereby to variations in ionization efficiency. When the drawing-out grid was used, the control grid potential required to regulate at a given collector current and ionization voltage was lowered, thus al lowing higher collector currents before deviations from linearity occurred. All measurements of ionization efficiencies and of ion intensities vs temperature were made at collector currents within the linear rauge for all voltages used.

\section{Temperature Measurement}

The corrections applied to the observed brightness temperatures of the hafnium filament included an emittance term in addition to the window correction factor. A value of 0.43 independent of temperature was used for emissivity, $\epsilon_{0.65}$, based on the data for $\beta \mathrm{Zr}$. The emissivities of the neighboring transition elements are not much different at the temperatures of our experiments. There appear to be general trends in $\epsilon_{0.65}$ at high temperature, decreasing with increasing atomic number in a given row of the periodic chart from group IVB to group VIB (from the titanium to the chromium subgroups) and increasing with increasing atomic weight within a given column or group. Since the trends are irregular and information is incomplete, and because of the close similarities in other properties of zirconium and hafnium, the emissivity of zirconium is probably the best estimate for that of hafnium. In getseral, $\epsilon_{0.65}$ decreases with increasing temperature; but sirce the temperature dependence for the neighboring elements is small in this temperature range and 0.65 for $\beta \mathrm{Zr}$ is reported to be independent of temperature 78 and was found to be independent of temperature within our precision, $\epsilon_{0.65}$ for hafnium was assumed to be constant within the temperature range of my experiments. Bradshaw 78 reports $\epsilon_{0.65}=0.436$ for $\alpha Z \mathrm{r}, 0.01$ greater than his value for $\beta Z \mathrm{r}$; but since emissivity variations tend to become smaller at higher temperatures, the difference in emissivity between $\alpha \mathrm{Hf}$ and $\beta \mathrm{Hf}$ is probably less than 0.01 and has been assumed to be negligible. 


\section{Background Corrections to Intensity Heasurements}

The residual gas backgrounds, $B_{r}^{m}$, were determined from the observed intensities at $\mathrm{m} / \mathrm{e}=89$ for $\mathrm{Zr}^{+}$and at $\mathrm{m} / \mathrm{e}=181$ for $\mathrm{Hf}^{+}$. Background intensities at 90 and 180 , etc., were calculated from $B_{r}^{89}$ and $\mathrm{B}_{\mathrm{r}}^{181}$ by using peak intensity ratios from spectra obtained with the sample filament off. Extensive baking reduced these background corrections to values ranging from 10 at the lower temperatures to about 70 at the highest temperatures. In all cases, these backgrounds wer ? much smaller than the uncertainties due to counting statistics.

In series 120, the thermal ion background, $B_{t}^{m}$, varied from 0.5 to 0.2 of the gross intensity as the temperature increased. In subsequent runs with the molecular beam slit, $B_{t}^{m}$ ran from ranges of 0.2 to 0.1 of the gross intensity to 0.01 to 0.001 of the gross intensity. Net ion intensities were calculated by use of Eq. III-1. Good agreement between results from runs in which the magnitude of thermal background corrections varied by several orders of magnitude indicates that the corrections are reliable and valid.

In runs made before the molecular beam siit was used and in runs with the slit in which no bias volitage was applied, I accumuiated quite a bit of thermal ion intensity-vs-temperature data. I attempted to correlate these data with the enthalpy of sublimation and the work function of hafniurn without success; the calculated total activation energies were always less than the enthalpies of sublimation calculated from net intensities of ions formed by electron uombardment of neutral atoms in the vapor. The problem in this procedure may have resulted from the effect of the magnetic field due to the filament-heating current on the thermal ions. The technique is sound in principle and should be an effective method of obtaining sublimation and workfunction data if a noninductive heating arrangement is used. The magnetic field from the filament current may also produce a systematic error in the results if net intensities are used; but the effect of the field on the ions produced by electron bombardment is much smaller, as they are formed at a distance from the filament and close to the ion exit slit. The ion source regulator parameters were unaffected by changes in filament heating current vrithin our ability to observe them. 
Results

Hafnium ion intensity vs temperature data were analysed by the second-law method, using Eq. III-4. Free energy functions tabulated by Hultgren et al. ${ }^{70}$ were used. The data are given in Tables III-2 through III-7 and in Figs. III-7 through III-12. Resılts are listed in Table III -8 .

The partial molal enthalpy of sublimation of zirconium from the alloy was determined by analysis of the data for $\mathrm{m} / e=90$ by using free energy functions extrapolated from those given in Hultgren's 77 compilation. Values extrapolated from $\alpha \mathrm{Zr}$ data were used below $2013^{\circ} \mathrm{K}$, the transition temperature of hafnium, and values for $\beta \mathrm{Zr}$ were used above $2013^{\circ} \mathrm{K}$. These data are given in Tables III -3 through III- 7 and Figs. III- 13 through III-18, and results are listed in Table III-9. The value obtained by combining the results, weighting each by the reciprocal of its variance, is $\overline{\Delta H}_{298}^{0}=148.8 \pm 2.0 \mathrm{kcal} / \mathrm{g}$ atom, which is slightly higher than the standard enthalpy of sublimation of pure zirconium, $145.5 \pm 1.0 \mathrm{kcal} / \mathrm{g}$ atom, given by Hultgren et al. 77 The uncertainty given for our results represents only the statistical variations in the final results assuming a random cistribution of errors. Estimated systematic errors in toth temperature and intensity measurements add arother 1 or $2 \mathrm{kcal} / \mathrm{g}$ atom uncertainty, and place my resclt for the standard partial molal enthalpy of sublimation of zirconium from a dilute solid solution in nafnium within the errors equal to the standard enthalpy of sublimation of pure zirconium, i. e., the solution is ideal.

Absolute $\mathrm{Hf}(\mathrm{g})$ pressures at each temperature were calculated from the experimental ion intensity ratios and estirnated $\mathrm{Zr}(\mathrm{g})$ pressures. If we assume that there was no significant mass discrimination in our instrument, $i . e .$, the ion extraction efficiency and transmission were independent of mass, we can obtain the $\mathrm{Hf}(\mathrm{g})$ pressures from the equation

$$
\begin{array}{r}
\mathrm{P}^{0}(\mathrm{Hf})=\mathrm{P}^{0}(\mathrm{Zr})\left(\mathrm{X}_{\mathrm{Zr}} / \mathrm{X}_{\mathrm{Hf}}\right)\left(\mathrm{I}^{180} / \mathrm{I}^{90}\right)\left(\mathrm{f}^{90} / \mathrm{f}^{180}\right)\left(\sigma_{\mathrm{Zr}} / \sigma_{\mathrm{Hi}}\right) \\
\left(r_{\mathrm{Zr}} / r_{\mathrm{Hf}}\right)\left(\mathrm{d}^{90} / \mathrm{d}^{180}\right),
\end{array}
$$


Table III-2, The sublimation of hafnium by mass spectrometry for Series 120.

\begin{tabular}{cccc}
\hline Run No. & $\begin{array}{c}\text { Temperature } \\
\left({ }^{\circ} \mathrm{K}\right)\end{array}$ & $\begin{array}{c}-\mathrm{R} \ln (\mathrm{IT}) \\
\text { (gibbs/mole) }\end{array}$ & $\begin{array}{c}-\Delta \text { (fef) } \\
\text { (gibbs/mole) }\end{array}$ \\
\hline 136 & 1828 & -26.798 & 32.947 \\
135 & 1835 & -27.711 & 32.942 \\
134 & 1869 & -30.008 & 32.919 \\
138 & 1891 & -30.289 & 32.904 \\
137 & 1914 & -31.809 & 32.890 \\
133 & 1923 & -31.564 & 32.885 \\
132 & 1990 & -34.233 & 32.848 \\
139 & 2016 & -35.201 & 32.835 \\
131 & 2069 & -36.765 & 32.786 \\
130 & 2106 & -38.722 & 32.751 \\
129 & 2148 & -40.166 & 32.712 \\
128 & 2178 & -41.449 & 32.684 \\
127 & 2179 & -41.657 & 32.683 \\
126 & 2217 & -42.618 & 32.649 \\
125 & 2267 & -44.229 & 32.609 \\
124 & 2309 & -44.920 & 32.575 \\
123 & 2337 & -45.434 & 32.553 \\
122 & 2366 & -46.176 & 32.531 \\
121 & 2372 & -46.430 & 32.526 \\
\hline & & &
\end{tabular}


Table III-3. The sublimation of hafnium by mass spectrometry for Series 540 .

\begin{tabular}{|c|c|c|c|c|c|c|c|c|c|}
\hline $\begin{array}{l}\text { Run } \\
\text { Hf }\end{array}$ & No. & $\begin{array}{l}\text { Tempera- } \\
\text { ture }\left({ }^{\circ} \mathrm{K}\right)\end{array}$ & $\begin{array}{c}-R \ln (\mathrm{IT}) \\
(\mathrm{m} / \mathrm{e}=180) \\
(\mathrm{gibbs} / \\
\text { mole) }\end{array}$ & $\begin{array}{c}-\mathrm{R} \ln (\mathrm{IT}) \\
(\mathrm{m} / \mathrm{e}=90) \\
(\mathrm{gibbs} / \\
\text { mole })\end{array}$ & $\begin{array}{l}\text { Pressure } \\
\text { for } \mathrm{Zr} \\
\text { (atm) }\end{array}$ & $\begin{array}{c}\text { Pressure } \\
\text { for Hf } \\
\text { (atm) }\end{array}$ & $\begin{array}{l}-\Delta \text { (fef) } \\
\text { for Hff } \\
\text { (gibbs/ } \\
\text { mole) }\end{array}$ & $\begin{array}{l}-\Delta \text { (fef) } \\
\text { for } \mathrm{Zr} \\
\text { (gibbs/ } \\
\text { mole) }\end{array}$ & $\begin{array}{l}\triangle \mathrm{H}^{2} 98 \\
\text { for Hf } \\
\text { (kcal/ } \\
\text { atom) }\end{array}$ \\
\hline 564 & & 1770 & -26.676 & & & & 32.984 & & \\
\hline 563 & 562 & 1802 & -28.252 & -25.228 & $3.667 \times 10^{-11}$ & $1.291 \times 10^{-11}$ & 32.965 & 32.987 & 149.20 \\
\hline 560 & 561 & 1878 & -31.413 & -28.543 & $1.846 \times 10^{-10}$ & $6.016 \times 10^{-11}$ & 32.913 & 32.939 & 149.64 \\
\hline 565 & & 1915 & -33.109 & & & & 32.889 & & \\
\hline 559 & 558 & 1927 & -33.702 & -30.578 & $5.127 \times 10^{-10}$ & $1.898 \times 10^{-10}$ & 32.883 & 32.989 & 149.10 \\
\hline 556 & 557 & 2009 & -37.014 & -33.777 & $2.358 \times 10^{-9}$ & $9.241 \times 10^{-10}$ & 32.839 & 32.965 & 148.99 \\
\hline 555 & 554 & 2058 & -38.976 & -35.602 & $5.324 \times 10^{-9}$ & $2.236 \times 10^{-9}$ & 32.795 & 32.832 & 148.97 \\
\hline 566 & 567 & 2087 & -39.882 & -36.508 & $8.574 \times 10^{-9}$ & $3.600 \times 10^{-9}$ & 32.769 & 32.812 & 149.01 \\
\hline 552 & 553 & 2120 & -41.077 & -37.543 & $1.472 \times 10^{-8}$ & $6.700 \times 10^{-9}$ & 32.738 & 32.790 & 148.71 \\
\hline 569 & 568 & 2136 & -41.437 & -37.862 & $1.882 \times 10^{-8}$ & $8.742 \times 10^{-9}$ & 32.723 & 32.779 & 148.64 \\
\hline 551 & 550 & 2178 & -42.769 & -39.134 & $3.586 \times 10^{-8}$ & $1.717 \times 10^{-8}$ & 32.684 & 32.750 & 148.54 \\
\hline 548 & 549 & 2212 & .43 .702 & -40.030 & $6.007 \times 10^{-8}$ & $2.930 \times 10^{-8}$ & 32.653 & 32.724 & 148.50 \\
\hline 546 & 547 & 2252 & -44.549 & -40.801 & $1.059 \times 10^{-7}$ & $5.364 \times 10^{-8}$ & 32.621 & 32.690 & 148.39 \\
\hline
\end{tabular}


Table III-4. The sublimation of hafnium by mass spectrometry for Series 570 .

\begin{tabular}{|c|c|c|c|c|c|c|c|c|c|}
\hline $\begin{array}{l}\text { Run } \\
\text { Hf }\end{array}$ & $\begin{array}{l}\text { No. } \\
\mathbf{Z r}\end{array}$ & $\begin{array}{l}\text { Tempera- } \\
\text { ture }\left({ }^{\circ} \mathrm{K}\right)\end{array}$ & $\begin{array}{c}-\mathrm{R} \ln (\mathrm{IT}) \\
(\mathrm{m} / \mathrm{e}=180) \\
(\mathrm{gibbs} / \\
\text { mole })\end{array}$ & $\begin{array}{c}-R \ln (\mathrm{IT}) \\
(\mathrm{m} / \mathrm{e}=90) \\
(\mathrm{gibbs}) \\
\text { mole })\end{array}$ & $\begin{array}{l}\text { Pressure } \\
\text { for } \mathrm{Zr} \\
\text { (atm) }\end{array}$ & $\begin{array}{l}\text { Pressure } \\
\text { for Hf } \\
\text { (atm) }\end{array}$ & $\begin{array}{c}-\Delta \text { (fef) } \\
\text { for Hf } \\
\text { (gibbs/ } \\
\text { mole) }\end{array}$ & $\begin{array}{c}-\Delta \text { (fef) } \\
\text { for Zr } \\
\text { (gibbs/ } \\
\text { mole) }\end{array}$ & $\begin{array}{l}\Delta \mathrm{H}_{2 \mathrm{~g}}^{0} \\
\text { for Hf } \\
\text { (kcal/ } \\
\text { atom) }\end{array}$ \\
\hline 582 & 581 & 1933 & -34.421 & -30.678 & $5.794 \times 10^{-10}$ & $2.376 \times 10^{-10}$ & 32.879 & 33.003 & 148.69 \\
\hline 579 & 580 & 1980 & -35.888 & -32.455 & $1.508 \times 10^{-9}$ & $5.533 \times 10^{-10}$ & 32.853 & 33.113 & 143.93 \\
\hline 578 & 577 & 2071 & -37.689 & -35.268 & $6.634 \times 10^{-9}$ & $1.462 \times 10^{-9}$ & 32.783 & 32.823 & 151.64 \\
\hline 583 & & 2108 & -40.364 & & & & 32.749 & & \\
\hline 575 & 576 & 2143 & -41.978 & -37.570 & $2.105 \times 10^{-8}$ & $1.262 \times 10^{-8}$ & 32.717 & 32.774 & 147.56 \\
\hline 574 & 573 & 2202 & -43.462 & -39.116 & $5.130 \times 10^{-8}$ & $2.979 \times 10^{-8}$ & 32.662 & 32.734 & 147.72 \\
\hline \multirow[t]{2}{*}{571} & 572 & 2248 & -44.602 & -40.284 & $1.006 \times 10^{-7}$ & $5.764 \times 10^{-8}$ & 32.624 & 32.693 & 147.83 \\
\hline & & 2271 & -45.045 & & & & 32.605 & & \\
\hline
\end{tabular}


Table III-5. The sublimation of hafnium by mass spectrometry for Series 540 .

\begin{tabular}{|c|c|c|c|c|c|c|c|c|c|}
\hline $\begin{array}{l}\text { Run } \\
\text { Hf }\end{array}$ & $\begin{array}{l}\text { No. } \\
\mathrm{Zr}\end{array}$ & $\begin{array}{l}\text { Tempera- } \\
\text { ture }\left({ }^{\circ} \mathrm{K}\right)\end{array}$ & $\begin{array}{c}-R \ln (\mathrm{IT}) \\
(\mathrm{m} / \mathrm{e}=180\rangle) \\
(\mathrm{gibbs} / \\
\text { mole })\end{array}$ & $\begin{array}{c}-\mathrm{R} \ln (\mathrm{IT}) \\
(\mathrm{m} / \mathrm{e}=90) \\
(\mathrm{gibbs} / \\
\text { mole) }\end{array}$ & $\begin{array}{c}\text { Pressure } \\
\text { for } Z r \\
\text { (atm) }\end{array}$ & $\begin{array}{c}\text { Pressure } \\
\text { for Hf } \\
\text { (atm) }\end{array}$ & $\begin{array}{l}-\Delta \text { (fef) } \\
\text { for Hf } \\
\text { (gibbs/ } \\
\text { mole) }\end{array}$ & $\begin{array}{c}-\Delta(f e f) \\
\text { for Zr } \\
\text { (gibbs/ } \\
\text { mole) }\end{array}$ & $\begin{array}{l}\Delta \mathrm{H}_{2}^{0} 98 \\
\text { for Hf } \\
\text { (kcal/ } \\
\text { atom) }\end{array}$ \\
\hline 678 & & 1800. & -28.898 & & & & 32,966 & & \\
\hline 677 & & 1830 & -30.216 & & & & 32.946 & & \\
\hline 679 & & 1887 & -32.285 & & & & 32.907 & & \\
\hline 676 & 675 & 1928 & -33.902 & -29.843 & $5.254 \times 10^{-1 C}$ & $2.231 \times 10^{-10}$ & 32.882 & 32.992 & 148.57 \\
\hline 673 & 674 & 1986 & -36.216 & -32.017 & $1.695 \times 10^{-9}$ & $7.728 \times 10^{-10}$ & 32.850 & 33.127 & 148,05 \\
\hline 672 & 671 & 2031 & -37.641 & -33.449 & $3.333 \times 10^{-9}$ & $1.514 \times 10^{-9}$ & 32.820 & 32.851 & 148.63 \\
\hline 680 & & 2041 & -37.993 & & & & 32.812 & & \\
\hline 669 & 670 & 2071 & -39.500 & -36.210 & $6.634 \times 10^{-9}$ & $1.913 \times 10^{-9}$ & 32.783 & 32,823 & 150.54 \\
\hline 667 & 666 & 2114 & -40.755 & -36.501 & $1.338 \times 10^{-8}$ & $6.271 \times 10^{-9}$ & 32.744 & 32.794 & 148.58 \\
\hline 647 & 648 & 2131 & -41.425 & -37.327 & $1.745 \times 10^{-8}$ & $7.559 \times 10^{-9}$ & 32.728 & 32.782 & 148.93 \\
\hline 663 & 664 & 2167 & -42.552 & -37.824 & $3.045 \times 10^{-8}$ & $1.811 \times 10^{-8}$ & 32.694 & 32.758 & 147.60 \\
\hline 644 & 642 & 2191 & -43.469 & -39.174 & $4.371 \times 10^{-8}$ & $2.090 \times 10^{-8}$ & 32.672 & 32.741 & 148.60 \\
\hline 652 & 651 & 2198 & -43.525 & -39.140 & $4.865 \times 10^{-8}$ & $2.434 \times 10^{-8}$ & 32,665 & 32.736 & 148.37 \\
\hline 660 & 659 & 2238 & -44.828 & -40.381 & $8.634 \times 10^{-8}$ & $4.458 \times 10^{-8}$ & 32.633 & 32.703 & 148.28 \\
\hline 655 & 656 & 2274 & -45.645 & -41.246 & $1.430 \times 10^{-7}$ & $7.211 \times 10^{-8}$ & 32.603 & 32.672 & 148.44 \\
\hline
\end{tabular}


Table III-6. The sublirnation of hafnium by mass spectrometry for Series 680 .

\begin{tabular}{|c|c|c|c|c|c|c|c|c|c|}
\hline $\begin{array}{l}\text { Run } \\
\text { Hf }\end{array}$ & No. & $\begin{array}{l}\text { Tempera- } \\
\left.\text { ture ( }{ }^{\circ} \mathrm{K}\right)\end{array}$ & $\begin{array}{c}-\mathrm{R} \ln (\mathrm{IT}) \\
\langle\mathrm{m} / \mathrm{e}=180) \\
(\mathrm{gibbs} / \\
\text { mole })\end{array}$ & $\begin{array}{c}-\mathrm{R} \ln (\mathrm{IT}) \\
(\mathrm{m} / \mathrm{e}=90) \\
\text { (gibbs } / \\
\text { mole) }\end{array}$ & $\begin{array}{l}\text { Pressure } \\
\text { for } \mathrm{Zr} \\
\text { (atm) }\end{array}$ & $\begin{array}{l}\text { Pressure } \\
\text { for Hf } \\
\text { (atm) }\end{array}$ & $\begin{array}{c}-\Delta \text { (fef) } \\
\text { for Hf } \\
\text { (gibbs/ } \\
\text { mole) }\end{array}$ & $\begin{array}{c}-\Delta \text { (fef) } \\
\text { for } \mathrm{Zr} \\
\text { (gibbs/ } \\
\text { mole) }\end{array}$ & $\begin{array}{c}\Delta \mathrm{H}_{298}^{0} \\
\text { for Hf } \\
\text { (kcal/ } \\
\text { atom) }\end{array}$ \\
\hline 681 & 682 & 1971 & -35.421 & -31.545 & $1.249 \times 10^{-9}$ & $4.108 \times 10^{-10}$ & 32.858 & 33.091 & 149.40 \\
\hline 684 & 683 & 2074. & -39.101 & -34.834 & $6.902 \times 10^{-9}$ & $2.763 \times 10^{-9}$ & 32.731 & 32.821 & 149.19 \\
\hline 685 & 687 & 2229 & -44.080 & -39.617 & $7.657 \times 10^{-8}$ & $3.382 \times 10^{-8}$ & 32.639 & 32.710 & 148.96 \\
\hline 691 & 690 & 2296 & -47.474 & -41.762 & $1.923 \times 10^{-7}$ & $1.593 \times 10^{-7}$ & 32.586 & 32.653 & 146.20 \\
\hline
\end{tabular}


Table III-7. The sublimation of hafnium by mass spectrometry for Serles 740 and 750 .

\begin{tabular}{|c|c|c|c|c|c|c|c|c|c|}
\hline \multicolumn{10}{|c|}{ (Hf intensity datu treated as a single series) } \\
\hline \multicolumn{2}{|c|}{$\mathrm{Hf}_{\mathrm{Z}}^{\text {nun }}$} & $\begin{array}{l}\text { Tempera- } \\
\left.\text { ture ( }{ }^{\circ} \mathrm{K}\right)\end{array}$ & \multirow[t]{2}{*}{$\begin{array}{c}-R \ln (\text { IT) } \\
(\mathrm{m} / \mathrm{e} \cdot 180) \\
\text { (gibba/ } \\
\text { mole) }\end{array}$} & $\begin{array}{c}-\mathrm{R} \text { In (IT) } \\
\text { (m/e }=90) \\
\text { (glbbs/ } \\
\text { mole) }\end{array}$ & $\begin{array}{l}\text { Pressure } \\
\text { for } \mathrm{Zr} \\
\text { (atm) }\end{array}$ & \multirow[t]{2}{*}{$\begin{array}{c}\text { Pressure } \\
\text { for Hf } \\
\text { (atm) }\end{array}$} & \multirow[t]{2}{*}{$\begin{array}{l}-\Delta \text { (fef) } \\
\text { for Hff } \\
\text { (gibbs/ } \\
\text { mole) }\end{array}$} & \multirow[t]{2}{*}{$\begin{array}{c}-\Delta \text { (fef) } \\
\text { ror Zr } \\
\text { (glbbs) } \\
\text { mole) }\end{array}$} & $\begin{array}{l}3 \mathrm{H}_{298}^{0} \\
\text { for Hff } \\
\text { (kcal/ } \\
\text { atom) }\end{array}$ \\
\hline \multicolumn{6}{|c|}{ Series $740\left(\mathrm{X}_{\mathrm{Zr}} / \mathrm{X}_{\mathrm{Hf}}=0.0312\right)$} & & & & \\
\hline 752 & 751 & 2062 & -37.720 & -32.911 & $5.655 \times 10^{-9}$ & $2.810 \times 10^{-17}$ & 32.792 & 32.830 & 148.29 \\
\hline 749 & 750 & 2142 & -40.501 & -35.586 & $2.066 \times 10^{-8}$ & $1.004 \times 10^{-8}$ & 32.718 & 32.775 & 148.09 \\
\hline 748 & 747 & 2205 & -42.426 & -37.448 & $5.408 \times 10^{-8}$ & $2.926 \times 10^{-8}$ & 32.659 & 32.731 & 148.03 \\
\hline 745 & 746 & 2273 & -44.450 & -39.416 & $1.407 \times 10^{-7}$ & $7.830 \times 10^{-8}$ & 32.604 & 32.673 & 147.99 \\
\hline 743 & 744 & $23 ! 5$ & -45.828 & -40.813 & $2.491 \times 10^{-7}$ & $1.373 \times 10^{-7}$ & 32.570 & 32.637 & 148.09 \\
\hline \multicolumn{10}{|c|}{ Series $750\left(\mathrm{x}_{\mathrm{Zr}_{\mathrm{r}}} / \mathrm{x}_{\mathrm{Hf}}=0.0264\right)$} \\
\hline 782 & & 1838 & $-2 H .688$ & & & & 32.939 & & \\
\hline 781 & & 1873 & -30.197 & & & & 32.918 & & \\
\hline 754 & & 187.9 & -30.593 & & & & 32.912 & & \\
\hline 783 & & 1898 & -31.188 & & & & 32.899 & & \\
\hline 784 & & 1926 & -32.238 & & & & 32.883 & & \\
\hline 778 & & 1968 & -33.823 & & & & 32.860 & & \\
\hline 753 & & 1988 & -35.240 & & & & 32.848 & & \\
\hline 785 & 786 & 2023 & -36.177 & -31.358 & $2.884 \times 10^{-9}$ & $1.218 \times 10^{-9}$ & 32.028 & 32.856 & 148.91 \\
\hline 774 & 775 & 2050 & -37.187 & $-32.14 \mathrm{~J}$ & $4.623 \times 10^{-9}$ & $2.183 \times 10^{-9}$ & 32.809 & 32.838 & 148.49 \\
\hline 779 & 776 & 2054 & 37.221 & -32.133 & $+412 \times 10^{-9}$ & $2.373 \times 10^{-9}$ & 32.800 & 32.835 & 148.40 \\
\hline 779 & 780 & 2054 & -37.221 & -32.287 & $4.112 \times 10^{-9}$ & $2.197 \times 10^{-9}$ & 32.800 & 32.835 & 148.71 \\
\hline 773 & 772 & 2124 & -39.871 & -34.867 & $1.558 \times 10^{-8}$ & $7,218 \times 10^{-9}$ & 32.735 & 33.787 & 148.64 \\
\hline 755 & 757 & 2166 & -41.399 & -36.357 & $2.990 \times 10^{-\mathrm{R}}$ & $1.412 \times 10^{-8}$ & 32.695 & 32.759 & 146.58 \\
\hline 770 & 771 & 2205 & -42.359 & -37.164 & $5.408 \times 10^{-8}$ & $2.758 \times 10^{-8}$ & 32.659 & 32.731 & 148.29 \\
\hline 788 & 787 & 2223 & -42.970 & -37.764 & $7.024 \times 10^{-8}$ & $3.602 \times 10^{-8}$ & 32.644 & 32.715 & 148.29 \\
\hline 760 & 759 & 2235 & -43.192 & -38.113 & $8.343 \times 10^{-9}$ & $3.993 \times 10^{-8}$ & 32.534 & 32.705 & 148.62 \\
\hline 768 & 767 & 2282 & -44.609 & -39.410 & $1.606 \times 10^{-7}$ & $8.203 \times 10^{-8}$ & 32.596 & 32.664 & 148.39 \\
\hline 763 & 764 & 2310 & $-45,547$ & -40.428 & $2.613 \times 10^{-7}$ & $1.283 \times 10^{-7}$ & 32.568 & 32.634 & 148.62 \\
\hline 789 & 790 & 2310 & $-\$ 5.596$ & -40.435 & $2.613 \times 10^{-7}$ & $1.310 \times 10^{-7}$ & 32.568 & 32.634 & 148.53 \\
\hline
\end{tabular}


Table III-8. Results of least-squares analyses of hafnium vaporization data by use of Eq. III-4.

\begin{tabular}{lccccc}
\hline & $\begin{array}{c}\text { No. } \\
\text { points }\end{array}$ & \multicolumn{2}{c}{$\begin{array}{c}\Delta \mathrm{H}_{298}^{0} \\
\text { (kcal/g atom) }\end{array}$} \\
\cline { 4 - 6 } 120 & 19 & $156.71 \pm 4.52^{\mathrm{a}}$ & $-80.3 \pm$ & 2.18 \\
540 & 13 & $154.19 \pm 2.93$ & $-80.8 \pm$ & 1.46 \\
570 & 7 & $145.57 \pm 7.10$ & $-76.8 \pm$ & 2.35 \\
640 & 15 & $150.52 \pm 3.06$ & $-79.3 \pm$ & 1.50 \\
680 & 4 & $166.51 \pm 24.2^{\mathrm{a}}$ & $-86.8 \pm 11.3$ \\
740 & 23 & $155.01 \pm 1.80$ & $-80.0 \pm$ & 0.86 \\
Weighted average & $153.62 \pm 1.34$ & & & \\
\hline
\end{tabular}

${ }^{a}$ Not included in composite results. 
Table III-9. Results of least-squares analyses of zirconium vaporization from hafnium alloy by use of Eq. III-4.

\begin{tabular}{lclc}
\hline Series & $\begin{array}{c}\text { No, } \\
\text { points }\end{array}$ & $\begin{array}{c}\Delta \mathrm{H}_{298}^{0} \\
(\mathrm{kcal} / \mathrm{g} \text { atom })\end{array}$ & $\mathrm{K}$ \\
\hline 540 & 11 & $145.76 \pm 4.09$ & $-73.3 \pm 2.00$ \\
570 & 6 & $136.77 \pm 2.81^{\mathrm{a}}$ & $-68.5 \pm 1.34$ \\
640 & 10 & $151.75 \pm 4.52$ & $-74.1 \pm 2.60$ \\
680 & 4 & $147.42 \pm 5.82$ & $-71.8 \pm 2.73$ \\
740 & 5 & $151.03 \pm 4.97$ & $-71.9 \pm 2.26$ \\
750 & 12 & $149.42 \pm 3.72$ & $-70.9 \pm 1.72$ \\
Weighted average & $148.84 \pm 2.06$ &
\end{tabular}

\footnotetext{
${ }^{\mathrm{a}}$ Not included in composite results.
} 


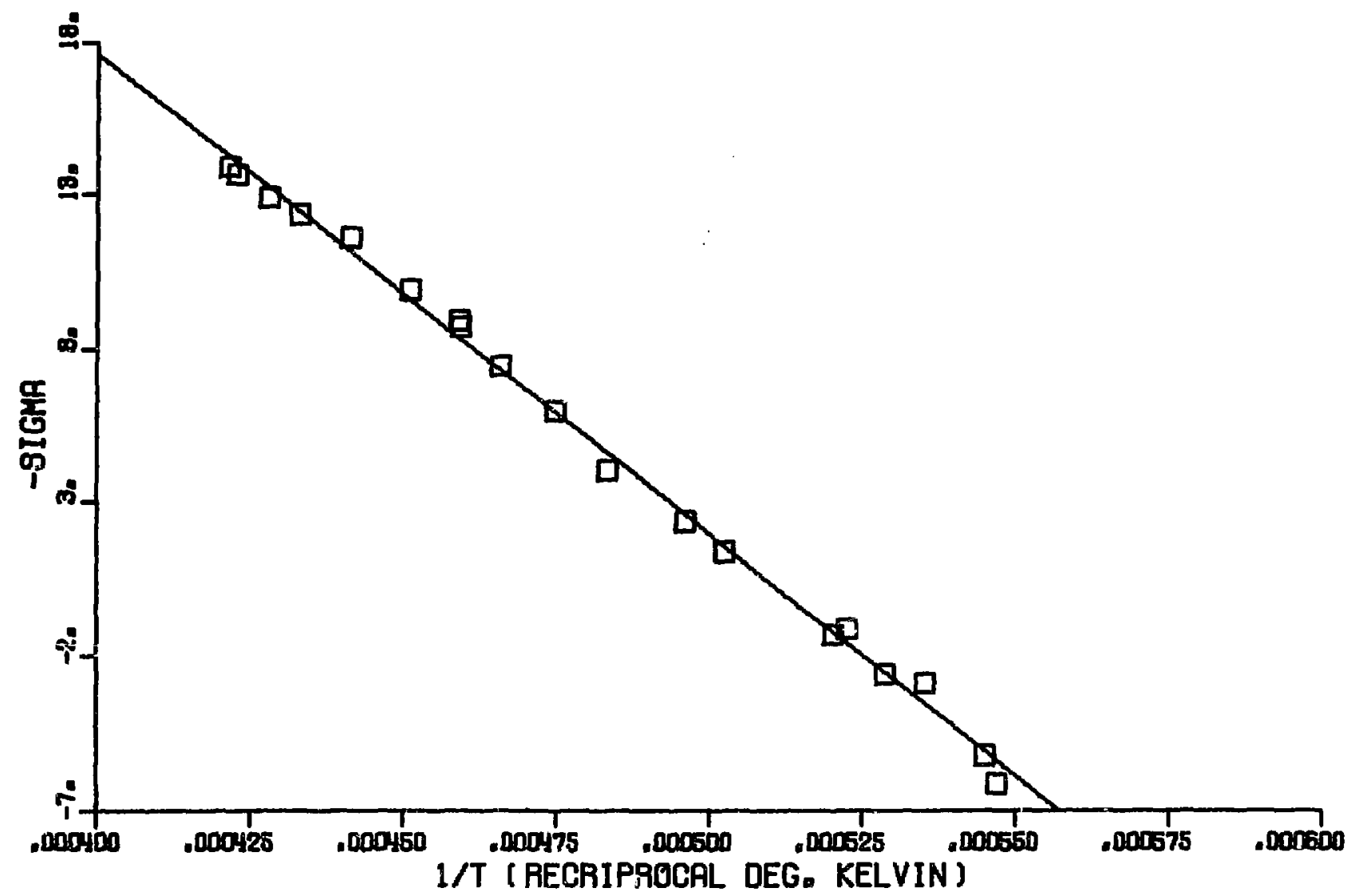

Fig. III -7. Sigma plot for the sublimation of hafnium, series $120 . \mathrm{m} / \mathrm{e}=178$.

$\vec{\omega}$ 


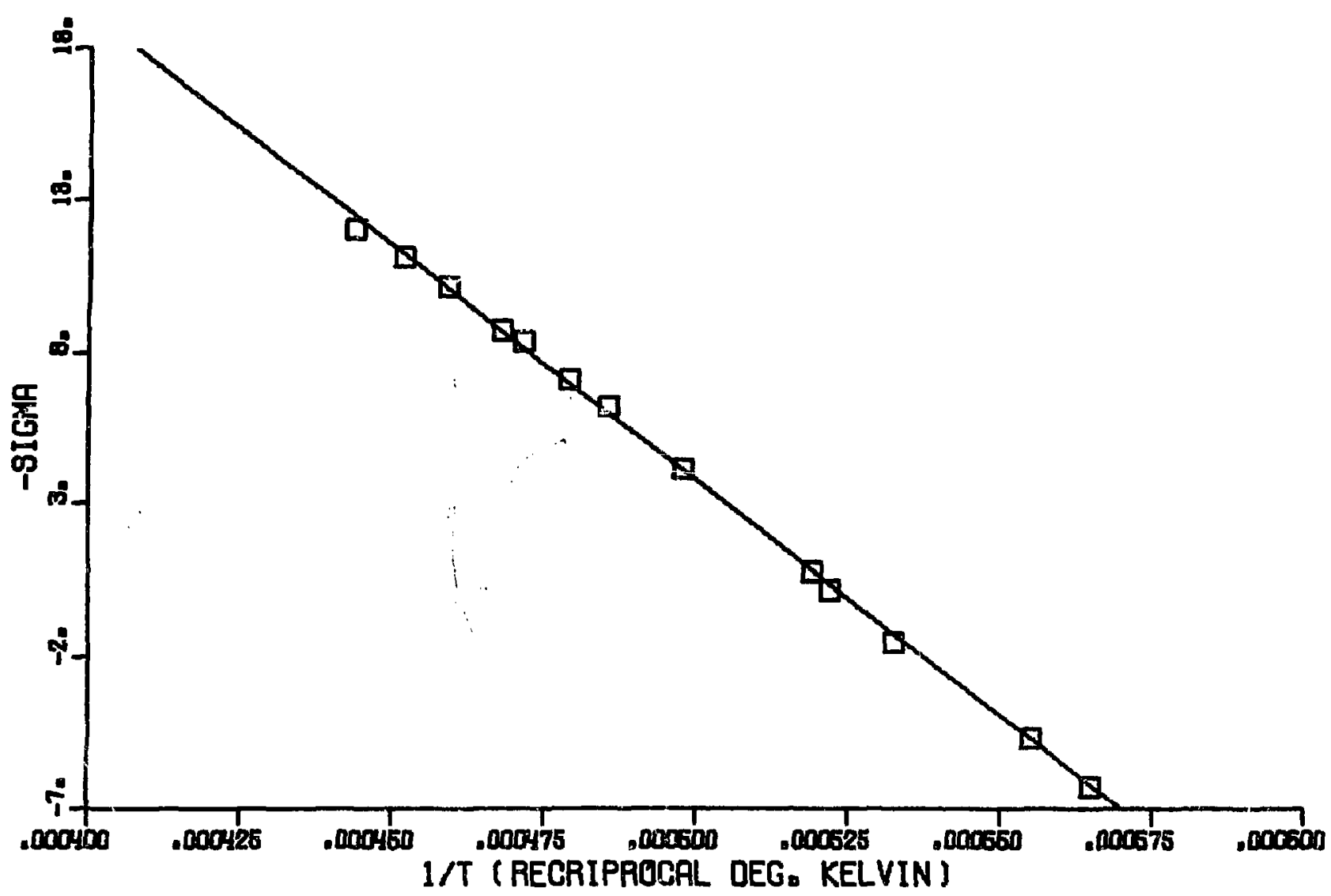

Fig. III-8. Sigma plot for the sublimation of hafnium, series 540 . $\mathrm{m} / \mathrm{e}=180$. 


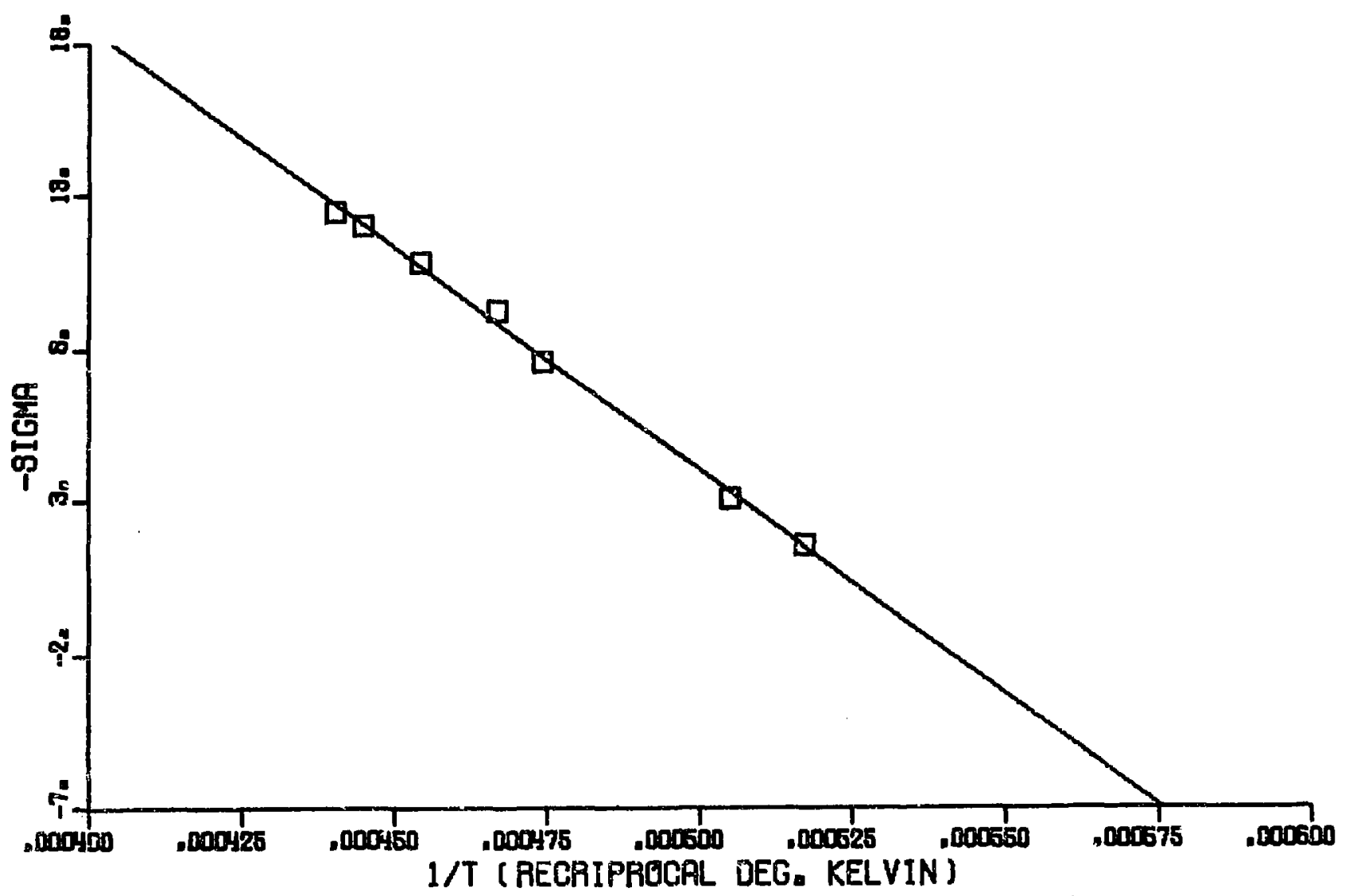

Fig. III-9. Sigma plot for the sublimation of hafnium, series $570 . \mathrm{m} / \mathrm{e}=180$. 


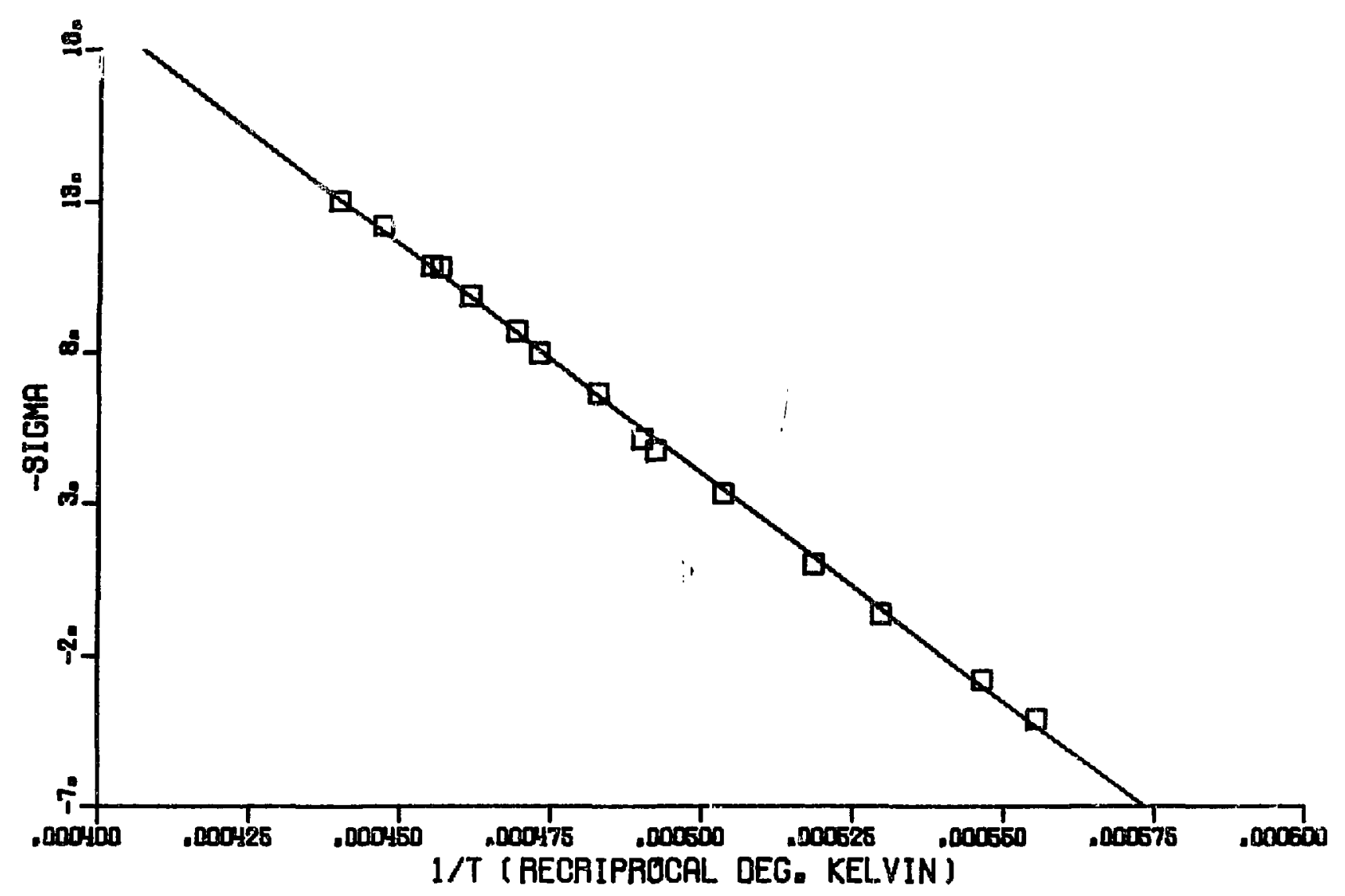

Fig. III-10. Sigma plot for the sublimation of hafnium, series $640 . \mathrm{m} / \mathrm{e}=180$. 


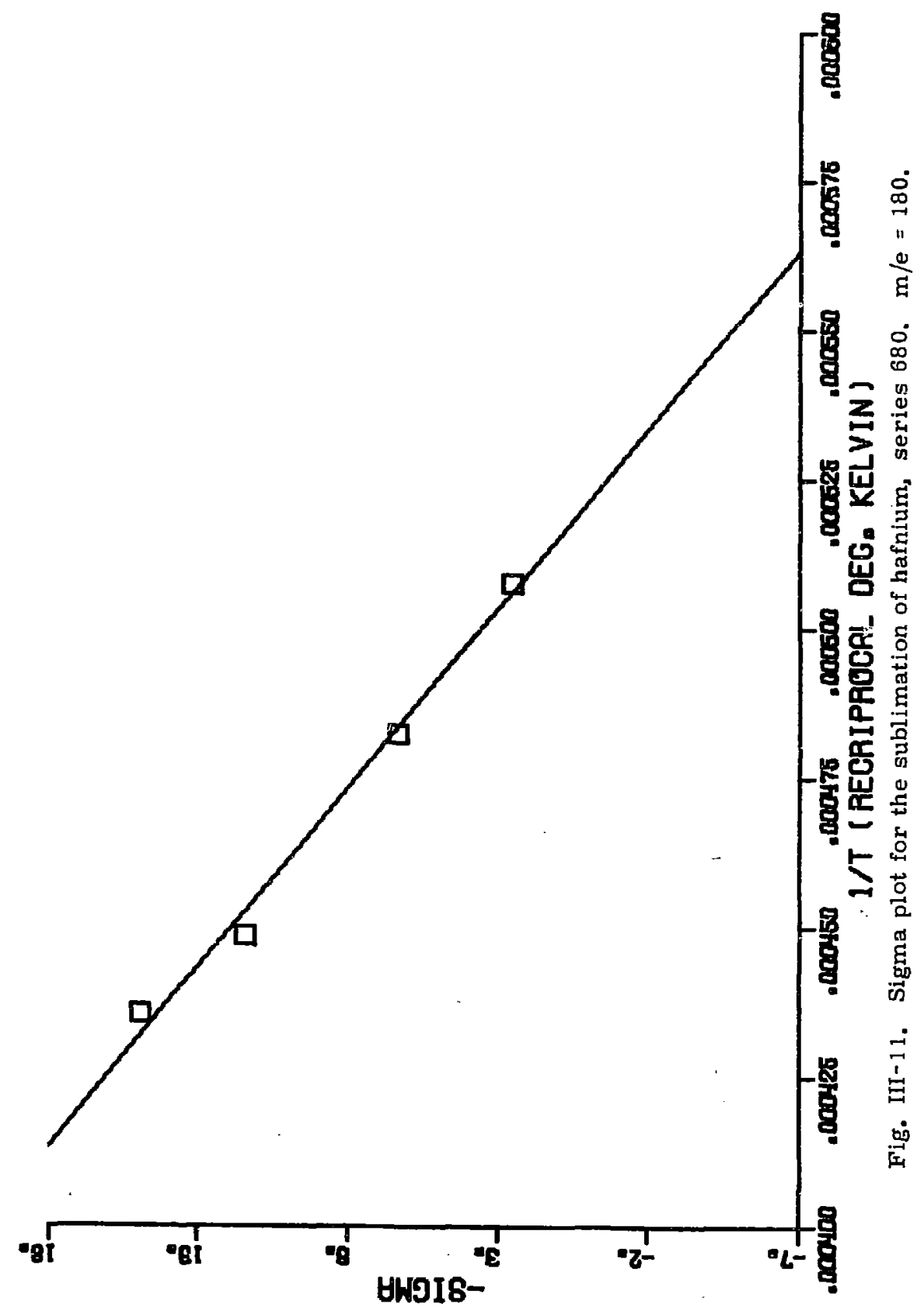




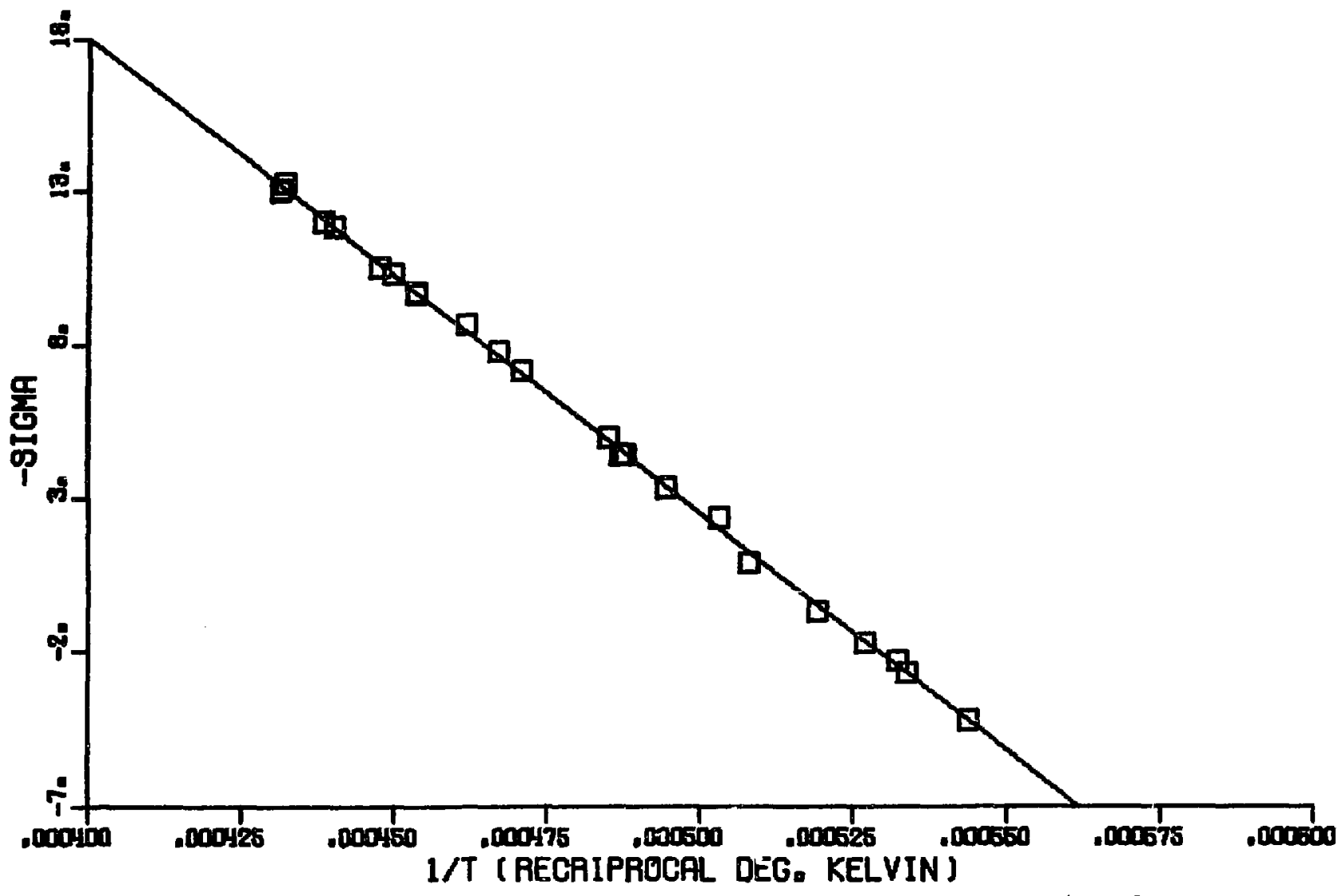

Fig. III -12. Sigma plot for the sublimation of hafnium, series $740 . \mathrm{m} / \mathrm{e}=180$.

$\infty$ 


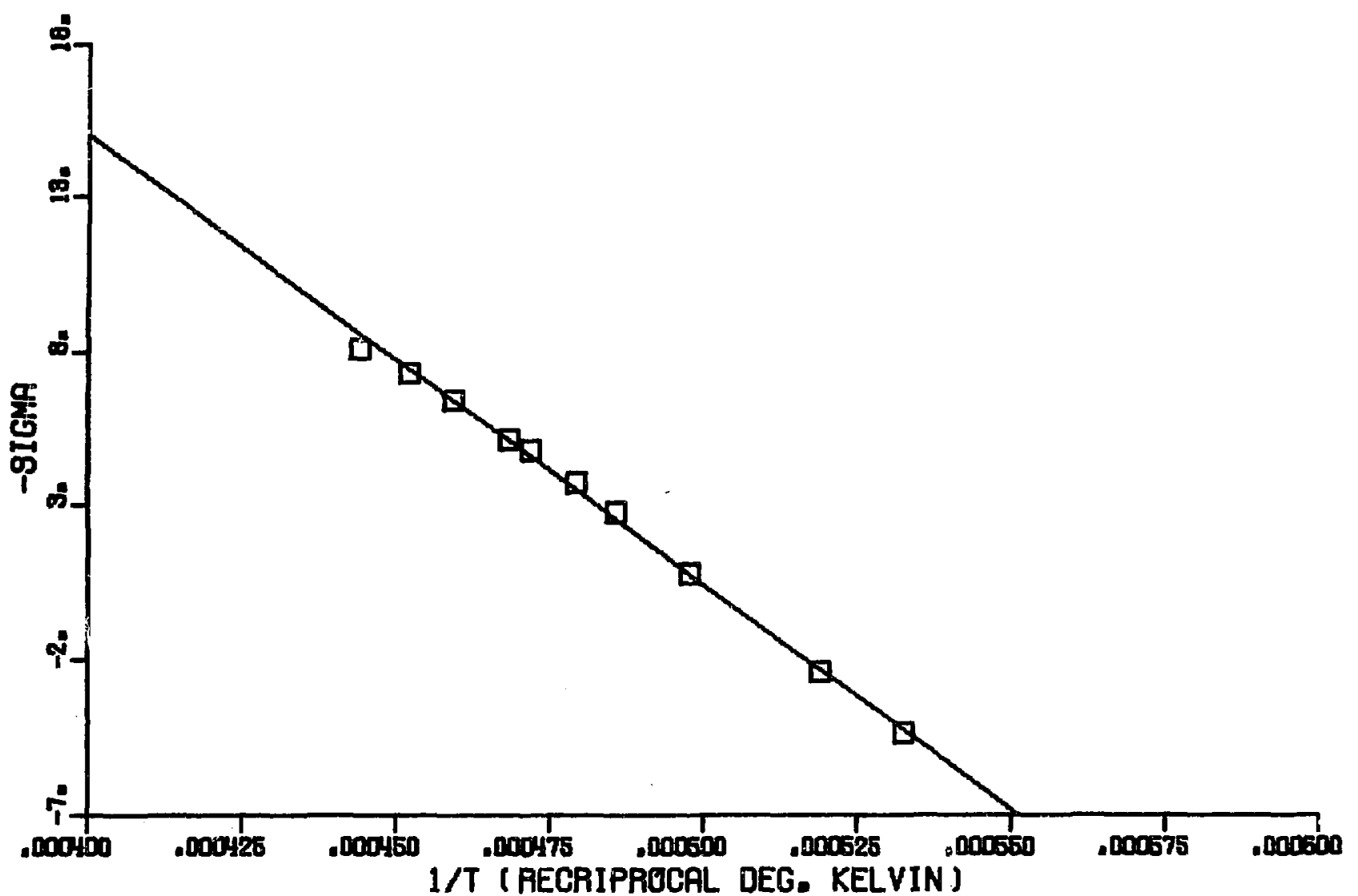

Fig. III-:3. Sigma plot for the sublimation of zirconium from a hafnium alloy, series $540 . \mathrm{m} / \mathrm{e}=90$. 


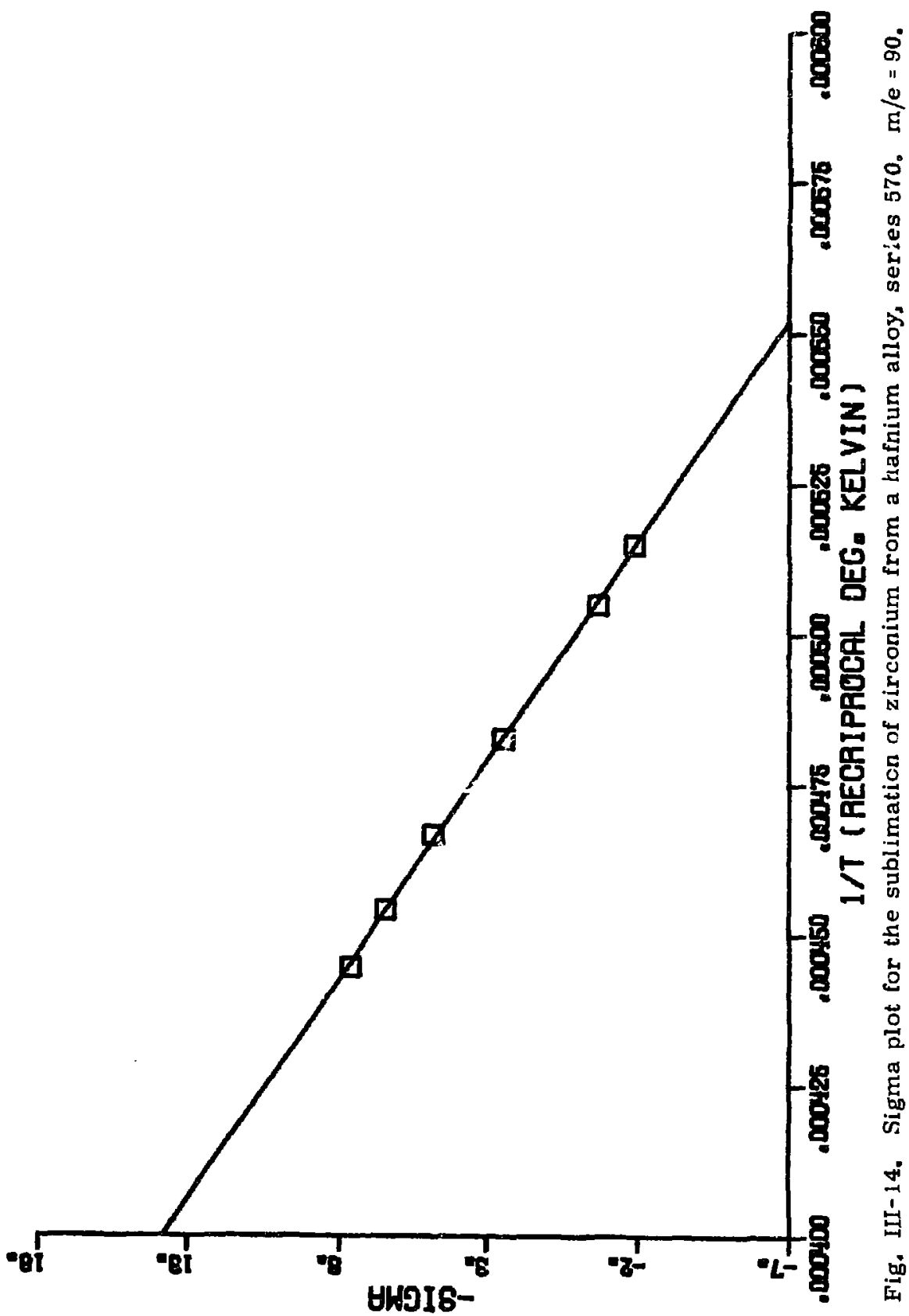




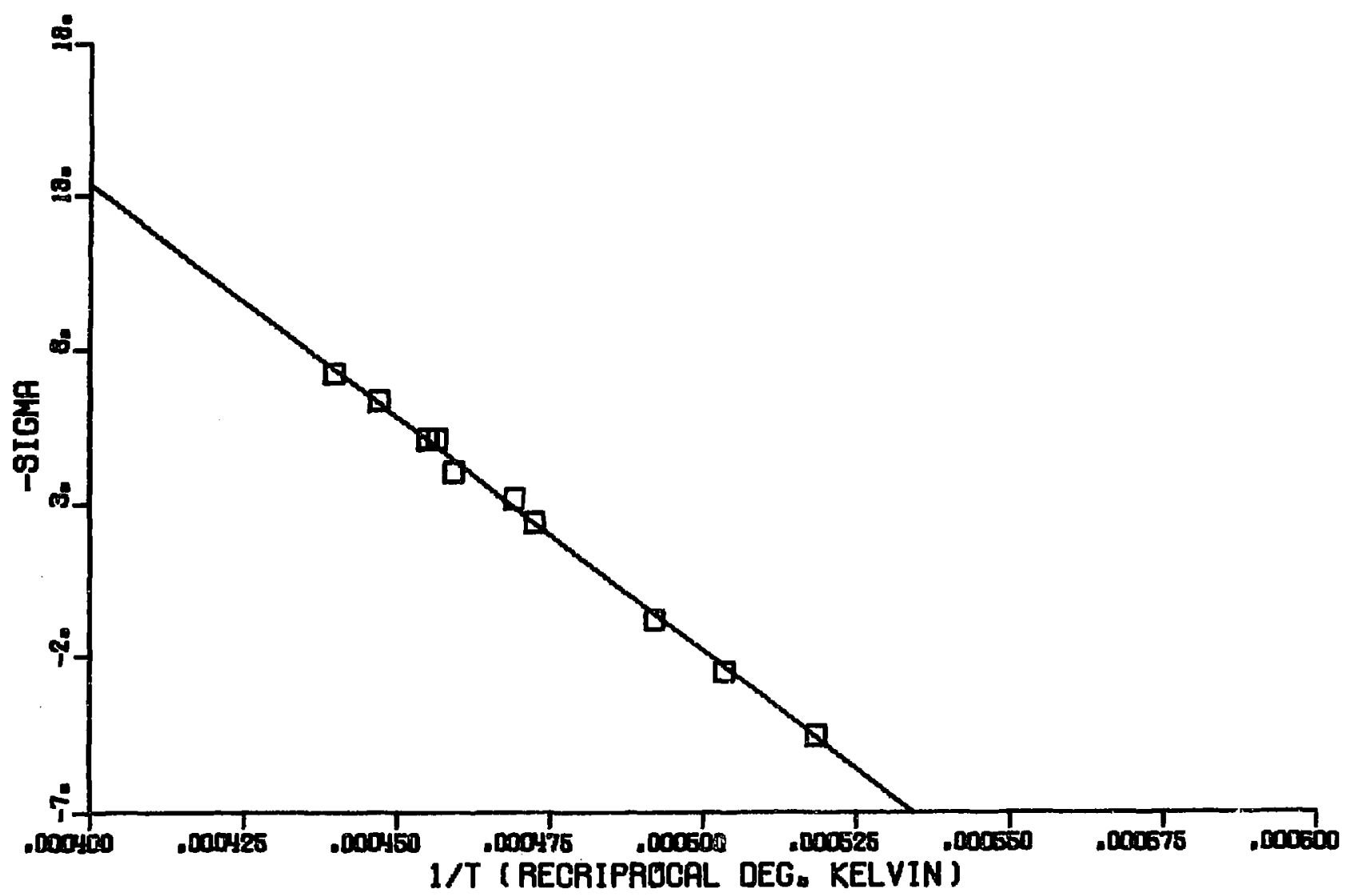

Fig. III-15. Sigma plot for the sublimation of zirconium from a hafnium alloy, series 640 . $\mathrm{m} / \mathrm{e}=90$. 


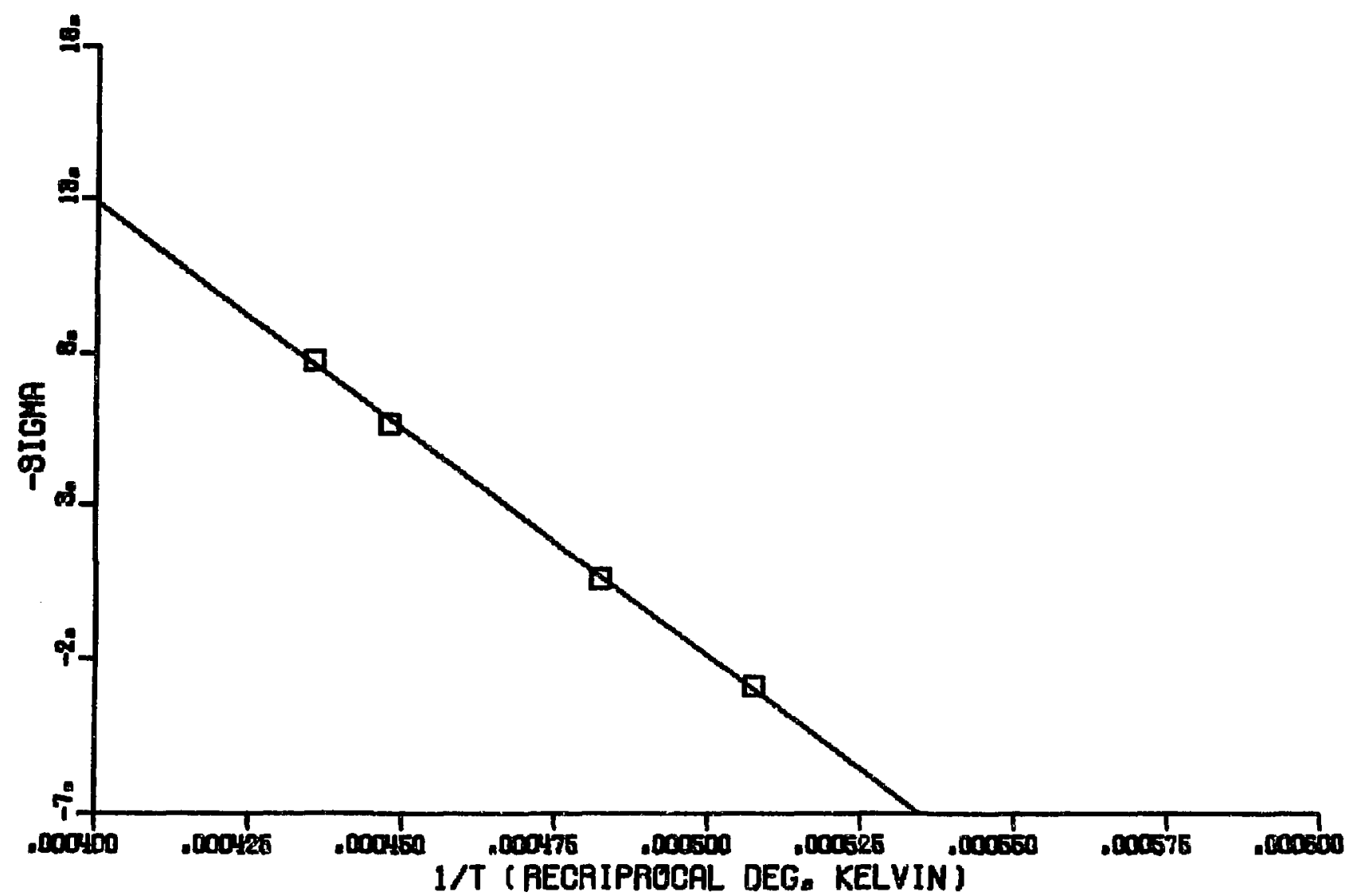

Fig. III-16. Sigma plot for the sublimation of zirconium from a hafnium alloy, series 680 . $\mathrm{m} / \mathrm{e}=90$. 


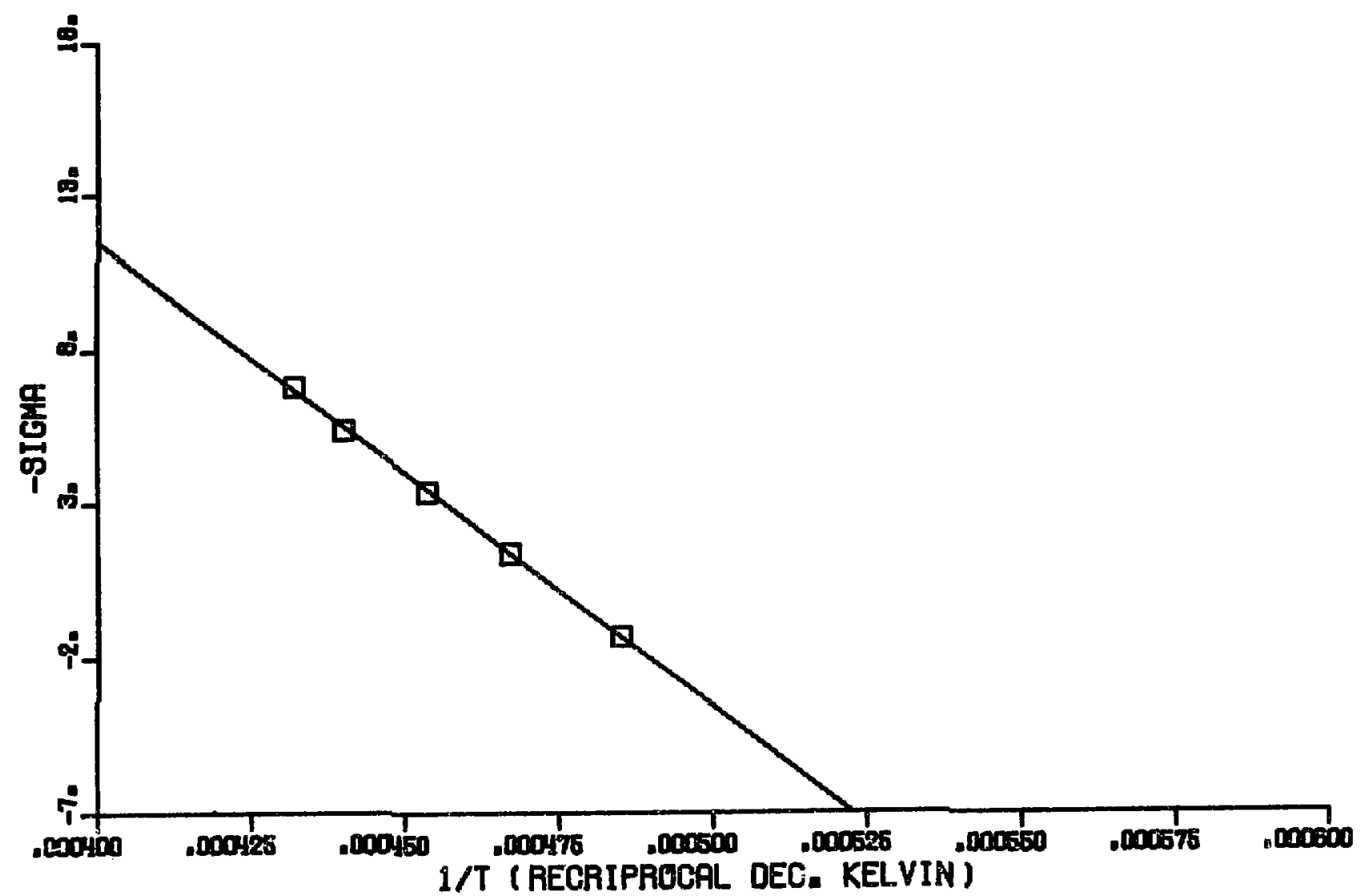

Fig. III-17. Sigma plot for the sublimation of zirconium from a hafnium alloy, series $740 . \mathrm{m} / \mathrm{e}=90$. 


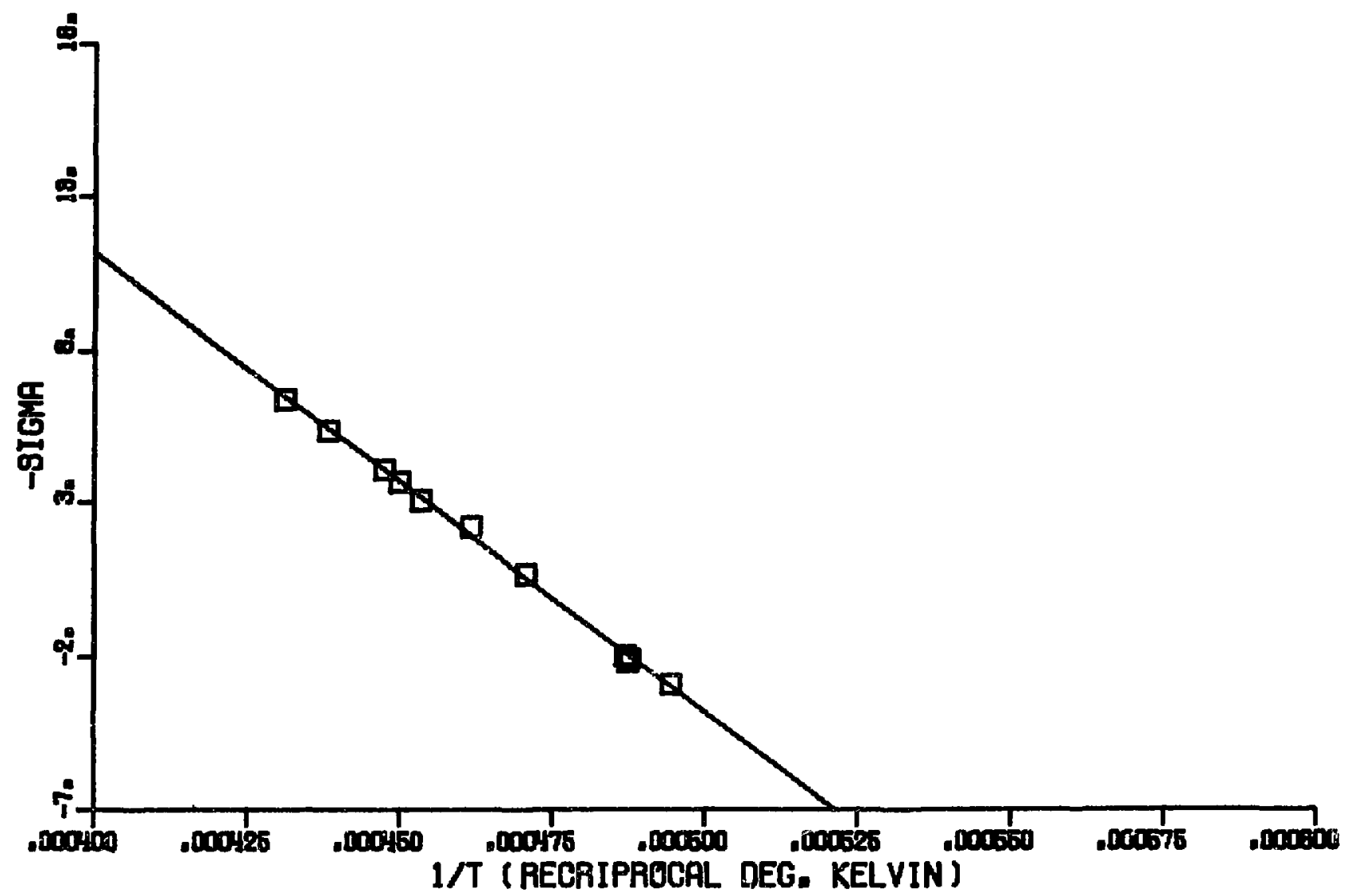

Fig. III-18. Sigma plot for the sublimation of zirconium from a hafnlum alloy, series 750 . $\mathrm{m} / \mathrm{e}=90$. 
where $P^{0}(A)$ is the vapor pressure of the pure substance, $X_{A}$ is the mole fraction of the substance in the sample, $I^{m}$ is the net intensity for $\mathrm{m} / \mathrm{e}, \mathrm{r}^{\mathrm{m}}$ is the isotopic abundance of the ion measured, $\sigma_{A}$ is the relative ionization cross section at high voltage $(70 \mathrm{~V}), \mathbf{r}_{\mathrm{A}}$ is the ratio of ionization efficiency at the voltage of the experiment to that at $70 \mathrm{~V}$, and $d^{m}$ is the detector efficiency.

Intensity ratios $I^{180} / I^{90}$ at comparable temperatures during the series of experiments showed that zirconium depletion of the sample occurred at a significant rate only when the sample was above about $2200^{\circ} \mathrm{K}$. From the analytical results on the first filament and the number of runs made at high temperatures, I estimated that the average depletion rate was 3 to $5 \%$ for each normal run above $2200^{\circ} \mathrm{K}$. In the calculations I used a constant concentration for each run and adjusted the value for each run for the estimated depletion that occurred during the previous run and during any intervening experiments, such as ionization efficiency measurements, in which the sample was heated hatter than $2200^{\circ} \mathrm{K}$.

Isotope abundances were taken from Strominger et al. ${ }^{80}$

Because zirconium and hafnium have similar electronic configurations ard nearly equal atomic radii, their ionization cross sections at high voltage were assumed to be equal. The ratios of cross sections at the voltages used for measurements to the cross sections at high voltage were taken from the results shown in Figs. III-3 and ILI-4.

Detector efficiency corrections were taken from data furnished by $R$. Newbury ${ }^{84}$; these data were obtained on another mass spectrometer in our laboratory with an identical detector. The dependence of detector efficiency on mass for mono-atomic metallic elements was found to obey the equation $\mathrm{d}^{m}: 114.6-2.71(\mathrm{~m})^{1 / 2}$, from $\mathrm{m} \cdot 40$ to is 238 .

The factors used in Eq. III-5 to calculate $H f(g)$ pressures were

$$
\begin{aligned}
\left(\mathrm{f}^{90} / \mathrm{f}^{180}\right) & =1.461, \\
\left(\sigma_{\mathrm{Zr}} / \sigma_{\mathrm{Hf}}\right) & =1.00, \\
\left|\mathrm{Z}_{\mathrm{Zr}}(12.0 \mathrm{~V}) / \mathrm{r}_{\mathrm{Hf}}(11.0 \mathrm{~V})\right| & =0.85, \\
\left(\mathrm{~d}^{90} / \mathrm{d}^{180}\right) & =1.14 .
\end{aligned}
$$

and 
Vaiues of $\left(\mathrm{X}_{\mathbf{Z r}} / \mathrm{X}_{\mathrm{Hf}}\right)$ used for each series are listed in Tables III-3 to III-7. The data were analysed by the second-law and third-law methods by use of Eq. III-2. The third law results are listed in Tables III-3 to III-7. The pressure-vs-temperature data are shown graphically in Figs. III-19 to III-24, and the second-law results are listed in Table III- 10 .

\section{Analysis of Errors}

The most significant uncertainty in temperature arises from the uncertainty in emittance of the hafnium filament surface. It seems unlikely that the true emissivity of hafnium differs from my estimated value by as much as $\mathbf{0 . 0 2}$. An error of that magnitude independent of temperatire would introduce an uncertainty corresponding to a standard deviation of about $0.5 \%$ or $0.7 \mathrm{kcal} / \mathrm{g}$ atom in the third-law results and would not affect the second-law values. The results of Bradshaw 78 for zirconium, and data for other refractory metals in this temperature range, suggest that the emissivity of hafnium probably changes less than 0.02 over the $500^{\circ}$ temperature interval of the experiments. Such a variation would lead to errors of less than $2 \%$ in the second-law results. I believe an estimated error of $1 \%$ or a standard deviation of $1.5 \mathrm{kcal} / \mathrm{g}$ atom is more realistic. Since a temperature trend would probably be in the direction of decreasing emissivity with increasing temperature, the error would be positive, i.e., second-1aw results would be too high.

Additional temperature errors arise from difficulties in reproducing the tumperature scale. These uncertainties are small, compared to uncertainties in emissivity corrections for the hafnium measurements, but are significant for the zirconium measurements because of the color matching difficulties mentioned earlier.

For the zirconium vaporization measurements from the zirconium filament, I estimaite an additional uncertainty corresponding to a standard deviation of $1 \mathrm{kcal} / \mathrm{g}$ atom, because of difficulties in achieving the temperature scale.

Systematic trends in intensity measurements are difficult to evaluate. Since total residual gas background corrections were less 


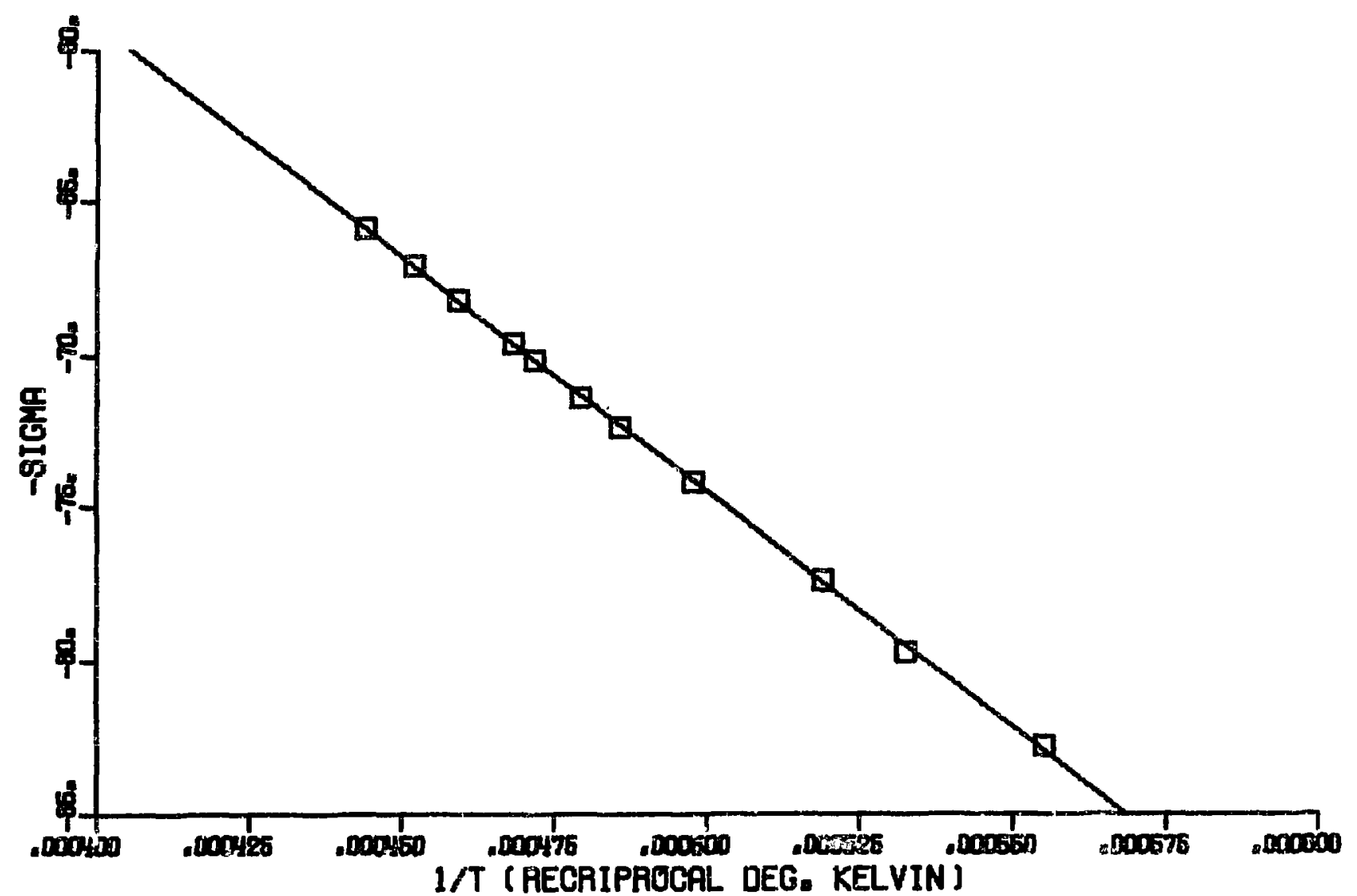

Fig. III-19. Sigma plots for the sublimation of hafnium, using Eq. 2. Pressures calculated using zirconium reference. Series 540 . - Sigma $=R \ln P 0+\Delta\left[\left(G_{T}^{0}-H_{298}^{0}\right) / T\right]$. 


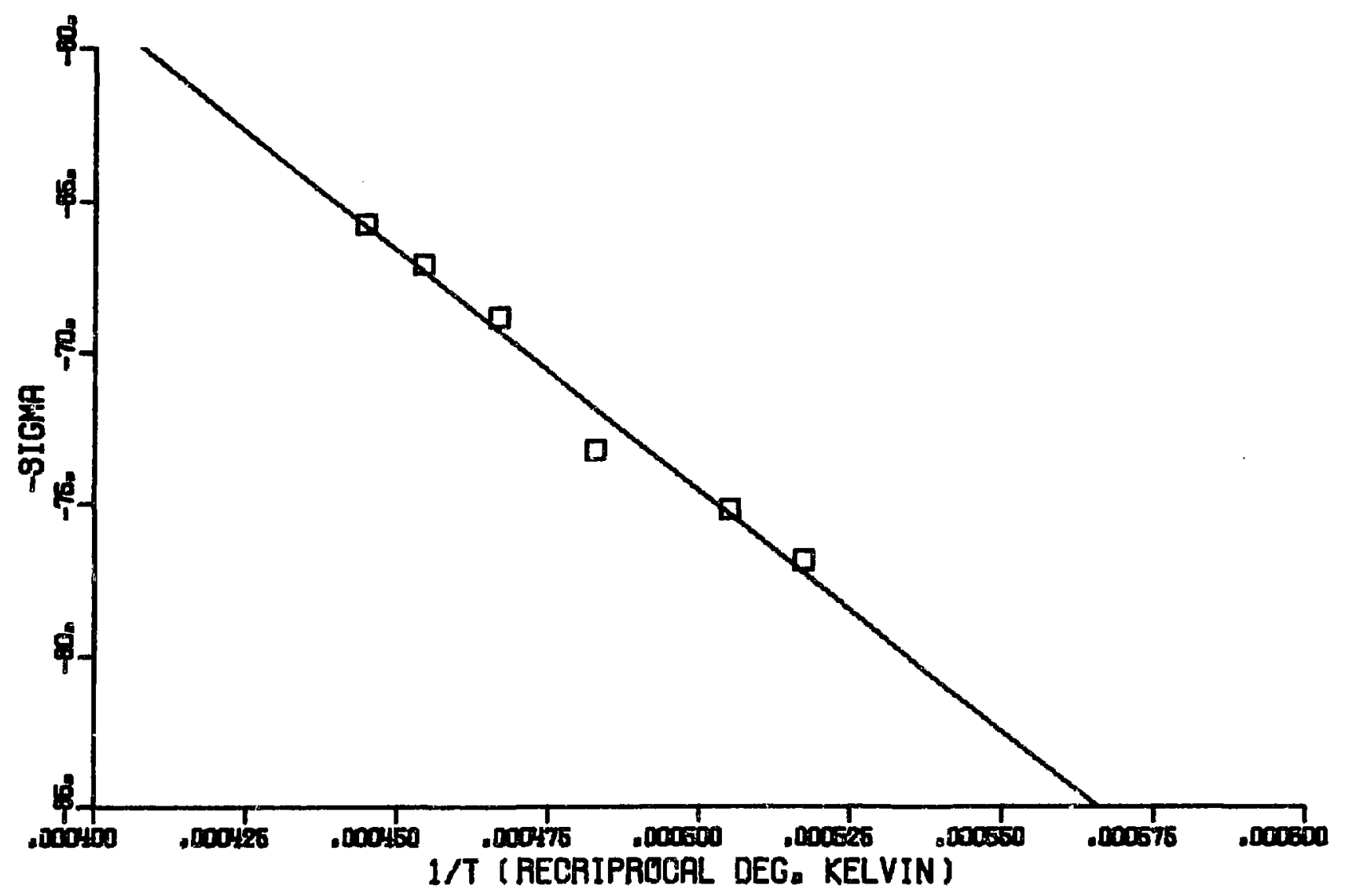

Fig. I1I-20. Sigma plot for the sublimation of hafnium, using Eq. 2. Pressures calculated using zirconium reference. Series 570. 


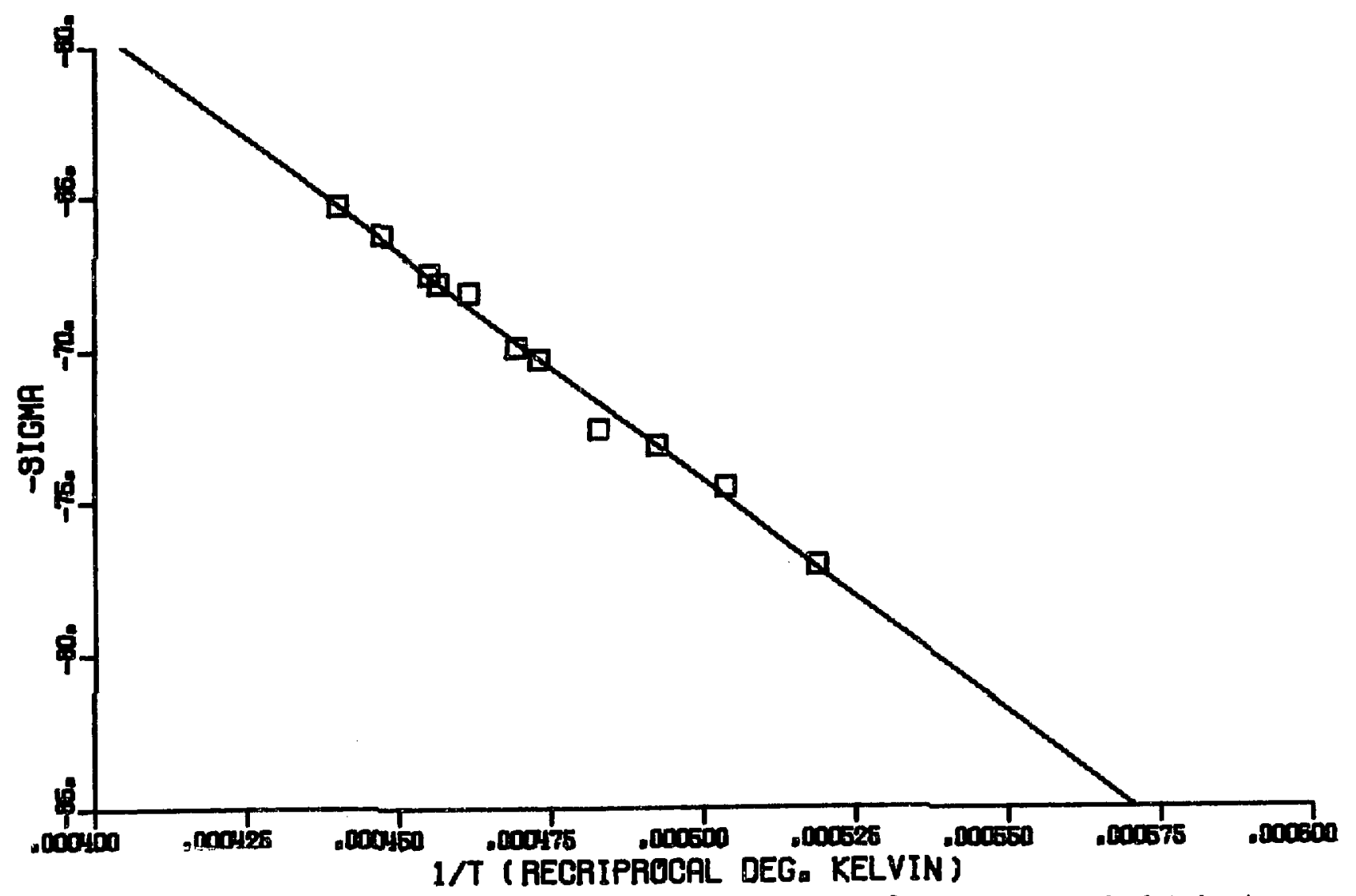

Fig. III-21. Sigma plot for the sublimation of hafnium, using Eq. 2. Pressures calculated using zirconium reference. Series 640 . 


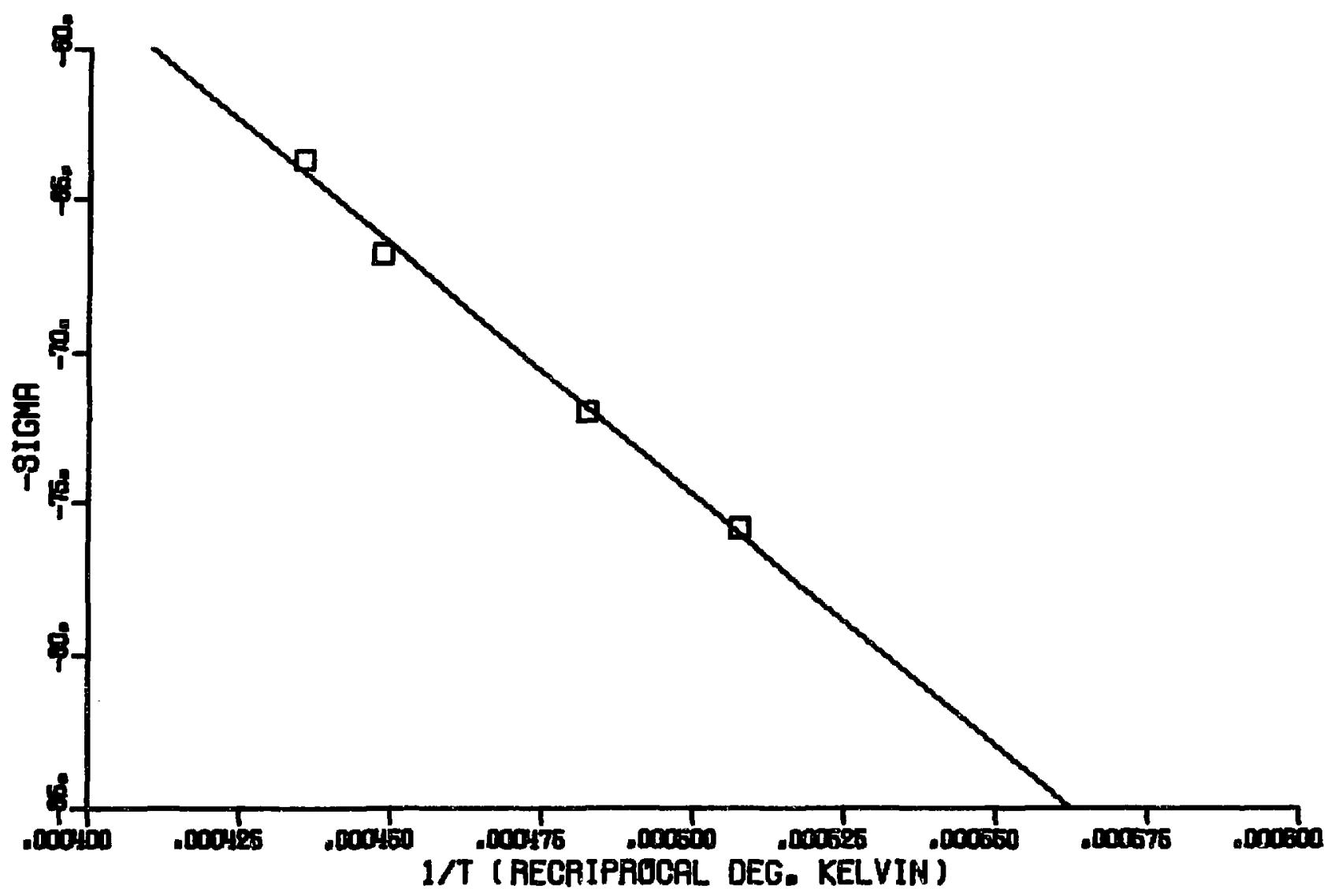

Fig. III-22. Sigma plot for the sublimation of hafnium, using Eq. 2. Pressures calculated using zirconium reference. Series 680 . 


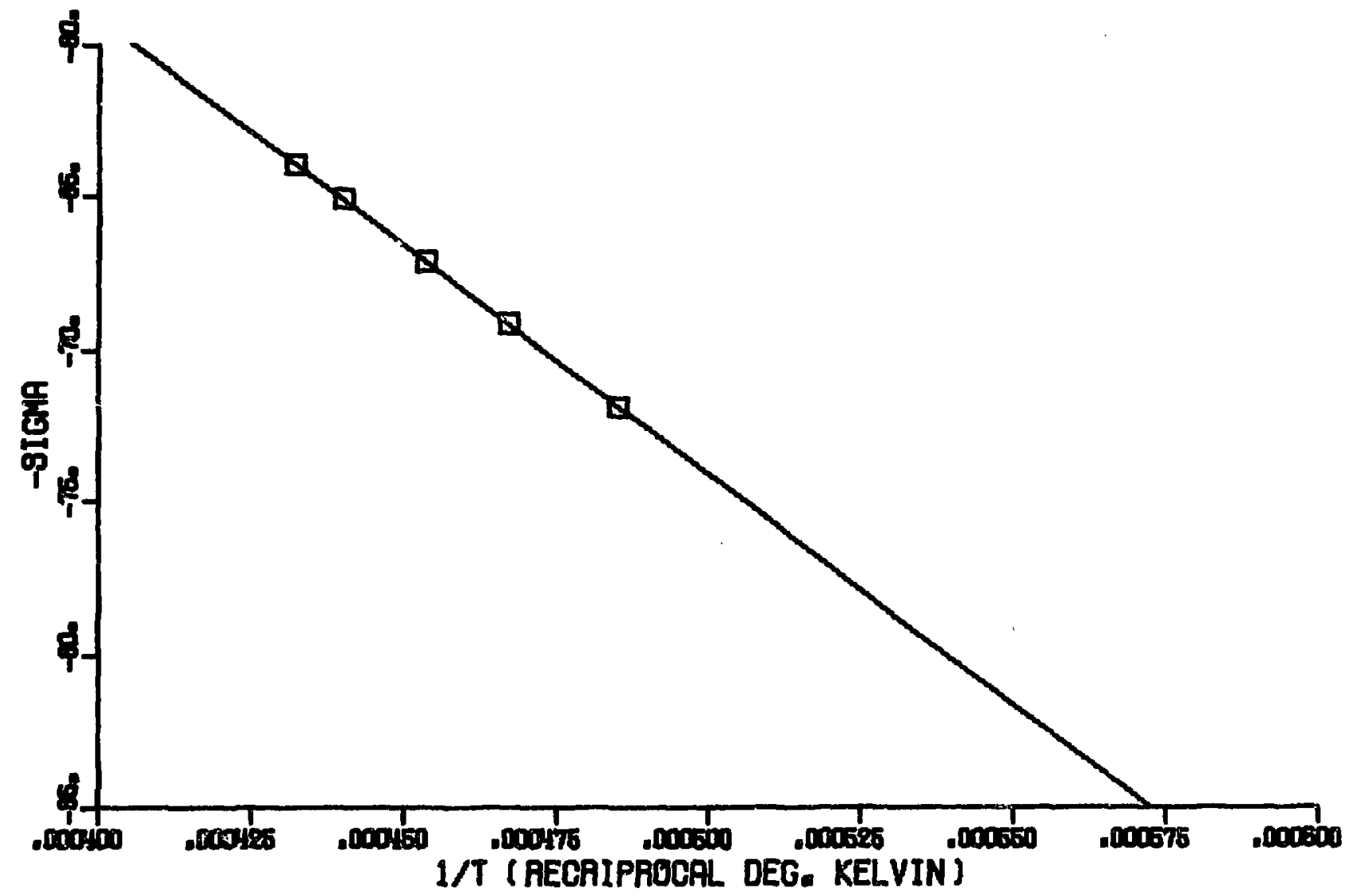

Fig. III-23. Sigma plot for the sublimation of hafnium, using Eq. 2. Pressures calculated using zirconium reference. Series 740. 


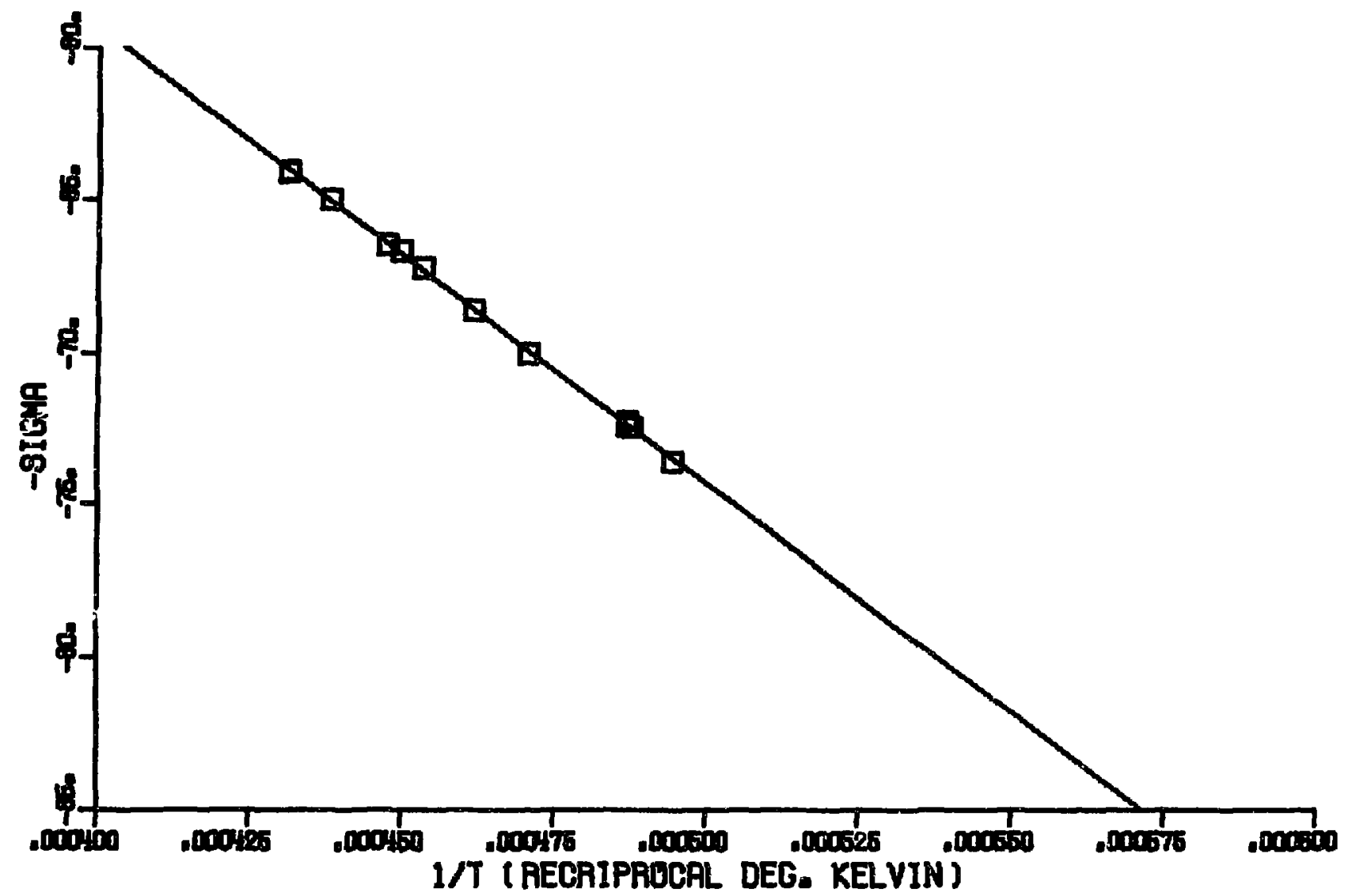

Fig. III-24. Sigma plot for the sublimation of hafnium, using Eq. 2. Pressures calculated using zirconium reference. Series 750 . 
Table III-10. Results of least-squares analyses of hafnium vaporization data by use of Eq. III- 2 and the second-law method.

\begin{tabular}{lclc}
\hline Series & $\begin{array}{c}\text { No. } \\
\text { points }\end{array}$ & $\begin{array}{c}\Delta \mathrm{H}_{2 \mathrm{g8}}^{0} \\
\text { (kcal/g atom) }\end{array}$ & \multicolumn{1}{c}{$\delta$} \\
\hline 540 & 11 & $153.52 \pm 1.60^{\mathrm{a}}$ & $-2.25 \pm 0.78$ \\
570 & 6 & $158.23 \pm 22.6^{\mathrm{a}}$ & $-4.53 \pm 11.3$ \\
640 & 11 & $150.80 \pm 8.14$ & $-1.04 \pm 4.45$ \\
680 & 4 & $164.55 \pm 18.4^{\mathrm{a}}$ & $-7.52 \pm 8.67$ \\
740 & 5 & $150.08 \pm 1.82$ & $-0.90 \pm 0.83$ \\
750 & 12 & $149.95 \pm 2.14$ & $-0.65 \pm 0.99$ \\
Weighted average & $150.04 \pm 1.38$ & $-0.80 \pm 0.64$
\end{tabular}

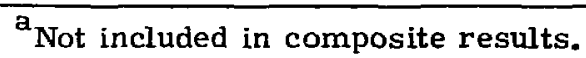


than $1 \%$ of gross intensities at all temperatures, errors in their magnitude could not have affected the results. In Series 120 , thermal backgrounds ran from 0.5 to 0.2 of gross intensities. Subsequent runs had thermal backgrounds from $10^{-1}$ to $10^{-4}$ of gross interisities, and there did not seem to be a correlation between runs with larger background corrections and higher or lower final results. Intensity ratios for the species observed agreed with the natural isotope abundances in all of the hafnium filament runs except for one case that was discarded for that reason. The background errors were more important in runs with the zirconium filament, as was discussed earlier, and the background conti-ibution to the uncertainty in those results is estimated to correspond to a standard deviation of $2 \%$ or $3 \mathrm{kcal} / \mathrm{g}$ atom. There may have been an intensity effect related indirectly to sample temperature, such as one related to the magnetic field of the heating current mentioned above or to a shift in geometrical position due to thermal expansion effects. These would affect the second-law results, second-law results from intensity ratio, and third-law results, in different ways. The agreement between the different methods and the validity of the zirconium results allows us to place an upper limit on such effects, and we estimate that such systematic intensity errors contribute standard deviations of $2 \%$ to the second-law and third-law results, ind $1 \%$ to the second-law results from ratio results.

Errors in concentration ratio, $\mathrm{X}_{\mathrm{Zr}} / \mathrm{X}_{\mathrm{Hf}}$, are estimated to be less than $25 \%$ and introduce uncertainties of $1 \mathrm{kcal} / \mathrm{g}$ atom standard deviation in the third-law results. Errors in the other factors in the pressure calibration, ionization efficiency ratios, transmission ratio, and detector efficiency ratios are believed to be less than $10 \%$, and the combined contribution to the overall uncertainty is estimated to be $0.5 \mathrm{kcal} / \mathrm{g}$ atom standard deviation.

For second-law calculations, the uncertainties in results due to uncertainties in free-energy functions is estimated to be one half of the uncertainty listed by Hultgren et a1. 70,77 in the standard enthalpy of vaporization, or $0.5 \mathrm{kcal} / \mathrm{g}$ atom. The contribution of uncertainties in the thermodynamic functions to the uncertainty in our third-law results is assumed to be equal to the uncertainties in $\Delta \mathrm{H}_{298}^{0}$ listed by Hultgren et al. 70,77 Small discrepancies between the tabulated 
free-energy functions and the true values for hafnium do not affect the comparison between the results obtained from independent experiments when all are evaluated by using the same functions.

Except for Series 540, which yielded the highest values of enthalpy both from second- and third-law treatments, there was no significant temperature dependence of derived third-law enthalpies. In Series 540, the third-law results decreased systematically by about $1 \mathrm{kcal} / \mathrm{g}$ atom from the lowest to the highest temperature. For that reason, the second-law results from that series have not been included in the composite results.

\section{Conclusions}

Results derived for the enthalpy of sublimation of zirconium, the partial molal enthalpy of sublimation of zirconium from a dilute solution in hafnium, and the standard enthalpy of hafnium from combined results by the three methods are listed with estimated uncertainties corresponting to two standard deviations from the mean in Tables $111-11$ and III-12.

Data for zirconium from pure zirconium and from hafnium alloy filaments yield standard enthalpies of sublimation in igreement with the accepted value for zirconium metal. This is evidance that $I$ have avoided large systematic errors and that the dilute solid solution of zirconium in hafnium is ideal.

Because the wide temperature interval yielded relatively precise second-law results while the pressure calibration for hafnium required somewhat uncertain approximations, the second-law results are probably as reliable as the third-law values. The second-law calculation in which intensity ratios are used is probably the most reliable, as it tends to provide cancellation of systematic errors. The fact that the third-law results did not show a temperature trend and were in good agreement with the second-law results is additional evidence that significant systematic errors were absent. The value chosen as the best representation of the results of my measurements 
Table III-11. Standard enthalpy of sublimation for zirconium with estimated errors.

\begin{tabular}{lcccc}
\hline Source & $\begin{array}{c}\Delta \mathrm{H}_{298}^{0} \\
(\mathrm{kcal} / \mathrm{g} \text { atom })\end{array}$ & $\begin{array}{c}\text { Random } \\
\text { errors } \\
(\sigma)\end{array}$ & $\begin{array}{c}\text { Estimated } \\
\text { systematic } \\
\text { errors }(\sigma)\end{array}$ & $\begin{array}{c}\text { Estimated } \\
\text { errors }(2 \sigma)\end{array}$ \\
\hline $\begin{array}{l}\text { Composite results } \\
\text { from m/e }=90 \\
\text { and 91 from } \\
\text { zirconium fila- } \\
\text { ment }\end{array}$ & 147.6 & 2.0 & 2.5 & \pm 6.4 \\
$\begin{array}{l}\text { Composite results } \\
\text { from hafnium } \\
\text { filament second } \\
\text { law, Eq. III-4 }\end{array}$ & 148.84 & 1.03 & 1.34 & \pm 3.4 \\
\begin{tabular}{l} 
Hultgren et al. 77 \\
\hline
\end{tabular} & 145.5 & 0.00 & & \pm 1.00 \\
\hline
\end{tabular}


Table III-12. Standard enthalpy of sublimation of hafnium with estimated errors.

\begin{tabular}{|c|c|c|c|c|}
\hline Source & $\begin{array}{c}\Delta H_{298}^{0} \\
(\mathrm{kcal} / \mathrm{g} \text { atom) }\end{array}$ & $\begin{array}{l}\text { Random } \\
\text { errors } \\
\text { (o) }\end{array}$ & $\begin{array}{l}\text { Estimated } \\
\text { systematic } \\
\text { errors }(\sigma)\end{array}$ & $\begin{array}{l}\text { Estimated } \\
\text { tatal } \\
\text { errors }(2 \sigma)\end{array}$ \\
\hline $\begin{array}{l}\text { Composite results, } \\
\text { second law, } \\
\text { Eq. III-4 }\end{array}$ & 153.62 & 0.67 & 1.34 & \pm 3.0 \\
\hline $\begin{array}{l}\text { Composite results, } \\
\text { second law, } \\
\text { Eq. III-4 }\end{array}$ & 150.04 & 0.69 & 1.03 & \pm 2.48 \\
\hline $\begin{array}{l}\text { Average third-law } \\
\text { results, Eq. III-2 }\end{array}$ & 148.59 & 0.05 & 1.50 & $\pm 2.50^{\mathrm{a}}$ \\
\hline $\begin{array}{l}\text { Average second- } \\
\text { and third-law } \\
\text { results, Eq. III-2 }\end{array}$ & 149.30 & 0.7 & 1.0 & \pm 2.5 \\
\hline Panish and Reif ${ }^{65}$ & 145.59 & & & \pm 2.0 \\
\hline Kibbler et al. 66 & 148.08 & & & $\pm 0.4^{2}$ \\
\hline Blackburn $^{67}$ & 149.18 & & & $\pm 0.75^{\mathrm{a}}$ \\
\hline Koch et al. ${ }^{68}$ & 148.3 & & & \pm 1.2 \\
\hline $\begin{array}{l}\text { Trulson and } \\
\text { Goldstein } 69\end{array}$ & 149.6 & & & $\pm 2.0^{\mathrm{a}}$ \\
\hline
\end{tabular}

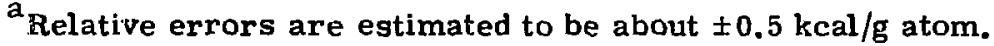


is the average of the second-law and third-law calculations for which Eq. III-2 was used, which is

$$
\Delta H_{298}^{0}=149.30 \pm 2.5 \mathrm{kcal} / \mathrm{g} \text { atom }
$$

Results from independent investigations of the vaporization of hafnium are listed in Table III-12. All data were reduced by using the thermodynamic functions given by Hultgren et al. ${ }^{70}$ The results of Panish and Reif ${ }^{65}$ are significantly lower than the other results. My observations indicate that reactions producing $H f O(g)$ may have contributed to the weight losses of all the investigations in which the conventional Langmuir technique was used, and that the effects would have been most pronounced under the conditions used by Panish and Reif. It is significant that the two mass spectrometric studies that are not susceptible to interference by such side reactions yield the higher results. The standard entropy of sublimation derived from my secondlaw results for which $E_{q}$. III -2 was used is $\Delta s_{298}^{0}=35.03 \pm 0.64$ gibbs; mole, which compares to values of $34.23 \pm 0.05$ gibbs/mole given by Hultgren, ${ }^{70}$ and $33.56 \pm 0.44$ gibbs/mole derived from the second-law results of Koch et al. The deviations between my results or thuse of Koch et al. and Hultgren's value arise from differences in experimental entropies of sublimation at the temperatures of the experiments and from uncertainties in the corrections to $298^{\circ}$ and imply inconsistencies in the integrated $\Delta \mathrm{Cp}$ terms rather than in the $\Delta \mathbf{S}_{298^{\circ}}^{0}$ The lower entorpy found by Koch et al. is associated with the lower enthalpy. However, the discrepancy among our results may not be as significant as it appears, since their measurements were made at much higher temperature on the liquid, and acceptable experimental heat content data on the condensed phase are not available above $1350^{\circ} \mathrm{K}$. 70 
Part IV

THE KINETICS OF SUBLIMATION OF GaN

AND THE COMPOSITION OF ITS VAPOR

Abstract

High concentration, of gaseous $\mathrm{GaN}$ and $(\mathrm{GaN})_{x}$ molecules in the vapor from gallium nitride sublimation have been reported by others. My observations indicate that the ion peaks that were believed to have originated from stable $(\mathrm{GaN})_{\mathbf{x}}$ gaseous molecules in the previous work probably resulted from ion-molecule reactions. I attempted to establish the nature of the activated complex involved in the sublimation of gallium nitride by observing the gaseous products of the decomposition reaction with a mass spectrometer. The kinetics study was inconclusive, but observations indicated that the $\mathrm{N}_{2}$ molecules that leave the gallium nitride surface may contain excess internal energy because the fragmentation pattern for $\mathrm{N}_{2}$ molecules from a gallium nitride surface is enriched in $\mathrm{N}^{+}$ions.

\section{Introduction}

The reaction $\mathrm{GaN}(\mathrm{s})=\mathrm{Ga}(\mathrm{g})+\frac{1}{2} \mathrm{~N}_{2}(\mathrm{~g})$ has a large activation energy. The experimental nitrogen pressures determined îrom Knudsen vaporization experiments are several orders of magnitude below the calculated equilibrium values. 85 The apparent enthalpy of activation for free surface sublimation under Langmuir conditions measured by Munir and Searcy ${ }^{85}$ is about $39 \mathrm{kcal} / \mathrm{mole}$ higher than the equilibrium value calculated from calorimetric data of Hahn and Juza. ${ }^{86}$ Lorenz and Binkowski ${ }^{87}$ report that the equilibrium nitrogen pressure above $\mathrm{GaN}(\mathrm{s})$ ał $800^{\circ} \mathrm{C}$ is greater than $0.5 \mathrm{~atm}$, which is consistent with the enthalpy of formation given by Hahn and Juza. It is of interest to determine if the excess energy of sublimation appears as internal energy in the products. Measurements by Mar and Searcy indicate excess kinetic energy to be negligible. 88

Excess internal energy could be incorporated in the $\mathrm{N}_{2}$ gas produced as excess vibrational or rotational energy. I investigated these possibilities by measuring the apfearance potentials of $\mathrm{N}_{2}^{+}$and $\mathrm{N}^{+}$ions 
produced from a molecular beam of nitrogen gas subliming rrom $\mathrm{GaN}(\mathrm{s})$ and by comparing the ratio of $\mathrm{N}^{+}$to $\mathrm{N}_{2}^{+}$ions obtained by electron bombardment of nitrogen vaporized from GaN to the ratio from bonbardment of residual nitrogen in the spectrometer.

It has betn reported that $\mathrm{GaN}$ and polymers of $\mathrm{GaN}$ are important species in the vapor of $\operatorname{GaN}(s) .{ }^{89}$ I searched the mass spectrum in an attempt to confirm the reports.

\section{Experimental}

GaN(s) powder was prepared by the reaction of $\mathrm{Ga}_{2} \mathrm{O}_{3}(\mathrm{~s})$ with flowing anhydrous $\mathrm{NH}_{3}(\mathrm{~g})$ in a tube furnace at $900^{\circ} \mathrm{C}$. Our observa tions of ihis reaction were in agreement with those of Lorenz and Binkowski. 87 Depending on the temperature and time of reaction, products range in color from bright orange through light yellow to grey. Measurements of the degree of reaction showed that the orange and yellow products were incompletely converted and contained as much as 20 wt\% unreacted $\mathrm{Ga}_{2} \mathrm{O}_{3}$, even though all products had identical $x$-ray powder diffraction patterns, except that patterns for samples with large excesses of oxygen were less sharp. The patterns corresponded to the hexagonal structure previously raported for GaN $\{=3.180 \AA, c=5.166 \AA$ ), 90 The very light yellow and grey materials were $\mathrm{GaN}_{0.98} \mathrm{O}_{0,02}$ and $\mathrm{Ga}{ }_{1.002} \mathrm{~N}$ as determined by the loss in weight of the starting materials.

The mass spectrometry experiments were carried out with an instrument similar to the one described in the previous section of this thesis. The source was modified to regulate by control of the cathode temperature ${ }^{01}$ and was attached to a flange rather than a removable carriage. The beam was focused by means of electrostatic deflection plates rather than by rotation of the ion source.

Several experiments were made with $\mathrm{GaN}(s)(\sim 1$ at.\% 0$)$ subliming from rhenium boats that were heated by self-resistance in the ion source, as described in Ref. 91 and this thesis. With the configuration used, I was unable to view the rhenium boat and could not measure the temperature, Furthermore, the gallium corroded the rhenium and limited the time of experiments to less than an hour. In most of 
these experiments, I observed only $\mathrm{Ga}^{+}, \mathrm{N}_{2}^{+}$, and $\mathrm{Ga}_{2} \mathrm{O}^{+}$ions. The $\mathrm{Ga}_{2} \mathrm{O}^{+}$peak intensities approached $50 \%$ of the $\mathrm{Ga}^{+}$peak intensities when some of the samples were first heated, but in all cases decayed completely away. In two cases I was able to observe $\mathrm{Ga}_{2}^{+}, \mathrm{GaN}^{+}$, and smaller peaks that may have corresponcied to $\mathrm{Ga}_{2} \mathrm{~N}_{2}^{+}$. This was possible only at the maximum temperature, and the filaments lasted only a few minutes under these conditions. Vaporization was very erratic, and only crude values of intensity ratio could be obtained.

I also observed mass spectra from samples of GaN evaporated from a tungsten crucible at $900^{\circ}$ to $1250^{\circ} \mathrm{K}$. The crucible was $1.9 \mathrm{~cm}$ in diameter and $1.4 \mathrm{~cm}$ high, with an orifice in the lid $3 \mathrm{~mm}$ in diameter, and was placed in a tungsten holder. Temperatures were measured with a platinum-vs-platinum-10\% rhodium thermocouple between the bottom of the cell and the cell holder. The furnace was mounted $11 \mathrm{~cm}$ beneath the ion source, with tungsten radiation shields and a water-cooled copper jacket surrounding the furnace. A tungsten helix resistance element was used as a heater. A manually operated shutter above the molecular beam hole in the furnace assembly permitted the determination of the signal from material originating in the furnace. In these experiments I could measure and control the temperature, but without a gas inlet tube into the furnace I could not control the nitrogen pressures independently or observe nitrogen gas from the furnace independently of the vaporization of a sample. The only ion peaks detected from sarnples heated in the furnace were $\mathrm{Ga}^{+}$, $\mathrm{N}_{2}^{+}, \mathrm{N}^{+}$, and $\mathrm{Ga}_{2}^{+}$

Ionization efficiency curves for $\mathrm{Ga}^{+}, \mathrm{N}_{2}^{+}$, and $\mathrm{N}^{+}$were measured, using the furnace molecular beam source, by the methods described in the previous section of this thesis. The electron energy distribution in the new ion source is due primarily to potential gradients within the source and is estimated to be $0.5 \mathrm{~V}$. Voltages were recorded to $\pm 0.05 \mathrm{y}$ by using a voltage-to-frequency converter and pulse iransformer system. The voltage scale was normalized by determining the appearance potential of $\mathrm{Ar}^{+}(40)$. Checks of the appearance potentials 
of $\mathrm{Ag}^{+}(107), \mathrm{H}_{2} \mathrm{O}^{+}(18)$, and $\mathrm{O}_{2}^{+}(32)$ agreed with accepted values of $\pm 0.3 \mathrm{~V} .92$

\section{Discussion}

My results contradict the findings of Gordienko et al., ${ }^{89}$ who observed $\mathrm{I}\left(\mathrm{GaN}^{+}\right) / \mathrm{I}\left(\mathrm{Ga}^{+}\right)$ratios from 0.6 to 2.0 and $\mathrm{I}\left(\mathrm{Ga}_{2} \mathrm{~N}_{2}^{+}\right) / \mathrm{I}\left(\mathrm{Ga}^{+}\right)$ ratios from 0.1 to 0.3 at temperatures from 1000 to $1150^{\circ} \mathrm{K}$. The maximum $\mathrm{I}\left(\mathrm{GaN}^{+}\right) / \mathrm{I}\left(\mathrm{Ga}^{+}\right)$ratio I $\mathrm{Baw}$ was 0.1 from samples sublimed from the rhenium filaments. The nitrogen pressure in the manifold at that time was $10^{-5}$ Torr, and nitrogen pressure in the source probably was at least 1 order of magnitude higher. I attempted to achieve high source pressures of $\mathrm{N}_{2}(\mathrm{~g})$ during the tungsten furnace experiments by throttling the pump. Runs with manifold pressures of $2 \times 10^{-5}$ Torr did not produce $\mathrm{GaN}^{+}$peaks, although the $\mathrm{Ga}^{+}$intensities we re as high as those for the previous experiments, where $\mathrm{GaN}^{+}$ions were seen.

Although 1 was not able to make measurements relating $\mathrm{GaN}^{+}$ intensity to $\mathrm{Ga}(\mathrm{g})$ and $\mathrm{N}_{2}(\mathrm{~g})$ concentrations and $\mathrm{Ga}^{+}$and $\mathrm{N}_{2}^{+}$intensities in order to show the occurrence of an ion-molecule reaction, I believe that the failure to find $\mathrm{GaN}^{+}$except under conditions of very high $\mathrm{N}_{2}(\mathrm{~g})$ and $\mathrm{Ga}(\mathrm{g})$ concentrations and high $\mathrm{N}_{2}^{+}$and $\mathrm{Ga}^{+}$ion intensities indicates that the $\mathrm{GaN}^{+}$ions were produced by ion-molecule reactions. Appearance potentials measured for $\mathrm{Ga}^{\dagger}$ were the same, within the precision of our measurements ( $\pm 0.2 \mathrm{~V}$ ), for experiments with $\mathrm{GaN}(\mathrm{s})$ or $\mathrm{Ga}(\ell)$ in the crucible. When the shutter was closed, the $\mathrm{Ga}^{+}$intensity was reduced to zero. The $\mathrm{N}_{2}^{+}$and $\mathrm{N}^{+}$appearance poisntials were the same for runs with $\mathrm{GaN}(\mathrm{s})$ in the furnace and for runs with $\mathrm{N}_{2}(\mathrm{~g})$ leaked into the spectrometer with the pump valve partially closed. All results agreed with values listed in Ref. 92. Since only a few percent of the nitrogen reached the detector from the sample without undergoing collisions, however, a difference in appearance potentials might not be observed even if all the $\mathrm{N}_{2}$ molecules from the cell contained significant excess energy.

The ion ratios $\mathrm{N}^{+} / \mathrm{N}_{2}^{+}$were distinctly higher when the shutter above the heated cell was open than when it was closed or when background gases were measured (Tables IV-1 and IV-2). The maximum possible partial pressure for nitrogen atoms can be calculated to be of 
Table IV-1. Typical intensity measurements taken with powder GaN in a tungsten cell. ${ }^{2}$

\begin{tabular}{|c|c|c|c|c|c|c|c|}
\hline \multirow{2}{*}{$\begin{array}{c}\text { Sample } \\
\text { temperature } \\
\left.{ }^{\circ} \mathrm{C}\right) \\
\end{array}$} & \multicolumn{2}{|c|}{ Shutter open } & \multicolumn{2}{|c|}{ Shutter closed } & \multirow{2}{*}{$\begin{array}{r}\mathrm{N}^{+} / \mathrm{N}_{2}^{+} \\
\text {from cell }\end{array}$} & \multirow{2}{*}{$\begin{array}{c}\mathrm{N}^{+} / \mathrm{N}_{2}^{+} \\
\text {outside } \\
\text { cell } \\
\end{array}$} & \multirow{2}{*}{$\frac{\mathrm{N}^{+} / \mathrm{N}_{2}^{+} \text {(cell) }}{\mathrm{N}^{+} / \mathrm{N}_{2}^{+} \text {(outside) }}$} \\
\hline & $\mathbf{N}_{2}^{+}$ & $\mathrm{N}^{+}$ & $\mathrm{N}_{2}^{+}$ & $\mathrm{N}^{+}$ & & & \\
\hline 907 & 70,863 & 4,505 & 48,835 & 3,003 & 0.0682 & 0.0615 & 1.11 \\
\hline 941 & 180,331 & 12,240 & 123,009 & 8,144 & 0.0715 & 0.0662 & 1.08 \\
\hline 962 & 259,701 & 19,157 & 181,516 & 12,529 & $C .0848$ & 0.0690 & 1.23 \\
\hline 979 & 368,068 & 30,284 & 259,400 & 19,583 & 0.0985 & 0.0755 & 1.30 \\
\hline 1004 & 529,989 & 52,307 & 393,682 & 33,683 & บ. 1366 & 0.0856 & 1.60 \\
\hline
\end{tabular}

arifice diarneter $3.0 \mathrm{~mm}, \mathrm{~N}_{2}^{+}$data taken at $27 \mathrm{~V}, \mathrm{~N}^{+}$data at $38 \mathrm{~V}$. 
Table IV-2. Ratios from residual gases in spectrometer with furnace cold.

\begin{tabular}{lrrr}
\hline Manifold pressure & $\mathrm{N}_{2}^{+}$ & $\mathrm{N}^{+}$ & $\mathrm{N}^{+} / \mathrm{N}_{2}^{+}$ \\
\hline $3.5 \times 10^{-8}$ Torr & 17,385 & 1049 & 0.0603 \\
$9.0 \times 10^{-8}$ Torr & 55,011 & 2556 & 0.0465 \\
$3.3 \times 10^{-7} \begin{array}{l}\text { Torr (pump valve } \\
\text { closed) }\end{array}$ & 210,135 & 8155 & 0.0388 \\
& Leaking $\mathrm{N}_{2}$ in from manifold & \\
$1.4 \times 10^{-8}$ Torr & 10,092 & 507 & 0.0502 \\
$4.4 \times 10^{-8}$ Torr & 42,068 & 1844 & 0.0438 \\
$8.4 \times 10^{-7}$ Torr & 119,862 & 4271 & 0.0356 \\
\hline
\end{tabular}


the order of $10^{-10}$ atm at $1300^{\circ} \mathrm{K}$, from the equilibrium data for gallium nitride and for the elements. Free surface fluxes corresponding to pressures of $10^{-5}$ atm were observed by Munir and Searcy. The increase of the $\mathrm{N}^{+} / \mathrm{N}_{2}^{+}$ratio when molecules from the cell were studied probably reflects, therefore, a higher fragmentation probability for $\mathrm{N}_{2}$ molecules from the gallium nitride surface. This change in fragmentation behavior would be reasonable if the $\mathrm{N}_{2}$ moiecules were not at internal equilibrium. However, simple thermal excitation to about $1000^{\circ} \mathrm{C}$ produces higher populations of vibrationally and rotationally excited states, which might greatly change the fragmentation probability from that characteristic of $\mathrm{N}_{2}$ at ambient temperatures. Proof of excess energy in $\mathrm{N}_{2}$ molecules originating from a gallium nitride surface would require comparison of the fragmentation patterns of $\mathrm{N}_{2}$ vaporized from $\mathrm{GaN}$ to patterns of $\mathrm{N}_{2}$ thermally excited to a corresponding temperature, about $1000^{\circ} \mathrm{C}$. 


\section{REFERENCES}

1. G. Brauer, in Progress in the Science and Technology of the Rare Earths, L. Eyring, Ed. (Pergamon Press, New York, 1964), Vol. 1, pp. 152-166; Vol. II, pp. 312-339 (1966); Vol. III, pp. $434-458$ (1968).

2. E. F. Westrum, in Progress in the Science and Technology of th a Rare Earths, L. Eyring, Ed. (Pergamon Press, New Yurk, 1964), Voi. I, pp. 3/0-350; Vol. II, pp. 35-89 (1966); Vol. III, pp.459-514 (1968).

3. V. M. Goldschmidt, F. Ulrich, and T. Barth, Slirifter Norske Videnskaps-Akad. Oslo, I: Mat.-Naturv. K1., No. 5, 5 (1925); Chem. Abstr. 19, 2764 (1926).

4. R. S. Roth and S. J. Schneider, Bur. Stand. J. Res. 64A, 309 (1960).

5. H. Bărnighausen and G. Brauer, Acta crystallogr. 15, 1059 (1962).

6. R. C. Rau, in Proc. The Third Rare Earth Res, Conf, Clearwater, Florida, April 1963, K. S. Vorres, Ed. (Gordon and Breach, New York, 1964), pp. 117-134.

7. G. Garton and D. A. Hukin, in Proc. The Third Rare Earth Res. Conf., Clearwater, Florida, April 1963, K. S. Vorres, Ed. (Gordon and Breach, New York, 1964), pp. 3-20.

8. H. Bärnighausen, J. prakt. Chem, 34, 1 (1966).

9. M. W. Shafer, J. Appl. Phys. 36, 1145 (1965).

10. M. F. Barrett and T. I. Barry, J. Inorg. Nucl. Chem. 27, 1483 (1965).

I1. F. H. Ellinger and W. H. Zachariasen, J. Am. Chem. Soc. 75, 5650 (1953).

12. H. A. Eick, N. C. Baenziger, and L. Eyring, J. Am. Chem. Soc. 78, 5147 (1956).

13. J. C. Achard, Compt. Rend. 245, 1064 (1957).

14. T. L. Felmlee and L. Eyring, in Proc. The Fifth Rare Earth Res. Conf., Ames, Iowa (1965), pp. 13-24.

15. J. C. Achard and G. Tsoucaris, Compt. Rend, 246, 285 (1958). 
16. G. Brauer, H. Bărnighausen, and N. Schultz, Z. Anorg. Allgem. Chem 356, 46 (1967).

17. T. L. Felmlee and L. Eyring, Inorg. Chem. 7, 660 (1968).

18. G. J. McCarthy, W. B. White, and R. Roy, Inorg. Chem. B, 1236 (1969).

19. A. E. Miller and A. H. Daane, J. Inorg. Nucl. Chem. 27, 1955 (1965).

20. S. J. Schneider, Bur. Stand. J. Res. 65A, 429 (1961).

21. M. Foex, Compt. Rerid. 260, 6389 (1965).

22. O. A. Mordovin, N, I. Timofeeva, and L. N. Drozdova, Izv. Akad. Nauk SSSR, Neorg. Mater. 3, 187 (1967). [Eng. Transl, lnorg. Mater. 3, 159 (1967).]

23. X-Ray Powder Data File 12-384, P. W. Brindley, Ed. (ASTM, Philadelphia, Pennsylvania 1962).

24. J. C. Achard, Compt, Rend, 250, 3025 (1960).

25. C. F. Guerci and M. W. Shafer, J. Appl. Phys. 37, 1406 (1966).

26. R. C. Rau, Acta crystallogr. 20, 716 (1966).

27. R, P. Elliott, Proc. The Fourth Rare Earth Res. Conf., Phoenix, Arizona, 1964, L. Eyring, Ed, (Gordon and Breach, New York, 1965), pp. 215-245.

28. R. P. Elliott, Constitution of Binary Alloys, First Suppl. (McGraw Hill, New York, 1965).

29. I. R. Harris, J. Less-Common Metals, 14, 459 (1968).

30. D. T. Cromer and A. C. Larson, Acta crystallogr. 12, 855 i. 959).

31. L. F. Bertaut, R. Lemaire, and J. Schweizer, Compt. Rend., 260, 3595 (1965).

32. K. H. J. Buschow, J. Less-Common Metals, 16, 45 (1968).

33. A. V. Virkar and A. Raman, J. Less-Common Metala, 1859 (1969).

34. W. Bronger, J. Less-Common Metals, 12, 63 (1967).

35. R. G. Bedford and E. Catalano, "Phase Diagrams of the $\mathrm{SmF}_{2}-\mathrm{SmF}_{3}, \mathrm{EuF}_{2}-\mathrm{EuF}_{3}$ and $\mathrm{YbF}_{2}-\mathrm{Yb}_{3}$ Systems, in Proc. The 8th Rare Earth Res. Conf., Reno, Nevata, 1970 (availability restricted to attendees).

36. J. M. Haschke and H. A. Eick, J. Phys, Chem. 73, 374 (1969). 
37. R. Hultgren, R. L. Orr, P. D. Anderson, and K. K. Kelley, "Supplement to Selected Values of Thern:ndynamic Froperties of Metals and Alloys," private communication by R. Hultgren (1966).

38. J. M. Haschke and H. A. Eick, J. Fhys. Chem. 72, 4235 (1968).

39. E. Catalano, R. G. Bedford, V. G. Silveira, and H. H. Wickman, J. Phys. Chem. Solids 30, 1613 (1969).

40. K. Lee, H. Muir, and E. Catalano, J. Phys, Chem. Solids 26 , \$23 (1965).

41. D. J. M. Bevan, R. S. Cameron, A. W. Mann, G. Brauer, ard A. Roether, Inorg. Nucl. Chem. Letters 4, 241 (1968).

42. W. H. Zachariasen, Acta, Cryst. 4, 231 (195i).

43. N. C. Bacnziger, J. R. Holden, G. E. Knudsen, and A. I. Popov, J. Ârĩ. Chem. Soc. T6, 4734 (1954).

44. D. H. Templeton and C. H. Dauben, J. Am. Chem. Suc. 76, 5237 (1954).

45. K, S. Vorres and $R$, Riviello, in Proc. The Fourth Rare Earth Res. Conf., Phoenix, Arizona, 1964, L. Eyring Ed. (Gordon and Breach, New York, 1965), p. 521.

46. L. R. Batsonova and G. N. Kustova, Russ. J. Inorg. Chem. 9. 181 (1964).

47. N. V. Podberezskaya, L. R. Batsonova, and L. S. Egorova, J. Struct. Chem. (LiSSR) 6, 815 (1965).

48. W. Finkelnburg and A. Stein, J. Chem. Phys, 18, 1296 (1950).

49. G. Brauer and U. Ruether, in Proc. The Seventh Rape Earth Res, Conf, Coronado, California 1968, p. 253 (availability restricted to attendees).

50. D. B. Shinn and H. A. Eick, Inorg. Chem. 8, 232 (1969).

51. M. W. Shafer and J. D. Kuptsis, J. Phys. Chem. Solids 30 , 2325 (1969).

52. L. E. J. Roberts, in Non-stoichiometric Compounds, R. F. Gould, Ed. (Am. Chem. Soc., Washington, D. C. 1963), pp. 66-73. 
53. E. Zintl and A. Udgard, Z. Bnorg. Allgm. Chem. 240, 150 (1939).

54. W. Klemm and H. A. Klein, Z. Anorg. Allgm. Chem. 248, 167 (1941).

55. J. Short and R. Roy, J. Phys. Chem. 67, 1860 (1963).

56. J. F. Druding and J. D. Corbett, J. Am. Chem. Soc. 83,2462 (1961).

57. R. A. Sallach and J. D. Corbett, Inurg, Chem. 2, 457 (1963).

58. L. F. Druding, J. D. Corbett, and .9. H. Ramsey, Inorg Chem. 2. 869 (1963).

59. J. E. Mee and J. D. Corbett, Inorg. Chem. 4, 88 (1965).

60. J. D. Corbett and B. C. Mccollum, Inorg. Chem. 5, 938 (1966).

61. G. 1. Novikov and O. G. Polyachenok Russ. J. Inorg. Chem. B, 545 (1963).

62. O. G. Polyachenok and G. I. Novikov, Russ. J. Inorg. Chem. 8 j478 (1963).

63. D, R. Stull and G. C. Sinke, Thermodynamic Properties of the Elements (American Chemical Society, Washington, D. C., 1956).

64. O. H. Krikorlan, High-Temperature Studies. University of California Radiation Laboratory, Berkeley, Rept. UCRL-2888 (1955).

65. M. B. Panish and L. Reif, J. Chem. Phys. 36, 253 (1963).

66. G. M. Kibler, T. F. Lyon, M. J. Linevsky, and V. J. De Santis, Carbonization of Plastics and Refractory Material Research AF Materials Laboratory, Research and Technology Division, Air Force Systems Command, Wright-Datterson Air Force Base, Chio, Rept. WADD-TR-60-646, Part 3, Vol, 2 (March 1964) pp. 32-39.

67. P. E. Blackburn, ir Thermodynamic and Kinetic Studies for a Refractory Materials Program, L. A. McClaine, Ed., Air Force Materials Laboratory, Research and Technology Division, Air Force Systems Command, Wright-Patterson Air Force Base, Onio, Rept. ASD-TDR-62-204, Part III (Apri) 1964), pp. 111-112.

68. R. K. Koch, W. E. Anable, and R. A. Beall, Vapor Pressures of Liquid Columbium $\left(2,740^{\circ}\right.$ to $\left.3,140^{\circ} \mathrm{K}\right)$ and Liquid Hafnium $\left(2,500^{\circ}\right.$ to $\left.2,810^{\circ} \mathrm{K}\right)$. Bureau of Mines, U.S. Department of the Interior, Rept, 7125 (May 1968). 
69. O. C. Trulson and H. W. Goldstein, in Research on Physical and Chemical Principles Affecting High Temperature Materials for Rocket Nozzles, R. Lowrie, Ed., Union Carbide Corp., Tarrytown, New York, Quarterly Progress Report, 1 July 30 September 1963, on Contract DA-30-069-ORD-2787, Part III, Rept. AD-419/809 (September 1963), p. 48.

70. R. Hultgren, R. I. Orr, P. D. Anderson, and K. K. Kelley, Supplement to Selected Values of Thermodynamic Properties of Metals and Alloys: Hafnium, University of California Lawrence Radiation Laboratory, Inorganic Materials Research Division, and Department of Mineral Technologs; College of Engineering, Berkeley, California (Jamary 1966).

7 I. J. Longfellow and J. D. Wood, J. Less-Common Metalis, 14, 445 (1968).

72. O. Kubaschewski, "Free-Energy and Phase-Diagrams," in Thermodynamics of Nuclear Materials. Proceedings of the Srmposium on Thermodynamics of Nuclear Materials, Internaticnal Atomic Energy Agency, Vienna, May 1962 (International Atomic Energy Agency, Vienna, 1962) pp. 219-241.

73. G. W. Barton, Jr., L. E. Gibson, and L. F. Tolman, Anal. Chem. 32, 1599 (1960).

74. G. W. Harton, Jr., L. F. Tolman, and R. E. Roulette, Rev. Sci. Instr. 31, 995 (1960).

75. M. P. Klein and G. W. Barton, Jr., "Enhancement of Signal-toNoise Rutio by Continuous Averaging, "in Paramagnetic Resonance, W. Low, Ed., Proceedings of the First International Conference, Jerusalem, 1962, Vol. II (Academic Press, New York, 1963), pp, 698-703.

76. C. M. Stevens, Rev, Sci, Instr, 24, 148 (1953).

77. R. Hultgren, R. L. Orr, P. D. Anderson, and K. K. Kelley, Supplement to Selected Values of Thermodynamic Properties of Metals and Alloys: Zirconium, University of California Lawrence Radiation Laboratory, Inorganic Materials Researrh Division, and Department of Mineral Technology, College of Engineering, Berkeley, California (March 1967).

78. F. J. Bradshaw, Proc. Phys, Soc. (London) B63, 573 (1950). 
79. C. Zwikker, unpublished datá quoted by J. H. DeBoer, Ind. Eng. Chem. 19, 1266 (1937).

80. D. Struminger, J. M. Hollander, and G. T. Seaborg, Rev, Mod. Phys. 30, 585 (1958).

81. F。 D. Rossini, in Experimental Thermochemistry, F. D. Rossini, Ed. (Interscience Publishers, Inc., New York, N. Y., 1956), pp. 297-320.

82. R. G. Bedford, J. Appl. Phys. 36, 113 (1965).

83. C. E. Moore, Atomic Energy Levels, Vol. III, National Bureau of Standards Circular 467 (1958).

84. R. Newbury, Lawrence Radiation Laboratory, Livermore, private communication, 1962.

85. Z. A. Munir and A. W. Searcy, J. Chem. Phys, 42, 4223 (1965).

86. H. Hahn and R. iuza, ‥ Anorg. Allgem. Chem. 244, 111 (1940).

87. M. Lorenz and B. Binkowski, J. Electrochem. Soc. 109, 24 (1962).

88. R. Mar and A. W. Searcy, J. Chem. Phys. 49, 182 (1968).

89. S. P. Gordienko, G. V. Samsonov, and V. V. Fesenko, Russ. I. Phys. Chem. (English Transl.) 38, 1620 (1964).

90. R. Juza and H. Hahn, Z. Anorg. Allgem. Chem., 244, 133 (1940).

91. O. H. Krikorian, J. H. Carpenter, and R. S. Newbury, High Temp. Science, 1, 313 (1969); and R. S. Newbury, G. W. Barten, Jr., and A. W. Searcy, J. Chem. Phys. 48, 793 (1968).

92. R. W. Kiser, Tables of Ionization Potentials, U. S. Atomic Energy Commission, Office of Technical Information, Rept. TID-6142 (1960). 


\section{ACKNOWLEDGMENTS}

I thank Professor Alan W. Searcy for his guidance and patience throughout the time this work was in progress. I which also to express $m y$ appreciation to many others who contributed in various ways. I cannot list them all, but here are a few. Dr. Edward Catalano first interested me in the phase equilibria of the rare earth oxides and fluorides, and his cooperation in that work was indispensable. Mrs. Bettie Shroyer helped with the equilibrations and thermal analyses. Emmett Wrenn and Roland Reiss helped develop the techniques for encapsulating the samples and dic the electron-beam welding with only a couple of failures out of hundreds of samples. Donald McCoy and $\mathrm{Dr}$. Ralph Gutmacher did $x$-ray fluorescence and microprobe analyses of our rare earth materials. Vern Silveira's x-ray powder work on the rare earth materials and the gallium nitride preparations was above and beyond the call of duty. Drs. William Morris, Edgar Peck, and John Stevens contributed spectrographic analyses. Dr. Roman Bystroff developed the procedure and carried out the analyses for zirconium in the hafnium alloys. Thomas Haratani programmed and ran preliminary thermodynamic calculations ior the hafnium vaporiza. tion studies on an IBM 650 computer. Dr. Quentin Johnson made single crystal $x$-ra: studies on the rare earth intermetallic compounds and contributed helpful suggestions. Special thanks are due to Dr. Leo Brewer who predicted in 1965 , before any samarium or europiuin intermetallic with platinum or iridium had to our knowledge been reported, the stability and structures of $\mathrm{LnM}_{3}$ and $\mathrm{LnM}_{5}$ for $\mathrm{Ln}=\mathrm{Sm}$ and Ex and $M=P t$ and Ir. I am grateful to Dr. George W. Barton, Jr., for help in applying his mass spectrometer to the hafnium vaporization study and for sharing some of his understanding of mass spectrometry and insight into experimental science. The time and effort of the people who reviewed early versions of the manuscript are appreciated. The comments of Dr. Robert Taylor, Dr. Lawrence Himmel and Dr. Oscar Krikorian were particularly helpful.

I wish aiso to express my sincere gratitude for the sacrifices made by my wife, Eleanor, and children, Stephen, Denice, and Debra, 
without complaint. Their encouragement and moral support was necessary for the completion of this pruject.

Finally I thank Dr. Roger Batzel and the other people at the Lawrence Radiation Laboratory, Livermore, who made possible a paid leave of absence during my work for the degree and approved my program of study. This work was done under the auspices of the U.S. Atomic Energy Commission. 